Portland State University

PDXScholar

$10-23-2020$

\title{
History and Memory in the Intersectionality of Heritage Sites and Cultural Centers in the Pacific Northwest and Hawai'i
}

Leah Marie Rosenkranz

Portland State University

Follow this and additional works at: https://pdxscholar.library.pdx.edu/open_access_etds

Part of the Museum Studies Commons, and the Social and Cultural Anthropology Commons Let us know how access to this document benefits you.

Recommended Citation

Rosenkranz, Leah Marie, "History and Memory in the Intersectionality of Heritage Sites and Cultural Centers in the Pacific Northwest and Hawai'i" (2020). Dissertations and Theses. Paper 5627.

https://doi.org/10.15760/etd.7499

This Thesis is brought to you for free and open access. It has been accepted for inclusion in Dissertations and Theses by an authorized administrator of PDXScholar. Please contact us if we can make this document more accessible: pdxscholar@pdx.edu. 
History and Memory in the Intersectionality of

Heritage Sites and Cultural Centers in the Pacific Northwest and Hawai' $i$

by

Leah Marie Rosenkranz

A thesis submitted in partial fulfillment of the requirements for the degree of

\title{
Masters of Arts \\ in \\ Anthropology
}

\author{
Thesis Committee: \\ Jeremy Spoon, Chair \\ Doug Deur \\ Doug Wilson \\ Theresa Langford
}

Portland State University

2020 
C 2020 Leah Marie Rosenkranz 


\begin{abstract}
While working to maintain contemporary and future relationships with stakeholders, heritage sites and cultural centers across the United States attempt to tell the history and experiences of the land and people who were once there, are there in the present, and will be there in the future. Fort Vancouver National Historic Site is one of these heritage places. This study is a response to current management needs identified for the Fort Vancouver National Historic Site. Through an internship with the ongoing Fort Vancouver National Historic Site Traditional Use Study, my research examines how heritage sites and cultural centers fulfill the needs of tribes and other diverse stakeholders, such as community members and park visitors. Using an inductive approach, my research focused on the roles of history and memory in the intersectionality of meaning at heritage spaces and how this influences the diverse aspects of these places. I analyzed the interpretive content and programming of 10 case study sites and two supplementary sites in Washington, Idaho, and Hawai' $i$ and completed 15 semistructured interviews. I identified five themes in the results: (1) stories told at sites are controlled by a set of established interpretive themes; (2) stories have a lack of shared authority; (3) shared stories have little hybridity; (4) contemporary Indigenous relationships with sites are rooted in ancestral memories and connections; and (5) sites share contemporary relationships with the public through live cultural programming. Building on this knowledge, heritage sites and cultural centers can develop interpretation and programming that is more representational of the memories, history, and Indigenous experiences of sites.
\end{abstract}




\section{ACKNOWLEDGMENTS}

I would like to acknowledge all of the research collaborators and individuals who supported me during this research. I especially appreciate the guidance and support of my advisor Jeremy Spoon, Doug Deur, Doug Wilson, and Theresa Langford throughout this project. Thank you to the Fort Vancouver Traditional Use Study Collaborators for helping to guide and encourage my work. Thanks also to Mark Alvarez, Daniel Kawaiaea Jr., Mary Jane Keffer, and Benjamin Saldua who made special efforts to host me at their sites while I was on research trips. Thank you to David Harrelson of the Confederated Tribes of Grand Ronde for his efforts in supporting and guiding my research and work. I would also like to acknowledge the support from my family and friends, especially Chris Wurst. Finally, I would like to thank and acknowledge Fort Vancouver National Historic Site and the Wayne Suttles Graduate Fellowship; without their funding, this research project would not have been possible.

I would also like to acknowledge those in Hawai' $i$ who were working to protect their sacred land and mountain, Mauana Kea, while I was conducting research. It is also important to acknowledge the Black Lives Matter movement occurring at this time that is working to end police violence and racism. The efforts of these groups were remembered throughout the analysis and writing of this paper. 


\section{TABLE OF CONTENTS}

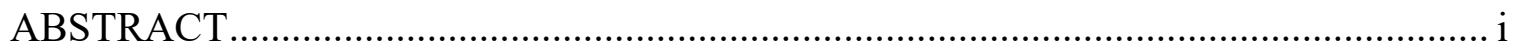

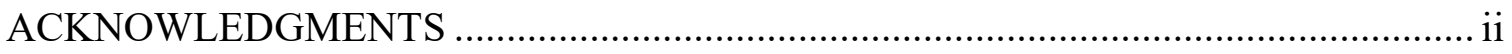

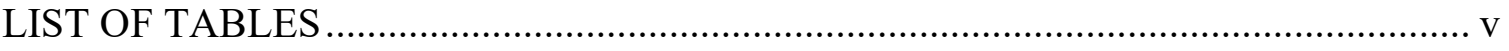

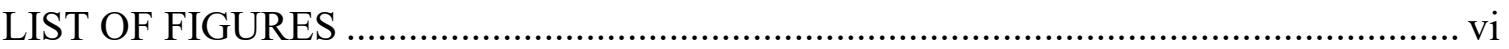

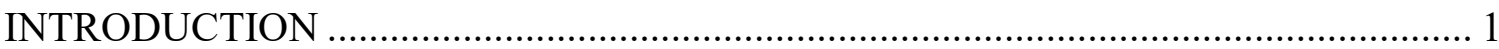

FRAMING HERITAGE AND HISTORY THROUGH INTERSECTIONALITY AND

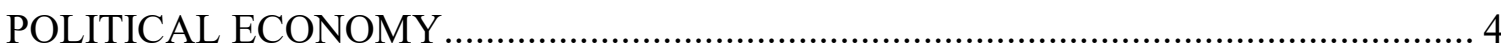

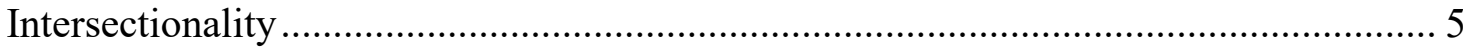

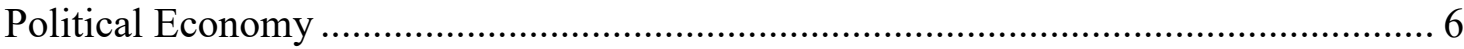

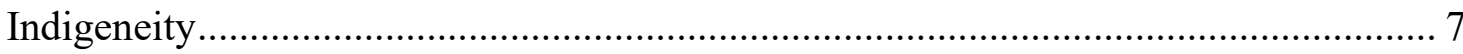

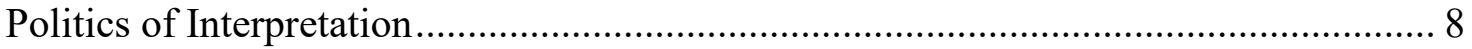

CONEXT: FORT VANCOUVER NATIONAL HISTORIC SITE ……………………... 15

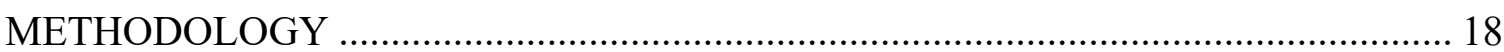

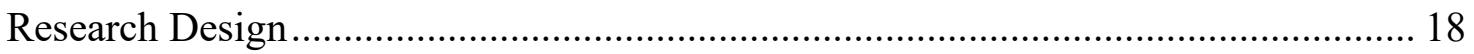

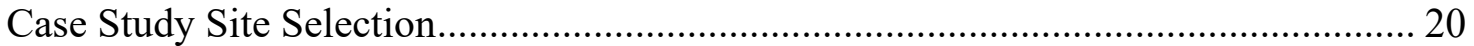

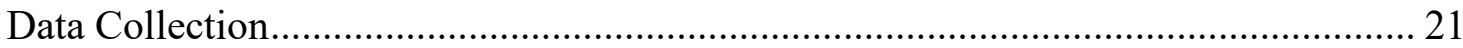

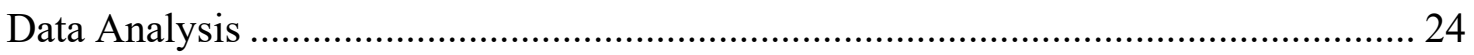

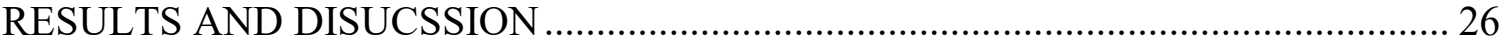

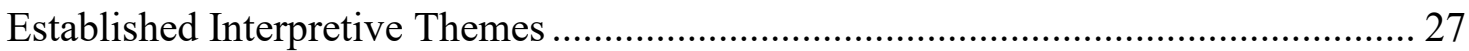

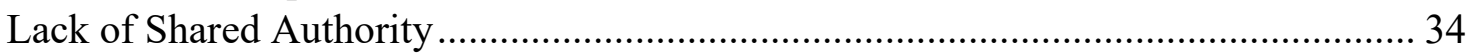

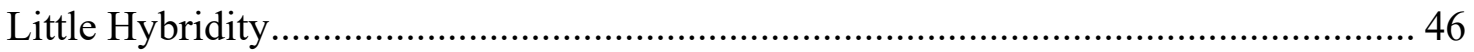

Contemporary Indigenous Relationships Rooted in Ancestral Memories and

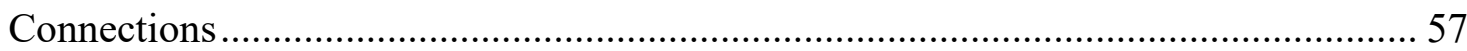

Contemporary Relationships Shared Through Live Cultural Programming................. 63

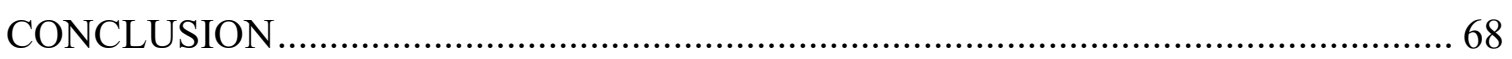

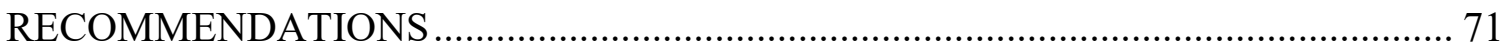

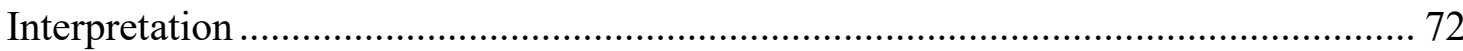

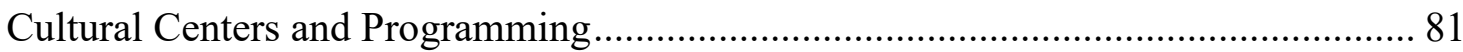

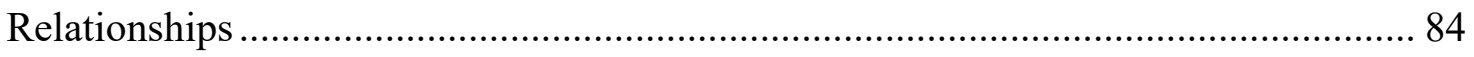

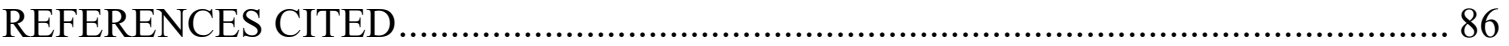

APPENDIX A: LIST OF RESEARCH PARTICIPANTS …………………………..... 93

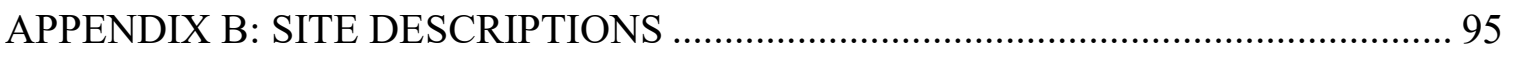

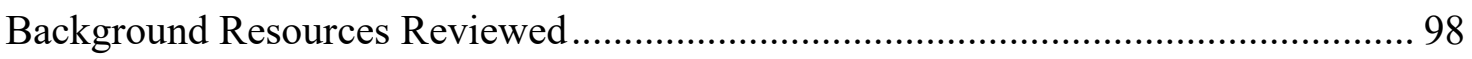




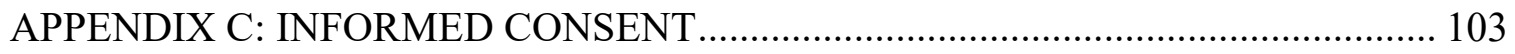

APPENDIX D: RESEARCH QUESTIONS .......................................................... 104

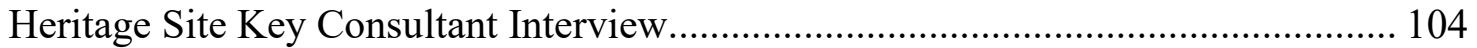

Cultural Center Key Consultant Interview............................................................ 106

APPENDIX E: SITE EVALUATION RUBRIC .................................................... 108 


\section{LIST OF TABLES}

Table 1: Top Interpretive Themes Occurring in More Than 15\% of Interpretive Units............................................................. 29

Table 2: Voice Used in Interpretive Units................................ 36

Table 3: Frequency of People from History Named in Interpretation............. 38

Table 4: Frequency of People from History Named in Interpretation by Site....... 39

Table 5: Frequency of Citations, Quotes, and References from People in

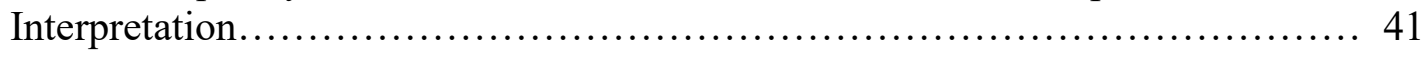

Table 6: Frequency of Univocality in Interpretive Units..................... 47

Table 7: Frequency of Multivocality in Interpretive Units.................... 49 


\section{LIST OF FIGURES}

Figure 1: Indigenous Site Name - Nez Perce National Historical Park............ 72

Figure 2: Indigenous Site Statement in Park Brochure - Nez Perce National Historical Park ...................................................... 73

Figure 3: Site Welcome - Sacajawea Historical State Park................... 73

Figure 4: Indigenous Language Interpretive Sign - "No ka Hanau ana o Kamehameha," Pu'ukoholā Heiau National Historic Site..................... 74

Figure 5: Simple Indigenous Language Inclusion in Interpretive Sign - "Beaver or Money," Spokane House, Riverside State Park........................ 75

Figure 6: Multiple Perspectives Interpretation - "Viewpoints," Sacajawea Historical State Park.................................................. 76

Figure 7: Extended Interpretive Timeline - "Timeline of the Northern Plateau," Fort Spokane, Lake Roosevelt National Recreation Area...................... 77

Figure 8: Contemporary People in Interpretation - "For Generations to Come," Sacajawea Historical State Park....................................... 78

Figure 9: Contemporary People in Interpretation - "Celebrating Hawaiian Culture,” Pu'ukoholā Heiau National Historic Site.

Figure 10: Site Comment Box - Fort Spokane, Lake Roosevelt National Recreation Area.................................................... 80

Figure 11: Visitor Reflections - Fort Spokane, Lake Roosevelt National Recreation Area........................................................ 81

Figure 12: Designated Quiet Area Sign, Hawai'i Volcanoes National Park......... 82

Figure 13: Hula Platform: Kahua Hula, Hawai'i Volcanoes National Park......... 83

Figure 14: Hale - Hawai'i Volcanoes National Park............................ 83 


\section{INTRODUCTION}

Heritage sites across the United States attempt to tell the history and experiences of the places and peoples who once were there, while working to maintain contemporary relationships with culturally-affiliated tribes and diverse stakeholders, such as community members and park visitors. These sites often attempt this through cultural centers, visitor centers, museum exhibits, reconstructed and preserved historic structures, monuments to the past, and public art. Commemorations of the past, such as heritage sites, cultural centers, museums, and interpretive trails, often exclude the experiences of Indigenous peoples of North America and construct the past primarily through the perspectives of Euro-Americans (Zerubavel 1995, 11). Heritage work can create a story of the past that recognizes and teaches difficult histories (Little and Shackel 2014, 128). Heritage spaces like Fort Vancouver National Historic Site (FOVA) in Vancouver, Washington are heritage places with unique histories of cultural contact, military activity, and colonial influences. Researchers at this site identified unequal representation in interpretive programs and a lack of recognition of cultural and historic forces that maintain a historical status quo in interpretation (Langford 2000, 42). Additionally, recent community outreach at the site indicates a desire from connected Indigenous populations and FOVA staff for improved Indigenous representation and programming.

This paper takes a political economy approach to understanding the intersectionality of history and memory in public heritage spaces, looking at both heritage sites and cultural centers that serve the community and provide a gateway to heritage. Two research questions guided my research: (1) What are the roles of history and 
memory in the intersectionality of meaning at public heritage spaces, such as contested heritage sites and cultural centers? And (2) How does this intersectionality of heritage space influence the establishment, governance, management, interpretation, and use of these places? Analysis focused on 10 heritage and cultural center case study sites and two supplementary sites using participant observation of site interpretation and programming and 15 key consultant, semi-structured interviews. I selected research sites based on a set of criteria around government management and Indigenous connections and key consultants through reputational case selection. Participant observation documented interpretation and programming and interviews focused on key consultants' knowledge of site programming, interpretation, and management. Using inductive content analysis, I analyzed and coded the results from both participant observation of site content and key consultant interviews for key themes across the sites. I found that (1) the stories told at sites are controlled by a set of established interpretive themes, (2) stories lack shared authority, (3) shared stories have little hybridity, (4) contemporary Indigenous relationships with sites are rooted in ancestral memories and connections, and (5) contemporary relationships are shared with the public through live cultural programming.

Through this research, I aim to provide guidance for the Traditional Use Study (TUS), interpretation projects, and the creation of a cultural center located on the FOVA grounds that will serve the site's multiple stakeholders. Recommendations from this project aim to provide the first steps to interpretive planning and management projects. The recommendations at the end of this paper provide actionable steps that can be useful to people on the ground and working at heritage sites and cultural centers. These 
recommendations can be adjusted to meet site needs and incorporated into planning documents. More information can be found in the deliverable report created from this project by Rosenkranz, Spoon, and Deur (2020). The deliverable from this project may be useful for the National Park Service (NPS) and other heritage places with contested histories and cultural centers in their establishment, management, and interpretation. More broadly, this research contributes to the academic discussion of heritage, which still largely focuses on materials and technical processes (Winter 2013, 539). Recent attention to intangible heritage is beginning to reveal the importance of policies and work that is more understanding of the complexity of heritage and people's interactions with it (Winter 2013, 539). Theoretical debates around the larger topics, such as contestation and identity, have not adequately addressed heritage itself, its practices, or concepts (Waterson and Watson 2013, 546). Studies of heritage need to go further than looking at "things" and their representation and begin to look at the meaning of heritage spaces and lived experiences connected with these sites (Waterson and Watson 2013, 558). My research can add to these discussions of heritage, heritage's complex interactions with people, and heritage sites' roles in identity and society by highlighting what stories are being told at heritage sites, who is telling them, how the stories are told, what contemporary relationships at sites are, and how those contemporary relationships are shared with the public. These insights can thus assist sites in future interpretive and programming developments and planning. 


\section{FRAMING HERITAGE AND HISTORY THROUGH INTERSECTIONALITY}

AND POLITICAL ECONOMY

Most historical records and accounts of the past typically do not tell what actually happened, but how the recorder of the event experienced it (Trouillot 1995, 2-26). Parts of the past are often "silenced" or forgotten; these silences can occur in the "moment of fact creation," the creation of archives, the "making of narratives," and the "making of history in the final instance" (Touillot 1995, 26; emphasis in original). In North America, commemorations of the past often exclude Indigenous peoples' experiences, with historical representations framed through Euro-American perspectives (Zerubavel 1995, 11). Populations under colonial powers often struggle with representation and comply with standard Western views of history. They maintain their accounts of contested histories within community knowledge systems, such as oral traditions. History is about power, maintaining power, and giving people power; with power, history has been used to marginalize and 'other' people. Often when contested and absent histories are told, it is because they have been "allowed" (Smith 2010, 33-34). Understanding the complexity of history and memory is important in making sense of interpretation and dynamics at heritage sites. Through this understanding, occurrences of silence and marginalization can be better identified and understood in site interpretation.

Some heritage scholars define heritage, as anything that is important to people that provides a connection between the past and present, including tangible and intangible culture (Little and Shackel 2014, 39). Heritage is not history; societies construct heritage based on what is valued of the past as important (Baird 2017, 10; Hoelscher 2011, 203). 
The objects and places that display heritage serve to produce meaning and understanding of the past, while affecting the present (Jackson 2016, 24). Heritage landscapes often serve as places of memory and belonging, knowledge holders, and places of identity negotiation of communities and nations (Baird 2017,4). They may also be sites of conflict, death, loss, displacement, and other traumas that can make heritage difficult for certain people (Baird 2017, 4). Heritage sites have the potential to construct a misconception of common memory and agreement that often does not exist (Young 1993, 6). This lack of common memory can result in dissonance and disagreement over heritage, which may be difficult because of the different meanings, identities, and conflict associated with heritage places (Little and Shackel 2014, 40). These difficult and conflicting aspects of heritage sites are referred to as "contested" in this project. Contestation reflects the meanings and representations that are challenged by stakeholders of heritage places (Little and Shackel 2014, 40). When approached correctly, heritage work can create a story of the past that recognizes and teaches difficult histories (Little and Shackel 2014, 128).

\section{Intersectionality}

Additionally, intersectionality is a method for understating the relationships between "multiple dimensions and modalities of social relationships and subject formations" (McCall 2005, 1771). An intersectional approach can help to break hegemony and create a more complex and inclusive discussion (McCall 2005, 1777). The intersection of race, class, gender, and more can affect our understanding of events (Ulysse 2002, 17-24). People do not have a single identity or understanding of life 
experiences, such as being only a woman or colonized person, but rather have multiple and differing experiences. For example, Black women experience discrimination in multiple ways, with some similar and some different experiences to white women (Haraway 1991, 190-191; Crenshaw 1989, 149). Intersectionality challenges singularity and separation (McCall 2005, 1778). Combining the different 'situatedness' of people in their own knowledge, memories, and perspectives can create a better sense of reality and the complexity of people's experiences (Haraway 1991, 189-191). In this research, intersectionality is understood as the overlapping, intersecting, contested, and negotiated meanings and experiences of heritage places which are both an expression of and influence human experiences and relations (Smith 2006, 79). By taking an intersectional approach, the history and meanings of case study sites may be better understood in a manner that is more inclusive and integrative.

\section{Political Economy}

I use a political economy approach to understand the shifting roles and control of each heritage space and how they function. This approach allows for understanding different experiences, cultural meanings, and actions within contexts of unequal power, social relations, and deep historical contexts (Roseberry 1994, 36-44). Political economy can help to identify the processes that created the current relations and meanings at heritage places with colonial and contested histories and make it difficult to exclude groups or their influences on the past from interpretations of history (Di Leonardo 1993, 78). Research that is "historically deep" and "geographically broad" can provide a better understanding of erased and silenced histories and how these play out in the meaning of 
places (Farmer 2004, 309). For example, Jackson discusses the importance of descendent narratives in interpreting plantations, with the understanding that the historical slave trade still affects the current experiences of communities and individuals (Jackson 2016, 30). In understanding he memories and histories of events that shape the meaning of public heritage spaces and the spaces' interpretation, management, and use, a political economic lens that is spatially and historically broad provides recognition of the unequal power dynamics, and relations that created the current and past situations at research sites.

\section{Indigeneity}

There are several ways of defining the term Indigenous. Many descriptions define Indigenous peoples as those with "tradition-based cultures," who were sovereign before invasion and colonization, and who continue to work for independence and preservation of their culture (Corntessel 2003, 78; Secretariat of the United Nations Permanent Forum on Indigenous Issues 2009, 4). Several definitions also distinguish that Indigenous peoples are descended from the original inhabitants of the land they currently live on or wish to occupy, sharing language and cultural practices (Corntessel 2003, 78-79; Secretariat of the United Nations Permanent Forum on Indigenous Issues 2009, 4-5). Many scholars and organizations also recognize self-identification to Indigenous groups as important (Corntessel 2003, 81; Secretariat of the United Nations Permanent Forum on Indigenous Issues 2009, 5). The term Indigenous has been used in both a way that relationally distinguishes Indigenous peoples from others, that are non-Indigenous, and in a way that uses specific qualities or criteria (Trigger and Dalley 2010, 46-47). In this paper, I use a broad definition for the term Indigenous that recognizes groups in a manner 
that largely recognizes Indigenous peoples as groups other than non-Indigenous, who have been disrupted or displaced by colonization. A broad definition was used to incorporate Kanaka 'Ōiwi, Native Hawaiian, peoples in the research and analysis, without a need for separate terms. Hawaiian ancestors were Polynesians who navigated the ocean to the archipelago now known as Hawai' $i$, over time developing a distinct language and culture (Brown 2019, vii). This complicates how the term Indigenous might be defined. An additional complication to the definition used in this project was the need to include both traditionally associated Indigenous peoples and those colonially-relocated to a place; these two different relations to place effect the experience, knowledge, and history people have with sites. While there is value in discussing the unique experiences of local or traditionally associated Indigenous peoples with a special focus or as a unique category of Indigeneity, for this project these specifications needed to be set aside for a broader use of the term Indigenous in order to begin to quantify Indigenous representation in interpretation at the studied sites in a manner that addressed all Indigenous peoples connected with the sites. Indigenous peoples are heterogeneous and the groups represented in this project are those that were part of the exhibits studied and were part of interpretation because they were selected by those creating the interpretation, so there may be others not included for this reason.

\section{Politics of Interpretation}

Interpretation is a process of sharing with visitors the wonder, beauty, inspiration, understanding, appreciation, and meaning of places as well as the culture and history of a place (Benton 2012, 7; National Park Service 2007, 7; Tilden 2009, 25; Uzzell 1998). 
The process of creating meaning is an important aspect of interpretation that creates a deeper relationship between people and places, allowing visitors to create their own experiences and understandings of a site or space (Hunter 2012, 53-55). In the process of analyzing interpretation, there is a need to understand the mechanics of interpretation and the consequences and hazards of this process. Interpretive displays are developed in several different ways. This process can occur through in-house agency staff or nationwide agency interpretive staff, such as the NPS Harper's Ferry Center. The development of interpretation can also be done with private consultants, university cooperators, or others hired to work with site management. These processes go beyond simply writing and designing exhibits for interpretation, but include processes such as establishing project teams and goals, reviewing foundation documents, budgeting, evaluating site needs, consultation, gathering data and materials, creating and reviewing proposals, drafting exhibit plans, review and approval processes, final development and review, production, and installation (California State Parks 2013; Edwards 1994; Harpers Ferry Center 2009; Wells 2009). Interpretive displays help to maintain the availability of information to site visitors, but they are, in nature, static and unchanging, making the design and selection of information an important aspect (Ballantyne and Hughes 2003, $15)$.

In general, power and knowledge influence the interpretive processes and outcomes. The way past colonial governments and museums have identified and interacted with Indigenous peoples has created experiences of marginalization, exclusion, and disenfranchisement, that continue to impact relationships today (Onciul 2015; Smith 
2006, 281; Zerubavel 1995). When Indigenous peoples do choose to participate in interpretation on their ancestral lands that are now governed externally, it is only often after they have been invited by those with the power to do so (Smith 2006, 281). They may decide to participate because of government-to-government relationships, strong personal relationships, financial benefits, a general desire to participate, the potential to express their living presence, to challenge colonial concepts, for opportunities to engage and educate their own Indigenous communities and youth, to interact with their ancestral lands, and the potential to have some control over defining their identity, narratives, and representation (Beck et al. 2005; Krmpotich and Anderson 2005, 384; Lonetree 2012; Onciul 2015; Smith 2006). Euro-American perspectives often frame representations of the past and the information that is presented often comes from the interests and desired messages of rangers and managers (Ballantyne and Hughes 2003, 16; Zerubavel 1995, 11). Indigenous voices are often left silent or absent from the telling of history; this is a similar experience to the voices of enslaved peoples at plantation sites (Smith 2010; Benjamin and Alderman 2018). Some Indigenous voices may be heard and these may be the voices of Indigenous people and communities that sites have selected to work with, have relationships with, have determined traditional ancestral lineage, or work with in government consultation. Indigenous groups not included by site staff may also have their voices left absent from interpretation. Within and between Indigenous communities, there may also be rules and beliefs of who has a right to speak for the communities and share their stories and culture (Onciul 2015). 
In creating interpretation, sites often use interpretive plans, such as Long-Range Interpretive Plans used by the National Park Service, site missions, visions, statements of purpose, statements of significance, and historic timeframes or periods of significance. The stories eventually shared in interpretation are often selected by interpretive staff, consultants, and collaborators. Colonial dynamics of the past continue to impact government and Indigenous relationships, effecting the stories told in the interpretation established at sites (Onciul 2015). These stories, in turn, tend to fit within an established narrative of U.S. history, following a larger commemorative, shared memory and narrative that often legitimizes national ideologies (Smith 2006). When Indigenous stories are shared, they are often those that are allowed by the site and by Indigenous populations, often fitting within established themes and, in some instances, written by site staff and approved by Indigenous consultants (Smith 2010, 33-34; Onciul 2015). Depending on the information shared in interpretation, including Indigenous representation can further negative stereotypes of Indigenous cultures. Indigenous representations have the potential to homogenize diverse peoples, continue to ignore silences, may still present within the confines of society and sites, create dichotomies of western science and Indigenous knowledge, commodify indigenous cultures, essentialize or simplify Indigenous peoples and knowledge to fit interpretive spaces, maintain outsider views, and perpetuate primitive, materialistic, static, or natural history depictions of Indigenous peoples that can further negative stereotypes of Indigenous cultures (Lonetree 2012; Onciul 2015; Wrightson 2017). An additional concern in the process of interpretation is addressing the heterogeneity of Indigenous voices, both between and 
within Indigenous communities. It can be challenging to address the significance of and different voices within and between groups, creating difficulty in determining what information to include (Weisse and Ross 2017). In some instances the Indigenous people tasked with representing Indigenous groups have found it difficult to provide distinctions between different cultural and political groups, struggling with who has the right to speak on behalf of communities, differences in agreements of what should be shared, and with truly demonstrating the diversity within different groups (Onciul 2015). In these challenges, there are ways to articulate variation and allow Indigenous perspectives to be represented (Krmpotich and Anderson 2005).

Heritage sites and cultural centers commonly use live, public cultural 'performances' as part of their interpretive programming, which can have a set of its own issues. Live interpreters and cultural practitioners can be subject to extensive or invasive questions from visitors about their lives and experiences. When performing as their Indigenous selves, they may also become tokenized, 'othered,' viewed as objects, reinforce stereotypes of the "noble savage," or be made a spectacle as a human display by the tourist gaze of visitors (Benton 2011, 87; Onciul 2015). While these issues may emerge, live programming and knowledge holders at sites can help to build connections, bring community perspectives to the site, share personal stories, maintain traditions, challenge stereotypes, create pride, gain skills, and create new connections between people, benefiting both visitors and Indigenous peoples (Onciul 2015, 173-208). In this, live cultural programming provides both benefits and consequences for those participating in the 'performances.' 
Interpretation that includes Indigenous voices may complicate situations and the lives of Indigenous peoples. There can be concerns over who has the right to share information and speak for a group and what representations should be created. This can be further complicated through concerns of wanting to create pride in Indigenous communities and to share difficult truths and histories, while, in turn, providing these emotional and challenging pasts can be painful for those sharing and for those in the community that view the interpretation (Onciul 2015). Despite these potential pitfalls, there are a variety of positive outcomes that can result from Indigenous voice in public interpretation. Indigenous voice in interpretation can result in self-representation and selfdetermination, creating spaces in which Indigenous communities feel represented and have a voice in society (Krmpotich and Anderson 2005; Onciul 2015). These representations in interpretation can also authenticate and honor people's histories, experiences, and identities (Lonetree 2012; Onciul 2015). Spaces with Indigenous voice in interpretation also have the ability to reduce bias, challenge misinformation, encourage reflection, and address contested history in a purposeful manner, creating meaningful conversations and relationships between Indigenous populations and non-Indigenous populations represented (Balellantyne et al. 2012; Krmpotich and Anderson 2005; Kryder-Reid 2016; Onciul 2015). Additionally, Indigenous voice and discussions of difficult parts of history can encourage understanding and engagement across different cultures and assist with relationship building and healing (Baumann et al. 2011,38; Onciul 2015). Overall, in instances of sites that incorporate Indigenous voice, researchers such as Onciul (2015) have found that, for Indigenous community members the benefits 
from working with museums and heritage sites have outweighed the risks and difficulties because they view the work as important (Onciul 2015, 221). 


\section{CONEXT: FORT VANCOUVER NATIONAL HISTORIC SITE}

Located in the Portland Basin, the site of Fort Vancouver was a place of travel, trade, and contact and continues to serve as a travel destination and site of contact and cultural activity (Deur 2012, 1). Constructed between 1824 and 1835, the fort structure served as the administrative headquarters and main supply depot for the Hudson's Bay Company (HBC) Columbia Department (Deur 2012, 1). An ethnically and racially diverse population worked, lived, married, and died at the fort site (Deur 2012, 1). During HBC operations, nearly all Pacific Northwest tribes, Hawaiians, Iroquois, FrenchCanadians, British, Americans, and more were represented (Deur 2012, 2). The HBC occupied the site for about 25 years and was then replaced by the United States Military and the establishment of the Vancouver Barracks in 1849 to defend Oregon Territory settlement (Deur 2012, 141; United States Department of the Interior 2008, 25). The Vancouver Barracks served as the main administrative center for the U.S. Army in the Pacific Northwest until World War I (United States Department of the Interior 2008, 25). The occupation of the site by the U.S. military greatly changed the role of the fort in the lives of surrounding tribes, as residents of the Village slowly relocated and tribes from around the area were moved to reservations away from the Portland Basin (Deur 2012, 2). Vancouver Barracks housed Indigenous people that the government gathered to relocate to reservations and, during the mid-nineteenth century, the post served as central command and supply post for the wars with the Northwest region Indigenous peoples (United States Department of the Interior 2008, 25; Deur 2012, 2). The Vancouver Barracks held many Native Americans as prisoners of war, including members from 
tribes such as the Nez Perce, Yakima, Shoshone, Paiute, and Bannock (Deur 2012, 2). The site also served as a base for explorations, war efforts, spruce production during World War I, location of the Pearson Airfield, district headquarters for the Ninth Corps of the Civilian Conservation Corps, and port of embarkation during World War II (United States Department of the Interior 2008, 25).

Established on June 19, 1948, the Fort Vancouver National Monument preserved the HBC fur trade post and U.S. Army parade ground (United States Department of the Interior 2016). The park was expanded and dedicated as a National Historic Site in 1961 (United States Department of the Interior 2016). Later in 1996, the Vancouver National Historic Reserve was created as a public use area next to Fort Vancouver; it is 366 acres and contains the Fort Vancouver National Historic Site within its boundaries (United States Department of the Interior 2016; United States Department of the Interior 2011, 6). The U.S. Army relinquished ownership of the East and South Barracks to the National Park Service in 2011, including the space occupied by the HBC cemetery (United States Department of the Interior 2011, v). The site's cultural resources consist of archaeological sites, cultural landscapes, historic structures, and museum collections; included in these resources are the reconstructed Fort Vancouver Fur Trade Post, the historic military East and South Vancouver Barracks, the Pearson Air Museum Complex, the Mission 66 Visitor Center Complex, and Oregon white oak heritage trees (United States Department of the Interior 2016; United States Department of the Interior 2011, 11). Among these resources is building 410, a South Barracks structure constructed by the Civilian Conservation Corps in October 1935 (Vogt 2016; United States Department 
of Interior n.d., 1). Originally used as an automotive repair shop, the building has recently housed a bike camp and is a potential space for a new cultural center at FOVA. In 2017, more than 1.1 million people visited Fort Vancouver National Historic Reserve and approximately 11 thousand local students visited the park on field trips (United States Department of the Interior 2018, 12). 


\section{METHODOLOGY}

\section{Research Design}

The purpose of this research was to understand the roles of memory and history in the intersectionality of meaning at public heritage spaces and how these influence the use of these spaces, particularly on heritage sites, such as forts and missions, and cultural centers. With my research, I attempted to answer two questions: (1) What are the roles of history and memory in the intersectionality of meaning at public heritage spaces, such as contested heritage sites and cultural centers? and (2) How does this intersectionality of heritage space influence the establishment, governance, management, interpretation, and use of these places? Building on consultation and workshops in the development of the FOVA Traditional Use Study ${ }^{1}$ (TUS) and work with Drs. Jeremy Spoon, Doug Wilson, and Doug Deur, this research aimed to support the TUS. The product of the TUS will be a Re-Indigenization Plan for FOVA with suggestions on topics such as interpretation, programming, and resource stewardship. This research will support this plan. My work will help provide lessons learned and recommendations for ongoing work at FOVA and a proposed rubric ${ }^{2}$ for evaluating other heritage sites with Indigenous content. With this research, I also aim to add to discussions of heritage, specifically our understanding of Indigenous representation and discussions of contested history at heritage sites and cultural centers.

\footnotetext{
${ }^{1}$ Researchers Drs. Jeremy Spoon and Doug Deur implemented meetings and workshops with tribal and Native Hawaiian representatives to meet the needs of an ongoing Fort Vancouver National Historic Site (FOVA) Traditional Use Study (TUS). The FOVA TUS was created in collaboration with Native American tribes, Canadian First Nations, and Native Hawaiian organizations with historic ties to the area.

${ }^{2}$ The desire for a rubric for evaluating heritage sites with Indigenous content was identified in TUS meetings and discussions of this thesis research. See Appendix E for evaluation rubric.
} 
Because this research involved Indigenous populations who have traditionally been silenced or underrepresented, it is essential to recognize the perspectives of those whose stories are being told (Smith 1999; Zerubavel 1995). The experiences Indigenous populations have had with colonialism shape their encounters with research (Smith 1999, 19-20). The decolonization of anthropological research requires an understanding of the motivations and values that served as the basis of past research and considering that "telling stories about the marginalized populations of the world" is "institutionalized in western centers of power" (Smith 1999, 20; Behar 2003, 15). When interviewing Indigenous community members and sharing their stories, it is imperative to recognize how the colonial past has or is impacting these communities and how it may play out at research sites with long colonial histories (Behar 2003, 22; Ulysse 2002, 11-22). My goal was to attempt to shift the balance of power towards Indigenous populations throughout the research process by using terms, such as partner or consultant, staying connected with these communities after research has ended, sharing results, and using collaborative methods with the FOVA TUS working group to determine the research goals (Ulysse 2002, 12-24; Behar 2003, 22; Spoon 2014; Spoon and Arnold 2012). An additional aspect of this process was to ensure that communities and people were not essentialized, but recognized as different and unique individuals with varying roles and experiences.

Using an inductive approach, I gathered data to inform the creation of a synthesis of lessons learned, which in turn informs recommendations on next steps (LeCompte and Schensul 2010,18). One component of my research was visiting case study sites that work to interpret their multivocal histories and memories and serve multiple diverse 
stakeholders in order to determine the roles of history and memory in the intersectionality of meaning at public heritage sites and investigate how heritage sites and cultural centers are fulfilling the needs of Indigenous populations and other diverse stakeholders. I visited and compared 10 case study heritage sites and cultural centers and two supplementary sites. Focusing on these sites and key knowledge holders, I used two primary research methods: participant observation and in-depth interviews. I conducted the data collection on two research trips, one in June and July 2019 and one in August 2019.

\section{Case Study Site Selection}

I selected a total of 10 case study sites and two supplementary sites from across the Pacific Northwest and Hawai' $i$ for research. The heritage sites in this case study included: Fort Simcoe Historical State Park, Nez Perce National Historical Park, Fort Spokane in Lake Roosevelt National Recreation Area, Fort Nisqually Living History Museum in Point Defiance Park, and Pu'uhonua o Hōnaunau National Historical Park. One cultural center in the study was the Volcano Art Center in Hawai' $i$ Volcanoes National Park and Niaulani Campus Administrative Office \& Gallery in Volcano Village. Case study sites that serve as both heritage sites and cultural centers included: Spokane House Interpretive Center in Riverside State Park, Hawai'i Volcanoes National Park, Pu 'ukoholā Heiau National Historic Site, and Sacajawea Historical State Park and Interpretive Center. The two supplementary case study sites were Whitman Mission National Historic Site and Kamakahonu National Historic Landmark. I selected sites based on their accessibility via two research trips, one driving through Washington and Idaho and the other driving on the island of Hawai' $i$. Sites in Washington and Idaho were 
selected for their similarities to Fort Vancouver National Historic Site and Hawai'i sites were selected because of the Hawaiian population that was part of Fort Vancouver and the fur trade. Heritage sites were chosen that have Indigenous connections, links to multiple cultures, the potential for contestation, multiple meanings, are open to the public, and managed by non-tribal governments. I selected heritage sites based on the availability of interpretation. Cultural centers were selected that are associated with heritage sites, used by specific communities and the public, and are "living" centers used for activities and education. FOVA staff vetted and approved the selected research sites. See Appendix B for site descriptions.

\section{Data Collection}

My research methods included systematic participant observation at case study sites on two research trips and semi-structured key consultant interviews with 15 individuals, typically with one or two individuals from each site. Research at heritage sites and cultural centers examined how contested, multi-narrative sites interpret site information to the public, including, but not exclusively, descendant communities, vacation visitors, veterans' groups, genealogical societies, and boosters. Research at cultural centers examined how these venues fulfill the needs of tribes, descendant populations, and other diverse stakeholders, such as community members and park visitors. The study also focused on the sites use by diverse actors, programming, funding, administration, and public interpretation.

At each site, I conducted systematic participant observation to collect data on the sites use by diverse actors, programing, funding, administration, and public 
interpretation. Participant observation is a data collection method in which the researcher is present at, and involved in, the activity and site being observed; from within the field setting, the researcher observes and records the activities of people and the site itself (Schensul and LeCompte 2013, 83). During each visit, I spent three to four days at each site conducting participant observation in which I documented the site, activities at the site, and the programming and interpretation at the site. I used "walkabout" to document the site, while also photo documenting signage, interpretive displays, and other important features of the space, creating a full description of each space and its use with photographs and notes (Schensul and LeCompte 2013). During the walkabout method, researchers walk through spaces, observing and documenting the site, atmosphere, characteristics, and other aspects important to the research topic (Schensul and LeCompte 2013). I photographed all signage and displays relating to culture and history, including some signage on other information. If available during my visit, I participated in activities occurring at each site, such as cultural demonstrations or tours and collected all interpretive and promotional materials made available to visitors. In this process, I not only observed the physicality of the space, but also what interpretive content is included at sites and how information, especially contested stories, about the past are presented and communicated to site visitors.

During each site visit, I also conducted key consultant interviews. Key consultants were selected through reputational case selection and convenience sampling. Reputational case selection uses the recommendations of experts or participants in the community to identify people suitable for serving as experts on the research (Schensul 
and LeCompte 2013, 285). Convenience sampling is the selection of research participants based on who is willing to take part in the research (Bernard 2011). Key consultants from the sites included people closely involved with the sites in roles such as managers, employees, interpreters, community stakeholders, and cultural practitioners. Because of high turnover rates at many National Parks, I considered past employees for key consultant interviews. I provided all key consultants with informed consent paperwork and explained that all questions were voluntary. See Appendix C for informed consent. Across the 10 case study and two supplementary sites, I conducted a total of 15 interviews, based on the availability of participants at each site. A list of interviewees is provided in Appendix A. Interviews had a semi-structured format, in which questions are open-ended, informational, in-depth, and exploratory (Schensul and LeCompte 2013, 171). Interview questions drew on participant experience, opinion, feeling, and background with a focus on the history and memory of the site as it relates to the intersectionality of meaning and current relations with the site's stakeholders (Ervin 2005, 168-173). Interviews focused on each key consultant's knowledge of the space, its history, management, use, interpretation, and ability to meet the needs of diverse stakeholders, while considering how site meaning is constructed and represented. Questions attempted to trace stories and experiences through time and space, while looking for where silences may have occurred in the recording and interpreting of history (Farmer 2004; Touillot 1995). Research questions also looked at how this recording and interpreting of history impacts current and future relationships with Indigenous populations, descendent communities, and other stakeholders. With consent, all 
interviews were audio recorded and transcribed for analysis. See Appendix D for interview questions for both heritage sites and cultural centers.

\section{Data Analysis}

Initial data analysis began during fieldwork as themes emerged in participant observation and interviews. I took notes on these reoccurring themes for use during analysis. I completed analysis of the research results in two parts. First, I analyzed photographs of displays, signage, interpretation, and imagery from participant observation, interpretive materials, and audio tours using inductive content analysis to identify common themes, messages, voices, and perspectives (Bernard 2011). Inductive coding is a systematic approach for analyzing raw data through detailed study to determine themes and concepts throughout the data (Thomas 2006, 238). I compared these results for similarities and differences across each site. I transcribed key consultant interviews for use in the analysis. For the second part of analysis, I coded interview transcripts for key themes and variables through inductive and deductive content analysis (Schensul and LeCompte 2013, 183-187; Bernard 2011). A review of transcripts generated inductive codes, and deductive codes emerged during coding; I used these inductive and deductive codes in succeeding coding (Bernard 2011). I then compared these results for similarities and differences across the sites, looking for common occurrences throughout all the interviews. This recursive analysis process divides the collected information into categories of main concepts relating to the research questions (LeCompte and Schensul 2013, 84). In this analysis, I used a political economy lens to understand the contextual influences on the sites, their interpretation, and their 
programming. In a final stage of analysis, I compared results from participant observation and interviews, paying specific attention to the intersectionality of meaning of places and how heritage sites satisfy the needs of diverse stakeholders. Using identified themes and lessons learned, I created a categorically based evaluation of the state of Indigenous content and representation at the case study sites. I used a thematic approach which identified best practices from research to create a baseline for evaluation of sites, looking at site information such as the level of Indigenous content, the characterization of Indigenous populations, and the forms interpretation takes. Once I completed this analysis, I reviewed the results for larger patterns in the data, determining five major themes. 


\section{RESULTS AND DISCUSSION}

My research found that although staff and cultural practitioners at heritage sites and cultural centers recognize the importance of contemporary relationships, a living Indigenous presence at sites, and the need for multivocal and balanced perspectives, site interpretation is largely established within the confines of the perspectives of the United States government agencies that manage the sites, resulting in interpretation that follows specific topics, shares little authority, and is univocal. Many sites established at and after contact have a historic colonial presence that still remains. Through this lasting historic colonial presence, colonial dynamics of the past continue to impact government and Indigenous relationships today and affect the interpretation established at sites (Onciul 2015). While the majority of people on the ground and working at case study sites recognized the need for establishing the intersectionality of sites in their interpretation, the pre-established powers of the governments that manage and interpret sites still largely influence the manner in which sites present information to visitors, seemingly leaving out the voices of differing perspectives and memories.

In the following sections, I discuss the findings that emerged in my analysis of interpretive content and key consultant interviews. By looking at the different aspects of the sites and addressing the questions of (1) what is the story being told, (2) who is telling the story, (3) how is the story told, (4) what are the contemporary relationships at sites, and (5) how are contemporary relationships shared with the public, we can better understand how the different histories and memories of a site influence their interpretation and programming. I found that (1) an established set of interpretive themes 
control the stories told at sites, (2) stories have a lack of shared authority, (3) shared stories have little hybridity, (4) contemporary Indigenous relationships with sites are rooted in ancestral memories and connections, (5) and sites share contemporary relationships with the public through live cultural programming.

\section{Established Interpretive Themes}

In general, a set of established interpretive themes control the stories interpretation shares at research sites. The interpretive stories told to visitors include the themes of Indigenous peoples, non-Indigenous history, contact history, and nature and geology. ${ }^{3}$ The presence of these established interpretive themes across the sites suggests an established heritage site narrative that controls discourse and follows a larger, collective United States history narrative. Part of nation-building is creating shared narratives, identities, and a sense of community through the power of establishments, such as museums that create representations (Anderson 1991). Smith further emphasizes that nations have used tangible and monumental heritage to share and legitimize national ideologies and identities of a collective memory of the past $(2006,48-49)$. Power lies in the production and reproduction of stories at heritage sites (Jackson 2016, 23). What heritage interpretation excludes and shares creates an account of history that continues to enforce standard Western narratives of the past through Euro-American perspectives (Zerubavel 1995, 11; Smith 2010, 34). As the interpretation at studied sites demonstrates, established interpretive themes further tell a larger, collective U.S. history narrative. This

\footnotetext{
${ }^{3}$ In this research, I used the term theme to describe the codes used in interpretive content analysis. Therefore, some of the themes in this project are larger topics of interpretation and may not be as dynamic as traditional thematic interpretive themes.
} 
U.S. narrative presents a constructed, commemorative history of the lives of Indigenous peoples' before and at contact with Euro-Americans, Euro-American expansion and success in the northwest and Hawai $i$, a coexistence of Indigenous peoples and EuroAmericans, and nature and its protection in American parks. These established narratives reinforce power dynamics and prevent stories outside these narratives, such as negative aspects of history and stories valued by Indigenous communities, from being shared. Beyond site messages for guiding visitors, ${ }^{4}$ the most frequently used interpretive themes at the case study sites are Indigenous peoples, non-Indigenous history, contact history, and nature and geology. ${ }^{5}$ See Table 1 for frequencies of these themes. Each of these interpretive themes occurs in more than one quarter of interpretive units. With the exclusion of site messages, individual sites, have a similar pattern to this overall larger trend of established interpretive themes. At each site, there are two or more interpretive themes that occur in one-quarter or more of interpretive units at the site. This occurs at both heritage sites and cultural centers. With only a few exceptions, studied site's major interpretive themes stick to these four most common interpretive themes. ${ }^{6}$ Within these

\footnotetext{
${ }^{4}$ Site messages is the most commonly occurring interpretive theme, found in $56.2 \%$ of interpretive units. This was not an unexpected result, since visitors to sites often require guidance and parks may need to enforce certain rules and regulations. This theme includes the sub-themes: activity guidance, artifact and building description and identification, mission and collaboration, regulations and rule, park creation and development, welcome statement, and respect due to cultural significance. The majority of these focus on providing information that guides visitor experiences and behaviors at the site, which is a necessity at most sites, so it would make sense that this is the most common interpretive theme. Topics that guide visitors are considered to be site orientation and not interpretation, but because of the nature of signage many site orientation signs also include interpretive content.

${ }^{5}$ Many themes co-occur in an interpretive unit and, as a result, there can be more than $100 \%$ representation of interpretive themes across the case study sites.

${ }^{6}$ Some sites include discussions of negative contact history and preservation and conservation in onequarter or more of interpretive units. Discussions of negative contact history typically are combined with contact history and discussions of preservation and conservation are often integrated with site messages about protection of the site or integrated with discussions of nature and geology.
} 
four established interpretive themes, there is a division of narratives across topics represented in the interpretive content at sites. This division of interpretive themes at individual sites demonstrates attempts to interpret more than one topic and aspect of each site, but the discussions within these interpretive topics demonstrate an established narrative within the interpretive themes.

Table 1: Top Interpretive Themes Occurring in More Than 15\% of Interpretive Units ${ }^{7}$

\begin{tabular}{lc}
\hline & Top Interpretive Themes \\
\hline Theme & Frequency \\
\hline Site Messages & $56.2 \%$ \\
\hline Indigenous Peoples & $35.3 \%$ \\
\hline Non-Indigenous History & $28.7 \%$ \\
\hline Contact History & $27.9 \%$ \\
\hline Nature \& Geology & $26.5 \%$ \\
\hline$N=731$
\end{tabular}
$\mathrm{N}=731$

Of the established interpretive themes, Indigenous peoples was the most commonly used across the research sites, occurring in $35.3 \%$ of interpretive units. Within this interpretive theme, there are multiple sub-themes, including Indigenous materials and lifeways, Indigenous history, traditional practices and beliefs, sacredness and connection to place, and Indigenous people and nature. Indigenous materials and lifeways, Indigenous history, and traditional practices and beliefs were the most frequent of these sub-themes. At many sites, these discussions focused on the ways that Indigenous populations lived before contact with Euro-Americans, often discussing how they fed themselves, tools they used, the organization of societies and communities, and spiritual practices or belief systems. When discussing settlement and exploration, these themes often place Indigenous peoples in contrast with Euro-Americans. For example, at

\footnotetext{
${ }^{7}$ Many of the interpretive themes co-occur in an interpretive unit and, as a result, there can be more than $100 \%$ representation of interpretive themes across the case study sites.
} 
Sacajawea Historical State Park individual interpretive units focus on events in contact history and Indigenous peoples. One interpretive unit near the entrance of the center discusses Thomas Jefferson's hopes for westward expansion and the beginning of the Lewis and Clark Expedition. This leads to more interpretive displays discussing the expedition and the contact they had with Indigenous peoples along the way. At a different location in the interpretive center, there is an area with a larger focus on Indigenous peoples. In this section, an interpretive unit discusses the Indigenous peoples that have lived on the land and their way of life. Other sites organize Indigenous interpretation into specific interpretive topics such as basketry, tools and weapons, foods, and clothing and shelter. Sites focused on Hawaiian heritage still follow these patterns, discussing Indigenous history and events, while also focusing on traditional beliefs and practices. Displays on Indigenous peoples often fit within set timeframes and pre-historic representations, with minimal discussion of the present (Onciul 2015, 132). This type of presentation of Indigenous peoples is seen across the research sites and demonstrates an established narrative of Indigenous peoples' lives before and at contact with EuroAmericans.

Non-Indigenous history, used in $28.7 \%$ of interpretive units, is the second most frequently used established interpretive theme, focusing on Euro-American experiences in history. U.S. military, exploration and settlement, the fur trade, missions and missionaries, and U.S. development are sub-themes of Non-Indigenous history. The most common of these sub-themes are U.S. military, exploration and settlement, and the fur trade. At many of the studied sites where this established interpretive theme is present, 
the discussion is focused on the establishment and life of military and fur trading forts, the life of soldiers and fort residents, the exploration and establishment of EuroAmericans in the northwest, and the establishment of missions. These themes often follow the greater American narratives of westward expansion and American success in the west. At Fort Spokane in Lake Roosevelt National Recreation Area, a series of interpretive units present U.S. military history, discussing the daily lives of soldiers and the lack of violence seen by soldiers at the fort. One interpretive unit discusses information like life in the barracks for soldiers and their different nicknames. This representation of non-Indigenous history focused on the U.S. military, exploration of the west, and the fur trade is seen at many of the case study sites, indicating an established narrative of Euro-American and U.S. expansion and success in the northwest, a common theme presented in U.S. history.

Another established interpretive theme across the sites is contact history, found in $27.9 \%$ of interpretive units. Contact history discusses both the positive and neutral experiences of Indigenous peoples and Euro-Americans in contact-era events with subthemes such as exploration and settlement, the fur trade, and missions and boarding schools. The most commonly discussed theme of these sub-themes is settlement and exploration. In interpretive units with this established theme, discussion focuses on EuroAmericans' interactions with Indigenous populations during westward and Hawaiian Island exploration and establishment, fur trade efforts, roles, and relationships, and missionary and boarding school interactions with Indigenous populations. In many instances contact history themes focus on Euro-American success or efforts in contact 
and collaboration with Indigenous populations, further supporting a positive American narrative. For example, at Fort Nisqually Living History Museum interpretive displays discuss the collaboration and fur trade efforts between Euro-Americans and Indigenous peoples. As seen in one interpretive display, the text discusses collaboration between Euro-Americans and Indigenous populations along with a description of the different roles people played at the fort. These positive and neutral accounts of contact during the settlement and exploration of the west, the fur trade, and missionary efforts is common across the case study sites and follow an established narrative of the coexistence of EuroAmericans and Indigenous peoples.

In a less human-focused subject, nature and geology is the fourth established interpretive theme. The theme of nature and geology is discussed in $26.5 \%$ of interpretive units. The two sub-themes of this theme are nature and geology and natural history, with nature and geology occurring more frequently. This interpretive theme largely discusses regional plants and animals, environment, bodies of water, and geological features such as volcanoes. These narratives focus on the important aspects of nature at the sites and at times include other interpretive themes to discuss human interactions with the environment. At Hawai'i Volcanoes National Park there are many instances in which interpretive units mix information on nature and geology with Indigenous history themes. For example, one trail guidebook interpretive stop mixes Indigenous knowledge and traditions into nature and conservation information, discussing the information as one fluid topic. This approach also helps to bridge the artificial divide between nature and culture, often expressed in heritage and interpretation (Harrison 2012). National parks 
were established beginning at the end of the nineteenth century, resulting in people beginning to work to preserve the wilderness from human advancement, furthering views of humans and nature as separate, and ignoring Indigenous people's removal from their traditional lands (Cronon 1996). Overall, the established interpretive theme of nature and geology exhibits a common narrative of nature and its protection in American parks through the lens of western conservation where the land is seen as other than humans. This, in turn, adds to the grand American narrative by further emphasizing the importance of nature and geology and Euro-American efforts to study and protect it.

In total, the established interpretive themes at research sites demonstrate the presence of a defined heritage site narrative that follows a larger, collective United States history narrative. The established interpretive themes of Indigenous peoples, nonIndigenous history, contact history, and nature and geology provide a broad understanding of the history of sites. These themes demonstrate common narratives on Indigenous peoples' lives before and at contact with Euro-Americans, Euro-American and U.S. expansion and success in the northwest and Hawai' $i$, a coexistence of EuroAmericans and Indigenous peoples, and nature and its protection in American parks. Together these interpretive themes provide a broad understanding of the history and people of sites, discussing multiple aspects of history of different people and times. This allows for the representation of multiple people, events, and topics at a site, but does not ensure multiple perspectives are present. Although these multiple themes provide multirepresentational interpretation, they fit within an established narrative of U.S. history that favors a larger common narrative and shared memory (Smith 2006, 58). As heritage sites 
and cultural centers develop interpretive plans and create interpretive materials, the work they develop is often still required to fit within the established site timeframes and stories. For example, a site interpretive theme of "a place where diverse human communities have formed, overlapped, and interacted over time," can continue to perpetuate interpretation of positive contact between Indigenous peoples and EuroAmericans and the success of Euro-Americans in settlement and the fur trade (United States Department of Interior 2004, 13). Staff hired to work at these sites, in turn often continue to interpret and create content within the confines of these established themes, missing the opportunity to challenge common narratives. These established narratives reinforce power dynamics and do not allow for other stories to be told, such as the negative experiences of Indigenous peoples during contact, the stories and history valued by Indigenous populations, the different experiences of place-based Indigenous populations with colonially-relocated Indigenous populations, or other narratives that do not fall within the common U.S. narratives of a place. Communities ignored or misrepresented in these common narratives may see these interpretations as degrading or incorrect (Macdonald 2016, 267). By telling different narratives, sites can challenge common memories and narratives and expand their representation of the past (Smith 2006, 49).

\section{Lack of Shared Authority}

By and large, the stories at studied heritage sites and cultural centers are largely told by a generalized narrative voice that shares some authority in telling the story with Euro-American voices. Authority in interpretation, in this research, is the ability of a 
group or person to speak for themselves, be taken seriously as knowledge holders, and be represented in the data (Onciul 2015). Across the case study sites, there is little shared authority and Euro-Americans tend to have more authority. The voice used, percentage of citations and quotations, and people named in history in the interpretive units demonstrate this lack of shared authority. Interpretive content analysis results on each of these aspects demonstrate that there is very little first-person voice present, with much more narrative voice present, more Euro-Americans are cited and quoted, and more EuroAmericans are named across interpretive units. While quantitative data results revealed little shared authority in the telling of stories at research sites, qualitative data from key consultants emphasized the need for living Indigenous voices at sites.

Voice is the perspective and style of communication in an interpretive unit (Onciul 2015). Narrative voice is a general, omniscient style of communication that does not indicate a specific group or person as the communicator. Across the interpretive units, narrative voice is the most common voice, occurring in more than three quarters $(76.1 \%)$ of interpretive units. The second most frequently used voice is management and park voice, found in $14.9 \%$ of interpretive units. See Table 2 for frequencies. Management and park voice is typically found in interpretive units focused on communicating rules and regulations to visitors. Management and park voice often communicates site orientation information. These two voices maintain authority in the site and its interpretation's omniscient voice, giving little authority to outside parties. A passive voice, such as these, gives no agency and removes responsibility for what is shared (Onciul 2015, 7). Narrative voice in interpretive units can convey a variety of information, but gives little 
or no authority to the people discussed in and connected with the history, such as Indigenous peoples' experiences of the past and present.

Table 2: Voice Used in Interpretive Units

\begin{tabular}{lc}
\hline & Voice \\
\hline Type of Voice & Frequency \\
\hline Narrative Voice & $76.1 \%$ \\
\hline Management \& Park Voice & $14.9 \%$ \\
\hline Euro-American Voice & $5.1 \%$ \\
\hline Indigenous Voice & $4.5 \%$ \\
\hline $\mathrm{N}=731$ &
\end{tabular}

The results indicated that Euro-American and Indigenous groups have very little authority, with Euro-American voice used in $5.1 \%$ of interpretive units and Indigenous voice found in $4.5 \%$ of interpretive units. Both of these are very low percentages of representation, with even less representation for Indigenous peoples. Across the sites, the use of Euro-American voice in interpretive units ranges from $10.8 \%$ to $0.0 \%$ and the use of Indigenous voice in interpretive units ranges from $10.5 \%$ to $0.0 \%$. This researcher recognizes that in some instances non-Indigenous voices are disproportionately available to agencies within historical sources, and obtaining and incorporating content from historical Indigenous sources and Indigenous voices can be difficult, have extra costs, and require extra effort and expertise to engage contemporary Indigenous communities. In many instances, the use of Euro-American or Indigenous voice occurs as an interpretive unit that consists largely of quotes, rather than a direct unquoted message. For example, interpretive units at Whitman Mission National Historic Site use Euro-American voice in the form of quotations from missionary diaries, which make up the entirety of the text in some interpretive units. Indigenous voice also often occurs in direct quotes from Indigenous peoples or through the use of traditional stories, similarly to Euro-American 
voice. There are some instances of Indigenous voice in interpretive units that share a message directly from Indigenous peoples without a citation. At Fort Spokane in Lake Roosevelt National Recreation Area, one interpretive unit has this type of Indigenous voice, providing a message directly from the local tribes. This creates a powerful message, but was rare across the sites. Although Euro-American and Indigenous voice is used in some interpretive units, it is infrequent. Through this lack of first-person and shared voice, there is a lack of shared authority across the sites.

Research found that across the studied sites, of all named people in history, EuroAmericans make up nearly two-thirds (65.6\%) of named people, while Indigenous peoples make up only one-third (34.4\%) of all named people in history. See Table 3 and 4 for frequencies. The percentage of both named Euro-Americans and named Indigenous peoples in history at each site ranges from $0.0 \%$ to $100.0 \%$. Many interpretive signs name several Euro-Americans, while naming only one or no Indigenous person. At only three sites, all with a distinct interpretive focus on Hawaiian heritage, do Euro-Americans make up less than half of all named people in history and Indigenous peoples make up more than half of all named people in history at each site. One example of an interpretive unit with more Indigenous people named than Euro-Americans from history is at Pu'ukoholā Heiau National Historic Site, in which the interpretive unit names five Indigenous peoples and only one Euro-American. In this example, all named Indigenous people were rulers. Overall, at three-quarters of the case study sites, Euro-Americans in history are named more than Indigenous peoples in history in the interpretive units. With all sites having Indigenous history and Indigenous peoples involved at the sites, this is a 
significant difference. This researcher recognizes that in some cases there may not have been names on record for Indigenous peoples, resulting in a greater number of named Euro-Americans. By naming more Euro-Americans from history than Indigenous peoples, the interpretive content may be placing more emphasis on the importance of Euro-Americans' roles in history. This seemingly provides Euro-Americans with more authority through greater representation and emphasized importance, resulting in little shared authority with Indigenous populations in telling the story of sites. Providing names of Indigenous people within interpretation can indicate their contribution and knowledge, demonstrating authority in self-representation (Krmpotich and Anderson 2005).

Table 3: Frequency of People from History Named in Interpretation

\begin{tabular}{lc}
\hline \multicolumn{2}{c}{ Named People in History } \\
\hline Named People & Frequency* \\
\hline Named Euro-American Person in History & $65.6 \%$ \\
\hline Named Indigenous Person in History & $34.4 \%$ \\
\hline $\mathrm{N}=839$ & \\
$*$ of total named people &
\end{tabular}


Table 4: Frequency of People from History Named in Interpretation by Site

\begin{tabular}{|c|c|c|}
\hline \multicolumn{3}{|c|}{ Named People in History at Each Site } \\
\hline Site & $\begin{array}{l}\text { Euro- } \\
\text { Americans } \\
\text { Frequency* }\end{array}$ & $\begin{array}{l}\text { Indigenous } \\
\text { Peoples } \\
\text { Frequency* }\end{array}$ \\
\hline Volcano Art Center Gallery and Niaulani Campus & $100.0 \%$ & $0.0 \%$ \\
\hline Fort Simcoe Historical State Park & $92.5 \%$ & $7.5 \%$ \\
\hline Whitman Mission National Historic Site & $91.3 \%$ & $8.7 \%$ \\
\hline Nez Perce National Historical Park & $88.7 \%$ & $11.3 \%$ \\
\hline $\begin{array}{l}\text { Fort Spokane, Lake Roosevelt National Recreation } \\
\text { Area }\end{array}$ & $86.1 \%$ & $13.9 \%$ \\
\hline $\begin{array}{l}\text { Spokane House Interpretive Center, Riverside State } \\
\text { Park }\end{array}$ & $74.5 \%$ & $25.5 \%$ \\
\hline Hawai'i Volcanoes National Park & $66.7 \%$ & $33.3 \%$ \\
\hline Sacajawea Historical State Park & $65.3 \%$ & $34.7 \%$ \\
\hline $\begin{array}{l}\text { Fort Nisqually Living History Museum, Point Defiance } \\
\text { Park }\end{array}$ & $58.9 \%$ & $41.1 \%$ \\
\hline Pu'ukoholā Heiau National Historic Site & $32.3 \%$ & $67.7 \%$ \\
\hline $\mathrm{Pu}$ 'uhonua o Hōnaunau National Historical Park & $7.5 \%$ & $92.5 \%$ \\
\hline Kamakahonu National Historic Landmark & $0.0 \%$ & $100.0 \%$ \\
\hline
\end{tabular}

Analysis of interpretive content also revealed that the most cited, quoted, and referenced group in the interpretive units at case study sites is Euro-Americans. EuroAmericans make up almost half $(46.4 \%)$ of all quotes and citations. Less than a quarter $(23.2 \%)$ of citations and quotes across all interpretive units are from scientists, historians, historic texts, newspapers, and other like sources. Similarly, less than a quarter $(22.1 \%)$ of citations and quotes are from Indigenous peoples. An additional $8.4 \%$ of quotes and citations are from traditional Indigenous stories. See Table 5 for frequencies. In general, this demonstrates more authority given to Euro-Americans than other groups. For instance, at Sacajawea Historical State Park many interpretive units quote Meriwether Lewis and William Clark's journals multiple times, giving authority to their accounts of the Expedition and their interactions with others. Likewise, many sites rely on the 
historical records of Euro-Americans for quotes. References to scientists, historians, newspapers, and other similar sources are made in a variety of ways, with direct quotes from scientists, historians, and historic records and journals or simple mentions of historical records or historians and scientists supporting statements made by the narrative voice. Both citations and quotes from Indigenous peoples and references to traditional stories represent Indigenous populations. Most citations from Indigenous peoples are fairly recent, which helps to emphasize that Indigenous peoples remain connected to sites. In contrast, the use of traditional stories may place Indigenous peoples in the past if they are presented only in pre-contact times without appropriate context. Quoted and referenced traditional stories and songs as direct quotations and references provide an additional small part or Indigenous representation. With a much higher percentage of citations, quotes, and references from Euro-Americans, there is more authority provided to Euro-Americans. Moreover, the citations and quotes from scientists, historians, historic texts, newspapers, and other similar sources further give more authority to the site and narrative voice. Indigenous people can have multiple identities and roles, allowing for the potential for Indigenous site staff or scientists, for example, that could be part of citations and quotes that might not recognize or highlight their Indigenous identity. This was observed in Hawaiian parks that provided quotations from Hawaiian scientists in interpretation. Although there may be a lack of physically documented history from Indigenous populations, there are still people who could potentially share this knowledge. Overall, this provides very little authority to Indigenous populations. 
Table 5: Frequency of Citations, Quotes, and References from People in Interpretation Cited and Quoted People in Interpretation

Cited and Quoted People

Euro-Americans

Frequency*

Scientists/Historians/etc.

$46.4 \%$

Indigenous Peoples

$23.2 \%$

Traditional Stories

$22.1 \%$

$\mathrm{N}=440$

*of total cited

As a whole, the use of narrative voice and little use of first-person voice, the high percentage of citations and quotations from Euro-Americans, and the higher percentage of named Euro-Americans across the interpretive units at the case study sites demonstrate that there is a lack of shared authority, with more authority given to Euro-Americans. The use of narrative voice provides little to no authority to the people discussed in and connected with the history being interpreted. Additionally, the lack of first-person or shared voice from Euro-American and Indigenous voices results in very little shared authority. The high percentage of Euro-Americans named and referenced provides EuroAmericans with more authority through more representation and emphasized importance in history, resulting in little shared authority with Indigenous populations. As Trouillot suggests, most historical records and accounts of the past typically do not tell what actually happened, but how the recorder of the event experienced it (1995, 2-26). The production of history occurs in situations of unequal power that silence the stories of the less powerful (Trouillot 1995). In giving authority to tell the story of a site to a general narrative voice and Euro-Americans, sites largely favor the Euro-American experience of history. Smith further suggests that groups under colonial powers, such as Indigenous 
populations, are left absent in the telling of history or, in limited instances, are "allowed" to share their stories $(2010,33-34)$.

In qualitative data, key consultants discussed the importance of voice and representation at these venues. Many research participants emphasized the importance of descendent and Indigenous voices at sites and the need to let Indigenous people tell the story. In emphasizing this importance, concerns were expressed by some interviewees that this was lacking at their sites or needed to be improved upon. Quantitative data validates these concerns, demonstrating a lack of Indigenous voice and fewer references and citations of Indigenous peoples in interpretation at sites. In discussing Indigenous voice in interpretation, key consultants expressed concern over who should represent Indigenous peoples, the need for making sure Indigenous voices are in printed interpretation, and the importance of emphasizing the current presence of Indigenous peoples.

Interpretive staff at case study sites voiced concern over the need to ensure that interpretation, especially live interpretation, on Indigenous peoples comes from Indigenous people themselves, rather than Euro-American interpreters. Interviewees discussed concerns of permission, oversimplification, or destructive representations from improper presentation. Costumed interpreters discussed the importance of only representing their own heritage and over the last few years decided not to dress a white woman, as a Metis. Research participants emphasized that the most respectful, responsible, and empowering way to present Indigenous stories would be from the communities as they see fit and with the knowledge they wish to share. The right voice 
presenting information can be very powerful and as one interpretive staff interviewee stated,

[I]f I go to a place where there is a Native American presence and you see the presence, the Native American presence in the park, but then some white person comes and tries to tell you that story. That to me can sometimes be ineffective because it seems like it's not that person's voice or that person's place to tell this story. And sometimes you want to hear it from the face, that Native face or, you know, and I think when you do tell it from that perspective and it's a Native Hawaiian or a Native American Indian tribe that's sharing this story it's powerful. It's way more powerful... But I think for some people, you know, having that, the right face to the story is an experience in itself.

Some studies have raised concern over strictly using Indigenous interpreters, suggesting that non-Indigenous interpreters can also share authentic information and interpretive staff have been trained in specific interpretive skills (Onciul, 2015). Creating programs and opportunities for Indigenous people to share their knowledge, stories, and experiences can be more effective than a Euro-American retelling the story through their own lens, in that it can create a connection to the community, provide Indigenous peoples' perspectives, share personal stories, continue oral history traditions, challenge stereotypes, and create experiences of intercultural contact (Onciul 2015, 207).

Interview participants emphasized that sites should try to include Indigenous voices and perspectives in their printed and interpretive materials, especially local Indigenous voices. One participant discussed the need to send site brochures out to local tribes for assistance in redesigning and incorporating Indigenous voice. Generally, Indigenous voices should be at the forefront of interpretation and interviewed interpreters want to include firsthand Indigenous perspectives. For some sites, interpretive staff suggested that one way to bring Indigenous voice to sites would be through audio 
recordings or short podcasts. This would offer Indigenous voice and, for sites unable to update interpretive signage, provide a manner of featuring Indigenous voices in interpretation. One interview participant also emphasized the importance of listening to and accepting the opinions of Indigenous collaborators when developing print materials. This interviewee described a situation in which print material was written with Indigenous knowledge holders, but later questioned and changed by a non-Indigenous person, taking away from the Indigenous voice and knowledge.

Many key consultants believed that emphasizing that Indigenous peoples are still living and present at sites is an important aspect of having Indigenous voice and perspectives. In emphasizing the present, site interpretation brings Indigenous populations' voices into interpretation and emphasizes that they are not just in the past. At sites that may not have Indigenous voice or interpreters, changing the language and semantics can help to accomplish this. As one interpretive staff member described, they go out of their way to use present tense and explain that living artists create art using traditional methods to reinforce that the story still continues today. To further emphasize the living presence of Indigenous peoples in interpretation, research participants highlighted the effectiveness of living history and live Indigenous interpreters and cultural demonstrators. One cultural demonstrator stated, "Really driving towards that living history part of it. Like, Oh, we go to the temple, we do rituals. It's part of our life. The temple is part of, of who we are now. [emphasis added]" This presence and live Indigenous voice can stress that heritage structures are still used and Indigenous culture is still present. 
Scholars and practitioners have increasingly encouraged sharing voice and authority in museums and heritage sites (Jackson 2016; Krmpotich and Anderson 2005; Lonetree 2012; Onciul 2015; Quinn and Pegno 2014). By sharing authority and voice with multiple populations, especially Indigenous populations, interpretation can better demonstrate the intricacy, variety, and nuances of cultures and history. Also, through shared authority and voice, heritage sites and cultural centers can bring Indigenous voices forward and create a space in which Indigenous communities feel represented (Onciul 2015, 7-8). Similarly, Jackson emphasizes the importance of descendent narratives in interpreting plantations, with the understanding that the historical slave trade still affects the current experiences of communities and individuals (Jackson 2016, 30). Although research participants emphasized the importance of Indigenous voices in interpretation, interpretive materials at the sites suggest that the power to tell the sites' stories is still largely held by non-Indigenous peoples. Overall, interpretation at studied heritage sites and cultural centers is mainly told by a generalized narrative voice that shares some authority in telling the story with Euro-American voices. The limited use of first-person voice, cited and quoted Euro-Americans, and named Euro-Americans in history demonstrate a lack of shared authority in interpretation. Indigenous voice at heritage sites and cultural centers can authenticate people's histories, experiences, and identities (Onciul 2015, 8). In privileging Indigenous voices in interpretation, sites can honor Indigenous experiences and history (Lonetree 2012, 169-171). By shifting the power of storytelling to Indigenous populations, heritage sites and cultural centers may be able to 
move away from singular stories and present a more complex understanding of people's experiences at sites.

\section{Little Hybridity}

The stories shared with visitors at studied sites appear to lack hybridity. Hybridity in heritage and museum research is the presence and recognition of varying meanings and history shared from multiple perspectives and voices, with differences existing without hierarchy (Quinn and Pegno 2014). Hybridity in interpretation is the presence of multiple knowledges, including both multivocality and polyvocality. This lack of hybridity at research sites results from univocal interpretation, that has little multivocality and minimal inclusion of negative contact history. Interpretation that is univocal demonstrates this lack of hybridity. Univocality is the use of a single voice or perspective in an interpretive unit. Three quarters (75.4\%) of the interpretive units across the case study sites are univocal, while less than one quarter (20.4\%) of the interpretive units are multivocal. Multivocality is the use or presence of multiple voices or perspectives in an interpretive unit. Additionally, there is a very low representation of negative contact history in the interpretive themes. Together, this shows that the majority of interpretive units maintain a univocal narrative that shares interpretive themes through a single voice and perspective, without recognizing the potential for other perspectives or opinions. This results in a lack of hybridity or a lack of recognition of the varied and overlapping history and meanings that are shared at each site. While quantitative results revealed little hybridity in the telling of stories, qualitative data from research participants emphasized the need for multivocality and balanced history at sites. 
Univocal interpretive units provide a single voice or perspective on the interpretive theme presented, resulting in a lack of hybridity in interpretation. Across the sites, the percentage of univocality used ranges from $41.9 \%$ to $90.2 \%$. See Table 6 for frequencies by sites. This type of vocality appears as interpretation that often seems neutral, but does not recognize the presence of different perspectives. I selected case study sites based on their connection to multiple groups of people, which would suggest that there is some hybridity or variance in peoples' perspectives on the history of the sites. The univocality in interpretive units does not reflect this hybridity. One example of this is an interpretive display from Fort Nisqually Living History Museum, in which the text discusses changes occurring along a trade route without recognizing the potential for different perspectives on what this change meant, especially for the local Indigenous populations. Although very common across all the case study sites, univocality provides a narrow perspective of the past and present, resulting in a lack of hybridity in interpretation.

Table 6: Frequency of Univocality in Interpretive Units

\begin{tabular}{lr}
\hline \multicolumn{2}{c}{ Univocality in Interpretive Units at Each Site } \\
\hline Site & Frequency* \\
\hline Kamakahonu National Historic Landmark & $100.0 \%$ \\
\hline Fort Nisqually Living History Museum, Point Defiance Park & $90.2 \%$ \\
\hline Spokane House Interpretive Center, Riverside State Park & $88.3 \%$ \\
\hline Volcano Art Center Gallery and Niaulani Campus & $76.0 \%$ \\
\hline Hawai‘i Volcanoes National Park & $75.9 \%$ \\
\hline Sacajawea Historical State Park & $73.1 \%$ \\
\hline Whitman Mission National Historic Site & $72.0 \%$ \\
\hline Nez Perce National Historical Park & $70.9 \%$ \\
\hline Fort Spokane, Lake Roosevelt National Recreation Area & $67.4 \%$ \\
\hline Pu'ukoholā Heiau National Historic Site & $61.8 \%$ \\
\hline Pu'uhonua o Hōnaunau National Historical Park & $57.9 \%$ \\
\hline Fort Simcoe Historical State Park & $41.9 \%$ \\
\hline${ }^{*}$ of total number of interpretive units at each site &
\end{tabular}


Less than one-quarter of all interpretive units were multivocal. Multivocality allows for the presence of multiple voices or perspectives, creating hybridity in the interpretation. The percentage of multivocality used across the sites ranges from $2.2 \%$ to 29.1\%. See Table 7 for frequencies by sites. When used in interpretation multivocality can remain neutral or take a stance on the topic. The use of multivocality at the sites ranged from simply using terms or statements to suggest there may be other perspectives, to sharing multiple perceptions in one statement, or to interpretive units that place the different perspectives side-by-side. At Pu'ukoholā Heiau National Historic Site, one interpretive unit is multivocal by stating that there are multiple perspectives on a topic, even though only one may be presented in the following interpretive units. Other interpretive units create multivocality by stating contrasting views or opinions that might contradict a common narrative. Fort Spokane in Lake Roosevelt National Recreation Area has an interpretive unit that does this, making it clear that for many Indigenous populations the boarding schools were not a positive experience. Some interpretive units at Sacajawea Historical State Park create multivocality by putting different perspectives side-by-side on a rotating display, such as scientific and Indigenous views on salmon. These different approaches to multivocality can create an understanding that multiple perspectives and opinions are present at a site, creating hybridity in the interpretation of the site. But, with less than one-quarter of interpretive units using multivocality, hybridity, in general, is not being created. 
Table 7: Frequency of Multivocality in Interpretive Units

\begin{tabular}{lr}
\hline \multicolumn{2}{c}{ Multivocality in Interpretive Units at Each Site } \\
\hline Site & Frequency* \\
\hline Pu'ukoholā Heiau National Historic Site & $29.1 \%$ \\
\hline Hawai‘i Volcanoes National Park & $27.1 \%$ \\
\hline Nez Perce National Historical Park & $25.5 \%$ \\
\hline Fort Spokane, Lake Roosevelt National Recreation Area & $25.3 \%$ \\
\hline Sacajawea Historical State Park & $24.7 \%$ \\
\hline Whitman Mission National Historic Site & $24.0 \%$ \\
\hline Pu'uhonua o Hōnaunau National Historical Park & $21.1 \%$ \\
\hline Volcano Art Center Gallery and Niaulani Campus & $12.0 \%$ \\
\hline Fort Nisqually Living History Museum, Point Defiance Park & $4.9 \%$ \\
\hline Spokane House Interpretive Center, Riverside State Park & $3.3 \%$ \\
\hline Fort Simcoe Historical State Park & $2.2 \%$ \\
\hline Kamakahonu National Historic Landmark & $0.00 \%$ \\
\hline *of total number of interpretive units at each site &
\end{tabular}

The interpretive theme of negative contact history only occurs in $12.0 \%$ of interpretive units across all the research sites. Compared to many of the other interpretive themes, this is a low percentage. Sub-themes within negative contact history include war and violence, missions and boarding schools, reservations, disease, and land destruction; these aspects of sites are important in understanding a site's full history. These topics provide a different perspective of the past, that does not fit within the positive and neutral aspects of history. In this lack of negative aspects of history, there is less hybridity in interpretation. Negative aspects of history may be difficult to discuss at sites that do not want to offend visitors. Discussing negative parts of the past and topics such as war, violence, boarding schools, reservations, disease, and land destruction can provide a better understanding of the different aspects of a site's history and the multiple perspectives people have of the past. In providing these different perspectives and aspects of history, interpretation can demonstrate hybridity. For example, at Fort Simcoe 
Historical State Park one interpretive unit discusses treaties and addresses the negative aspects of this part of history, creating hybridity in the site's interpretation in that unit. Although these examples exist throughout the sites, they are very minimal. At case study sites that do attempt to interpret negative aspects of history, key consultants emphasized that visitors to sites tend to come to learn general American and site history, but respond well to negative information in interpretive texts and talks. Many interview participants emphasized that since their audience is so wide and changing, in interpretive talks they tried to gauge how much people were comfortable with. At Fort Spokane in Lake Roosevelt National Recreation Area, visitor reflection cards demonstrated sadness over the history they had learned about boarding schools, but also emphasized the importance of such difficult aspects of the past being shared in interpretation. An important aspect of negative messaging is considering who sets the agenda and consideration may need to be given to what topics are important to and approved by those connected with the history, especially Indigenous peoples. A lack of use of the interpretive theme of negative contact history results in a less hybrid interpretation and representation of the past through a lack of multiple perspectives. The limited discussion of negative contact history further perpetuates the existence of established interpretive themes. By excluding negative contact history and focusing on the neutral and positive aspects of contact, sites maintain the common U.S. narratives and present less diverse perspectives of the past (Smith 2006).

The high use of univocality, limited use of multivocality, and the low representation of the interpretive theme of negative contact history demonstrate a lack of 
hybridity in the interpretation at case study sites. Univocal interpretive units provide no hybridity by only representing a single perspective. Furthermore, the lack of multivocal interpretive units results in a lack of hybridity through the absence of multiple perspectives. The low percentage of interpretive units discussing the interpretive theme of negative contact history creates interpretation with less hybridity in its representation of the past. In total, this results in interpretive units that maintain a single perspective and little recognition of the varied and overlapping history and meanings at each site, suggesting a lack of hybridity in interpretation. Aspects of the past are often silenced in the creation of narratives of history that are univocal (Touillot 1995). Farmer suggests that the erasure of history is a part of the process of creating "hegemonic accounts" of history $(2004,308)$; through a lack of hybridity in interpretation, the history told largely remains neutral and there is less challenge to the grand U.S. narratives being shared.

Several key consultants stressed the importance of creating spaces, programs, and interpretation that support multivocal and balanced perspectives as an essential aspect of heritage sites and cultural centers. In emphasizing multivocality, some interviewees expressed concerns over sites having too narrow of a focus or not enough depth in certain aspects of interpretation, such as Indigenous perspectives. As quantitative data demonstrates stories told at case study sites lack hybridity through multivocality and the inclusion of negative and difficult aspects of history. Research participants expressed the need for sites to provide multiple perspectives and balance different aspects of history in their relationships and programming. Through these types of actions, interview participants felt that sites could provide the multivocal and balanced perspectives that are 
needed at sites to potentially allow for a better understanding of the intricacies of sites' histories and the people that experienced them.

Research participants identified the need for multiple viewpoints in interpretation and programming as a way to create sites that provide multivocal and balanced perspectives. Creating interpretation and programming that provides multiple perspectives comes from recognizing that there are different ways of knowing, using different methods to provide multiple perspectives and voices in the interpretation, and understanding that there is no singular group perspective.

By and large, each site has its own distinctive history and peoples connected to it. These histories are multi-faceted, with different ways of knowing and understanding the past and present. People will each bring their own perspectives to a site and these can be considered in the decisions made in interpretation in order to create a story at heritage sites and cultural centers that demonstrates these different perspectives and opinions. Some sites show this in how they name places and features. Names and languages can have different meanings depending on the understanding a person brings with them and this can be used to share difficult aspects of history. Thurston Lava Tube in Hawai ' $\mathrm{i}$ Volcanoes National Park is named after a man many Hawaiians disagreed with. As one interviewee explained,

And yet we have perhaps the world's most famous lava tube here named after him (Lorrin Thurston). I'm surprised that's not controversial. You see controversy can work both ways. And you know, you could have something like, like the name of a place... It reminds me of the confederate statues, you know, it's that this guy is honored and there are people and you know, we do have a name, Nahuku is the name of that, Hawaiian name that was given, it's more of a contemporary name, but officially it's still the Thurston Lava Tube. It's in all of our print media and all of the 
maps of the, but um, I think that we, you know, it should be named Nahuku and, and not Thurston as an example. And then maybe why that, letting people understand like why that could be offensive to some people to name, uh, this really cool feature with, um, someone who's connected to a huge injustice and tragedy.

Although this example focuses on a name, it demonstrates how understandings of sites and history can differ. Interview participants encouraged that the local and Indigenous perspectives were given priority, but for that to occur different ways of knowing needed to be recognized first. Another interview participant suggested the importance of recognizing different ways of knowing and encouraged combing these different knowledges. Referencing Dr. Robin Wall Kimmerer's Braiding Sweetgrass, Indigenous Wisdom, Scientific Knowledge and the Teachings of Plants, the interviewee stated, "[Y]ou've got these three different ways of knowing, of plant wisdom, Indigenous knowledge, and then scientific information. And so instead of pitting any of those against each other, she says, you know, braid those together and then let them inform each other." In recognizing multiple ways of understanding, sites can create spaces and interpretation that understand and incorporate these different perspectives.

Key consultants emphasized a desire to find creative ways to provide multiple perspectives and voices in order to provide sites with multivocal and balanced viewpoints in their interpretation. Participants cautioned the use of single stories and instead argued for interpretation that used multiple methods such as audio, visuals, personal stories from different individuals, and living history to tell multiple stories and perspectives. Some sites use Indigenous knowledge and views of the world and nature to incorporate multiple perspectives at a site. In discussing the nature and geology of Hawai ${ }^{i} i$ Volcanoes 
National Park, the site incorporates Indigenous perspectives and knowledge throughout the interpretation. Interviewees discussed that interpretation should recognize the contested and negative aspects of history that occurred at sites. At Fort Spokane in Lake Roosevelt National Recreation Area, an interpretive staff member discussed the site's use of side by side perspectives on different aspects of the site's history. Quotes from soldiers contrasted by quotes from children of the boarding school "brought the story to light for many folks." Another participant emphasized the need to address the difficult aspects of sites, explaining the importance of discussing unpleasant topics so that people can learn from the past. In providing these different voices and perspectives, sites can make different communities feel welcomed and validated, bringing relevancy to their sites.

Understanding that there is no singular group perspective can be a key aspect of creating heritage sites and cultural centers that provide multivocal and balanced perspectives. Several interview participants emphasized this point, with one stating, "No two people have the same opinion as to what really happened." Each person within a community has their own perspectives and opinions on what occurs in the past and present. This sentiment is true in Indigenous communities and perspectives presented at sites can try to recognize this. For example, at Fort Nisqually Living History Museum interpretive staff are aware of this in how they discuss Indigenous perspectives with visitors and in interpretation. As one staff member explained,

As I'm telling you this Native American's view, that person's view, remembering that's theirs and theirs alone. They're not speaking for a whole tribe of people and it's their experience and there's value in that, but it doesn't necessarily translate into a whole tribe's point of view or a group of individuals point of view. And so, looking at that that way that as I'm speaking to this, I recognize those individuals are sharing with me their 
individual stories, their individual experiences. And it's not necessarily broader than that.

By and large, in providing Indigenous perspectives and voice at sites, it is important to recognize that within groups there are several perspectives and different voices. There is no one Indigenous voice, but many, and in recognizing this, sites can create multivocal and balanced perspectives.

Research participants identified the importance of balancing different aspects of history, as a way to create sites that provide multivocal and balanced perspectives. By touching on all the different parts of history, a site can enhance interpretation and create a balance of what is presented. Site staff discussed that creating a balance in interpretation can be difficult, but they continue to try to be inclusive. As quantitative data demonstrated, established interpretive themes tend to guide interpretation and negative aspects of history are rarely discussed. By providing a balance of negative and painful aspects of history to the positive and neutral aspects that are more commonly discussed in interpretation, sites have the opportunity to create conversations and potentially lead to better cultural understanding. One interviewee explained the importance balance can have in cultural understanding, stating,

[I]f we can help the visitor understand the Hawaiian history, to the point where they... have some respect for Hawai' $i$ and for not only Hawaiians ...the whole history of Hawaiians... [T] he history is quite difficult at times, with the overthrow of the Hawaiian kingdom and then being annexed to the United States. And many Hawaiians feel it was an illegal annexation and that America is occupying Hawai' $i . .$. I think that side of the story is important to tell as well as the culture sharing, the cultural demonstrations, and all of that. But I think it's important to balance it. I think it's important to also say that history and have a place to say it in the park... And sometimes it can be difficult to share that story with folks. But I think when you share it with visitors who don't have all of that history 
about Hawai'i, it helps them to understand things even better. And it also helps to validate stuff with the Hawaiian community... If we can add into our interpretation parts of our history that are not as easily talked about or told, then I think that will help people better understand Hawaiians and Hawaiians today, the connection between the Hawaiians today and why there's so much mistrust in the government. So it helps for everyone else to understand why we, why Hawaiians may not trust the government... So, it's those difficult stories that need to be told.

Through a balance of topics, sites can move towards cultural understanding and make Indigenous populations feel more understood and represented.

Heritage sites and cultural centers can encourage reflection on history and diverse perspectives can be represented and better understood by incorporating multivocality and hybridity in interpretation (Kryder-Reid 2016; Balellantyne et al. 2012). In combining different perspectives of a site's history based on people's own knowledge and memories, interpretation can demonstrate the complexity of a site and its history and meaning to different people (Haraway 1991). Furthermore, including Indigenous and multiple voices in interpretation can help to provide multiple perspectives and ensure that non-colonizer voices are expressed in places where they lack power (Butler 2011). This process can reduce bias, challenge misinformation, and address contested history in a meaningful manner (Onciul 2015, 163). Altogether, studied heritage site and cultural center interpretation maintains a univocal narrative. This narrative shares interpretive themes through a single voice and perspective, with little recognition of the potential for other perspectives or opinions, resulting in a lack of hybridity in the discussion of sites' history and meanings. While recognizing this limitation, research participants emphasized the need for multivocality and balanced history at sites. By telling the story of sites in a manner that is multivocal and hybrid, heritage sites and cultural centers share the power 
of representation and the complexity of sites is better understood in a manner that can enhance cultural understanding.

\section{Contemporary Indigenous Relationships Rooted in Ancestral Memories and}

\section{Connections}

Heritage sites and cultural centers serve and provide meaning to varied groups and peoples in different ways. Interview participants discussed a variety of visitor connections and reasons to visit sites that demonstrate the contemporary relationships of people with places of heritage and cultural centers. The most commonly discussed meaning of sites to visitors and staff was ancestors' memory and connection. Visitors' desire to honor their ancestors' memories, connect with the past, visit a place important to their culture and people, and practice traditions on traditional lands is evidence of ancestral memories and connections importance in contemporary Indigenous relationships. Similarly, key consultants suggested that visitors, staff, and cultural practitioners wanted to teach and learn their own culture and identity at case study sites. Other reasons interviewees felt connected to sites and believed visitors felt connected to and drawn to sites were nostalgia for the site or park, history interests, recreation and fun, inspiration and experience, and science and learning.

Key consultants emphasized that a living Indigenous culture across the landscape and throughout the past and present is an important aspect for heritage sites and cultural centers. This Indigenous presence is important in understanding contemporary relationships at sites. The importance of cultural and ancestral connections to sites and the land expresses the presence of living Indigenous cultures across space and time. At 
several of the studied heritage sites with colonial histories, these connections were important to many different populations, but the importance of the connections for Indigenous peoples connected to the land was strongly emphasized. This cultural and ancestral connection is reinforced through ancestral memories and spirituality, the importance of these sites in teaching and learning one's own culture, and the ability to conduct cultural practices at sites.

According to research participants, many people connect to heritage places by the memories of their ancestors that were once at the site and visit to honor their ancestors and their cultural connections to the past. Although many interview participants emphasized this connection for Indigenous populations, this tie to ancestors from a site was a universal theme. Visitors to sites have military, fur trade, and missionary ancestral connections. Staff explained that many visitors come and share stories about their ancestors who were once there. Some visitors recall memories of their grandparents sharing about their experiences at sites, such as growing up in a boarding school or gathering food by a river. One interviewee explained,

I have had some tribal members talk about remembering their grandparents telling them stories of coming out here to harvest plants, to catch salmon. And prior to the dam, heard a lot of people talk about how a lot of the older folks who come out here talk about how the McNary Dam altered this, what it used to look like before the dam went in.

Other visitors point out pictures or the names of their family in interpretation at sites and ask questions about their family and ancestors that were there. Cultural practitioners strongly emphasized how a spiritual and personal connection was something that brought many people to sites, especially Indigenous populations. Cultural practitioners at 
Hawaiian sites emphasized the sacredness of some sites, describing how some people are spiritually called to these places. As one interview participant stated,

So, I have that, which is a very personal, very spiritual relationship with the place. And because I've taken the time to learn the rituals that also means I've basically made a commitment in my life to always come back and always to maintain those things, to make sure they happen. One day I'm going to have to teach these things to someone to pass it down to make sure that these traditions continue. Which is why we have a whole kind of a whole family, an entire Ohana, of people dedicated to these practices and to making sure that they can continue when the day comes that I'm not around, you know, and things like that. So, yeah, I have a very, a very personal relation, with the Place of Refuge, with these grounds through that cultural connection and as one of the Ritualists and caretakers of the site.

Through these ancestral memories and spiritual relationships with sites, people are able to connect with their ancestors' memory and culture.

The ability to teach and learn one's own culture and identity is an important aspect of living Indigenous culture and contemporary relationships at case study sites. Interview participants emphasized the importance of place-based leaning and teaching at these sites where the heritage and culture is in the landscape. Many emphasized that part of this cultural education was for children and community members who may not have had access to this knowledge. Although not all Indigenous visitors come to sites to learn the difficult parts of their history, some interview participants discussed how families have come to sites to learn those aspects and share them with their children, such as their great grandparents' experience at a boarding school. Many sites support this by providing Indigenous populations with the ability to teach and learn traditional crafts and practices on location. At Fort Nisqually Living History Museum one individual is working with the 
site to develop a Chinook Jargon language "guild" that speaks and learns the language and another individual offers basket working classes at the site. One cultural practitioner discussed visiting an important heritage site regularly and for events with students to teach them traditional cultural practices, learning chants, hula, crafts, gardening, food preparation, and more. By visiting these sites and learning or teaching traditional practices and crafts, Indigenous people are able to work towards perpetuating their culture and sharing it with others, especially children so that the knowledge and practices can continue. The importance of cultural perpetuation was recognized by both staff and practitioners interviewed at sites. As explained by one interview participant, "And that's all we do here is to perpetuate the culture or teach other people so they can teach other people too."

Cultural practices at sites are part of the important ancestral and cultural connections Indigenous populations may have with sites. Traditional cultural practices allow for Indigenous populations to honor ancestors and places and engage in spirituality. These practices can range from leaving offerings, to hula or chants, or more in-depth ceremonies. At Hawai' $i$ Volcanoes National Park many Indigenous people come to the park strictly to pay ho'okupu, or leave offerings. These types of practices happen at other sites as well. As one interviewee explained,

We have the local community come over. You know, a lot of them come and they like to place their ho 'okupu or say, do a chant, you know, oli before, and place the ho' okupu either, like I said, going on the Heiau to place the Ho'okupu, but letting us know, or just placing it where the lele is, yeah. And a lot of them come as a respect of the area, a lot of local people do that from all islands. 
Other cultural practitioners come to the site and perform hula to pay homage to Pele and access and use archaeological features in cultural practices and rituals. Typically, both private and public cultural practices are important. Many offerings are left in visible locations during the day while sites are open to visitors. At some sites, cultural practices occur when the site is closed to the public to provide privacy. Research participants expressed that an important aspect of cultural and traditional ceremonies and practices at sites is protecting and aiding the cultural practitioners. One part of this is helping the public to understand that sites are sacred and that the cultural practices, including offerings and ceremonies, deserve respect. At Hawai ' $\mathrm{i}$ Volcanoes National Park in order to provide a safe and respectful environment for reflection and cultural practices, a sign is placed along the trail requesting quietness and respect from visitors. At other sites such as Pu'uhonua o Hōnaunau National Historical Park, rangers help to explain cultural practices to visitors and request respect and distancing from them. A cultural practitioner described this, saying,

To be able to be down here, to be able to put on the loin cloth and carry our Lonomakua across the trail and do our rituals at the site, and to actually have Park Rangers not only witness the thing, but they'll actually help regulate crowds so that we can go in and, and, and complete our ritual and leave. And, and to know that we have Park Rangers that are letting visitors know that, 'Oh, you know, this, this isn't a show. It's not a performance, but if you want to stand here and witness it, you're absolutely welcome to do that.' And they actually explain to the visitors what we're doing and then we can just do our thing and leave and we don't even have to talk to the tourist. [F]or me, that's been really, really amazing. In contrast to going over to Kealakekua Bay in the same day... and we go up on the temple, a lot of times we have to have one of our own group, kinda stand outside the temple and you got to tell people, 'No, you can't follow us in. This is a cultural practice going on...' We have to, yeah, kind of ask people not to take pictures, not to interrupt us. And sometimes 
we have people shouting at us to get off... And so, it's, yeah, it's just a whole different environment. Whereas when we're here, it's like, it's almost like we're in a safe place to just do the practice... [B]y supporting cultural practices, you're actually supporting the park cause it's the cultural practice that brings the life to the park.

By providing protection and aid to cultural practitioners during traditional and cultural practices, sites enhance these practices and give more freedom to those doing them.

The contemporary relationships at sites vary by visitors and staff. Research participants felt connected to sites and believed visitors feel connected with and drawn to sites because of nostalgia for the site or park, history interests, recreation and fun, inspiration and experience, and science and learning, but most commonly because of ancestors' memory and connection. A living Indigenous culture and presence is important in understanding contemporary relationships at sites. This presence of living Indigenous cultures across space and time at sites is expressed in the importance of cultural and ancestral connections to sites and the land. Ancestral memories and spirituality, the importance of heritage sites and cultural centers in teaching and learning one's own culture, and the ability to conduct cultural practices at sites reinforce this cultural and ancestral connection. As Baird explains, heritage landscapes can serve as places of memory and belonging, knowledge holders, and places of identity negotiation of communities and nations $(2017,4)$. This contemporary relationship with sites serves to connect Indigenous populations to these aspects of heritage. In total, research participants suggested that contemporary Indigenous relationships are rooted in ancestral memories and connections. These cultural and ancestral connections are reinforced in the 
memory and spirituality of places, the importance of sites in teaching and learning one's own culture, and the ability to conduct traditional cultural practices at sites.

\section{Contemporary Relationships Shared Through Live Cultural Programming}

Contemporary relationships at sites look very different in site interpretation than in the programming discussed by interview participants and observed during field research. Case study sites share contemporary Indigenous relationships with the public with minimal interpretive content, relying largely on live cultural programming and demonstrations that create a living Indigenous cultural presence at sites. Similar to the patterns of who tells and how site stories are told, interpretive materials at sites do not meet the desires and programming established by research participants.

Quantitative analysis of interpretive units demonstrated minimal interpretive focus on the theme of cultural continuity, contemporary peoples, and cultural education. This theme included discussions of cultural continuity, contemporary Indigenous peoples, topics of continued Indigenous cultural education, current practices, and contemporary projects and collaborations. Many of these contemporary references were in the form of quotes from contemporary Indigenous people, discussions of contemporary traditional practices, beliefs, and education, and the sharing of contemporary projects and collaborations. Only $9.6 \%$ of interpretive units used this interpretive theme and $0.0 \%$ to $17.2 \%$ of interpretive units at each site discussed cultural continuity, contemporary peoples, and cultural education. This indicates fairly minimal interpretation of contemporary Indigenous people and relationships at sites. Excluding or minimally interpreting contemporary relationships and peoples can be problematic in that it tends to 
"reinforce the view of static, unchanging cultures," ignoring the living people and the cultural importance and relevance of places, structures, and artifacts (Lonetree 2012, 14).

Interview participants indicated that case study sites share contemporary relationships with the public through Indigenous programming that establishes a living presence of Indigenous cultures at sites. This effort to share contemporary relationships and a living Indigenous presence contrasts with the lack of these topics in interpretive units at sites. Case study heritage sites and cultural centers provide a variety of programming used to educate, engage, and entertain visitors. Established Indigenous programming at sites is offered in the form of collaborative educational programs, cultural demonstrations, and cultural events.

Staff at sites discussed a variety of educational programming offered at sites and Indigenous programs were largely the result of collaborations. With the help of collaborators, some sites are able to offer classes workshops, and other educational Indigenous programs on a weekly basis. These programs are often free to the public and funding often comes from partner organizations. A partner program at Sacajawea Historical State Park brought in a Nez Perce educator who talked with students from a local school. This interaction created a tribal voice and presence, that the site hopes to replicate with future programs. These types of programs are important to emphasizing Indigenous people's current presence and sharing meaningful stories. One interview participant stated,

[T] he live programming is kind of where it's at. Because like, that's where you can really get, like, modern relevancy to the context of these stories. To me, that's been some of the more memorable stuff in my career has been these events and these opportunities to participate in tribal 
community events in parks that are working with modern carvers doing traditional carving, but, you know, teaching people how to do that. I mean, there's a lot of things we could be doing in a modern programming sense...

Without these programs, many sites would lack much of their living Indigenous presence.

In general, cultural demonstrators are an important aspect of establishing and sharing an Indigenous presence and relationship at sites. Demonstrations from cultural practitioners and teachers create a regular tribal presence at sites that is educational and can result in close interactions. Staff at several sites discussed how cultural demonstrators provide hands-on teaching of traditional crafts, working closely with visitors.

Demonstrations include a variety of activities such as language teaching, basket making, lei making, food preparation, planting, and other traditional crafts. When discussing the effectiveness of sites, one cultural practitioner emphasized the importance of cultural demonstrations, stating they are effective because "they're constantly trying to ensure that it's the local/Hawaiian community that's leading those programs." Not all cultural demonstrators provide hands-on training. At Pu'uhonua o Hōnaunau National Historical Park cultural demonstrators wear costumes and spend time carving or basket weaving and speaking with visitors as they stop by. Other practitioners spend time doing demonstrations at the site, creating a living history for visitors.

[W] hen someone comes down and it becomes a regular part of the experience to, you know, 'Oh, there's people working on canoes.' And, and not just one guy working on canoes. It's, 'Oh, it's a class of students.' And it's like, 'wow, so the schools are involved here.' When they have the groups of women weaving in the other house and it's like, 'Oh wow.' And they can see how they take the leaves from the tree and how they use the resource and, and what the resource transforms into. That yeah, that just creates a sense of relevancy and they can see like, 'Oh, wow, yeah, this is a 
living cultural practice and we're getting to witness it happening right here.' And this is one of the places where that happens. And you know, there's not a lot of places where the culture can live in that way, that it does down here.

Having cultural demonstrations at sites continues cultural traditions and brings a living presence and relevancy to the site.

Cultural events at heritage sites and cultural centers can create large impact Indigenous programs and highlight contemporary relationships. Interview participants that described these events emphasized the large number of cultural demonstrators that participate in these events and the public draw these events have. Cultural events can often include cultural practices, hands-on learning of arts and crafts, and food. Staff discussed that these events are often hosted with partners and cultural practitioners are compensated in some form. At the Annual Ho'oku'ikahi \& Establishment Day Hawaiian Cultural Festival at Pu'ukoholā Heiau National Historic Site practitioners conduct both private and public ceremonies. An important aspect of this event is providing private opportunities for group interactions and ceremonies. One cultural practitioner stressed the importance of cultural demonstrations and ceremonies, but also the significance that the event feels like a reunion for those who attend and participate each year. The public ceremonies are open to anyone and those that attended the event in July 2019 were respectful. These types of cultural events are a significant experience and Indigenous presence for not just visitors but also those who participate.

In creating interpretive materials and programs that demonstrate an Indigenous presence at sites, contemporary relationships are shared with the public in meaningful ways. Although contemporary relationships are minimally represented in interpretation at 
sites, collaborative educational programs, cultural demonstrations, and cultural events serve to share contemporary Indigenous relationships and presence at sites. For example, a collaboration from southern Nevada illustrated Nuwu/Nuwuvi (Southern Paiute/Chemehuevi) connections to federally managed lands through welcome statements, various forms of dynamic interpretation and public art as well as programming, such as multigenerational events and cultural practitioner programs (Spoon and Arnold 2012). Through these interpretive messages and programming, sites are able to share contemporary Indigenous relationships with the public. Overall, interpretation at studied sites demonstrated minimal discussion of contemporary Indigenous people, while live cultural programming and cultural demonstrations create a living Indigenous presence at sites. 


\section{CONCLUSION}

In response to needs identified in collaboration with the ongoing Fort Vancouver National Historic Site Traditional Use Study, this research examined how heritage sites and cultural centers fulfill the needs of Indigenous and other diverse stakeholders, such as park visitors and community members. My research studied the roles of history and memory in the intersectionality of meaning at heritage spaces and how this influences a wide range of aspects of these places, such as their interpretation, use, and management. Using an inductive approach, I analyzed the interpretive content and programming of 10 case study sites and two supplementary sites throughout Washington, Idaho, and Hawai' $i$ and completed 15 semi-structured interviews. Overall, my research found that (1) an established set of interpretive themes control the stories told at sites, (2) stories have a lack of shared authority, (3) shared stories have little hybridity, (4) contemporary Indigenous relationships with sites are rooted in ancestral memories and connections, (5) and sites commonly share contemporary relationships with the public through live cultural programming.

Heritage sites and cultural centers managed by government agencies and their partners situate interpretation within the structure of historical colonial powers, which excludes stories and perspectives outside the common narrative. Sites often tell their history and stories within established narratives of colonial and imperialist Unites States nostalgia. These stories come from generalized, omniscient and Euro-American voices that share little authority with Indigenous peoples, and provide hegemonic, univocal accounts of history. Interpretation and shared history and memories often privilege 
colonial, Euro-American perspectives of history, ignoring the lasting effects of colonialism and the current presence of Indigenous peoples and their relationships with sites. Cultural practitioners and staff involved with sites are aware of these imbalances and are working to address them in their live programming and relationships with Indigenous groups. Cultural and ancestral connections with heritage sites are a vital aspect of contemporary Indigenous relationships with sites and live programming, cultural demonstrations, and events serve to build this relationship and communicate it to the public. Places that display heritage produce meaning and understanding of the past and these heritage landscapes serve as sites of memory and belonging, knowledge holders, and places of identity negotiation of communities and nations (Jackson 2016, 24; Baird 2017, 4). Lasting colonial influences continue to impact government and Indigenous relationships today and affect the interpretation established at sites. While the majority of people working at case study sites recognized the need for establishing the intersectionality of sites in their interpretation, the pre-established powers of the governments that manage and interpret sites still largely influence the manner in which sites present information to visitors. The intersectionality of the meaning and history of sites is lost in interpretation that follows common narratives, shares little authority, and lacks hybridity and multiple voices. Programming at sites recognizes some of this intersectionality as it brings Indigenous voices to the sites. As Onciul states, "Heritage sites and museums are important points of entry for Indigenous peoples' voices into mainstream society because they have the ability to validate identities, histories, culture and societies $(2015,8)$." As heritage sites and cultural centers identify the ways in which 
they tell stories of the past, they can work towards building interpretation and programming that raises Indigenous perspectives and voices and recognizes contemporary relationships with sites. Bringing Indigenous voices, multivocality and hybridity, stories outside the common U.S. narrative, and a live Indigenous presence to sites can help to broaden the representation and perspectives in interpretation and cultural centers.

The findings from case study and supplementary sites can guide other heritage sites and cultural centers in their own self-reflection and study. Although sites may find aspects that need attention, there is a possibility for change and improvement in interpretation and programming. Recommendations from this project suggest ways for sites to improve their interpretation, programming, and relationships. See Appendix E for the site evaluation rubric. These recommendations are based on and informed by the data and findings of this study and can serve as feasible steps for changing heritage sites and cultural centers. Some sample recommendations include incorporating a welcome statement from Indigenous groups, making interpretation multivocal by including the voices of many, allowing and protecting cultural practices, and engaging in regular and open conversations with Indigenous populations. 


\section{RECOMMENDATIONS}

This section includes recommendations developed in a report written based on the findings of this research project (See Rosenkranz et all 2020). The following discussion provides recommendations for use in updating and developing interpretation, programming, and relationships in a manner that will enhance. understandings of shared history, management of cultural resources, and potentially contribute to healing. Although developed in response to needs identified at Fort Vancouver National Historic Site, these recommendations are generalized so that they can be used by other heritage sites and cultural centers managed by government agencies. These recommendations were written with the understanding that implementing all of these at once is likely not feasible, but sites can work towards a select number that are reasonable based on funding and staff. In discussing heritage representation and interpretation of slavery and segregation in America, Antoinette Jackson, states, "There is no single solution, nor approach that can be applied universally $(2010,89)$." This is also the case for heritage sites in the Pacific Northwest and Hawai' $i$; staff and collaborators at sites will likely need to determine how these different recommendations would apply to their sites' history and can be implemented to meet their specific needs. Before beginning to take steps to implement changes, sites will likely need to evaluate their current interpretation and programming, determining immediate and long-term needs and changes that can be implemented. 
Recommendations are organized by (1) Interpretation, (2) Cultural Centers and Programming, and (3) Relationships. Examples from case study sites are provided for some recommendations.

\section{Interpretation}

- Include Indigenous names of sites to emphasize the Indigenous cultural connection and presence at the site. See Figure 1 for example.

Figure 1: Indigenous Site Name - Nez Perce National Historical Park

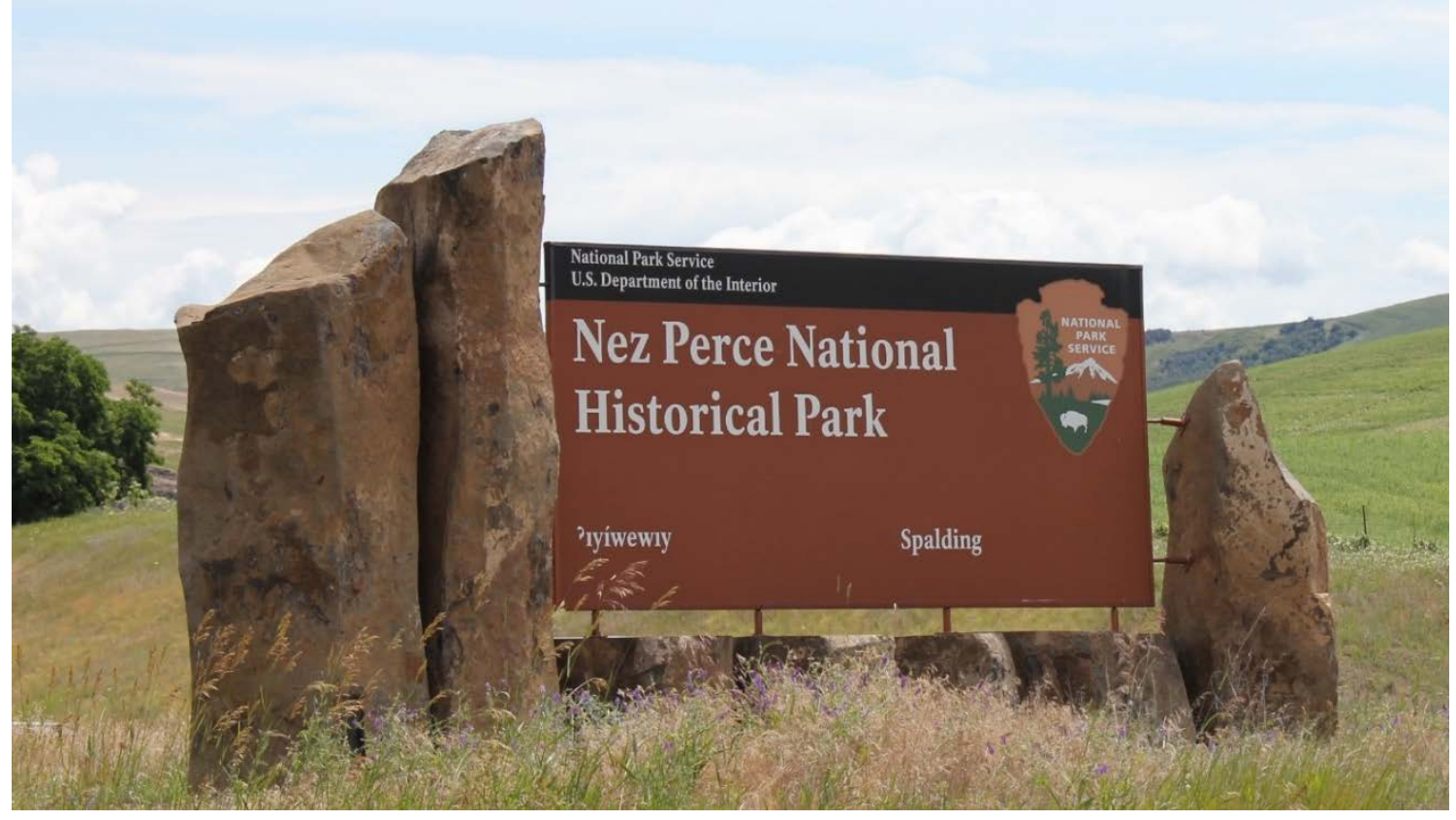

Note the Indigenous site name aligned with the Spalding site name, creating an immediate indication of Indigenous presence to site visitors.

- Include a welcome statement from Indigenous population at sites. These can be included in interpretive displays and in interpretive materials. These messages should be directly from an Indigenous group or person and if possible, cite those people or groups. See Figure 2 and Figure 3 for example. 
Figure 2: Indigenous Site Statement in Park Brochure - Nez Perce National Historical Park

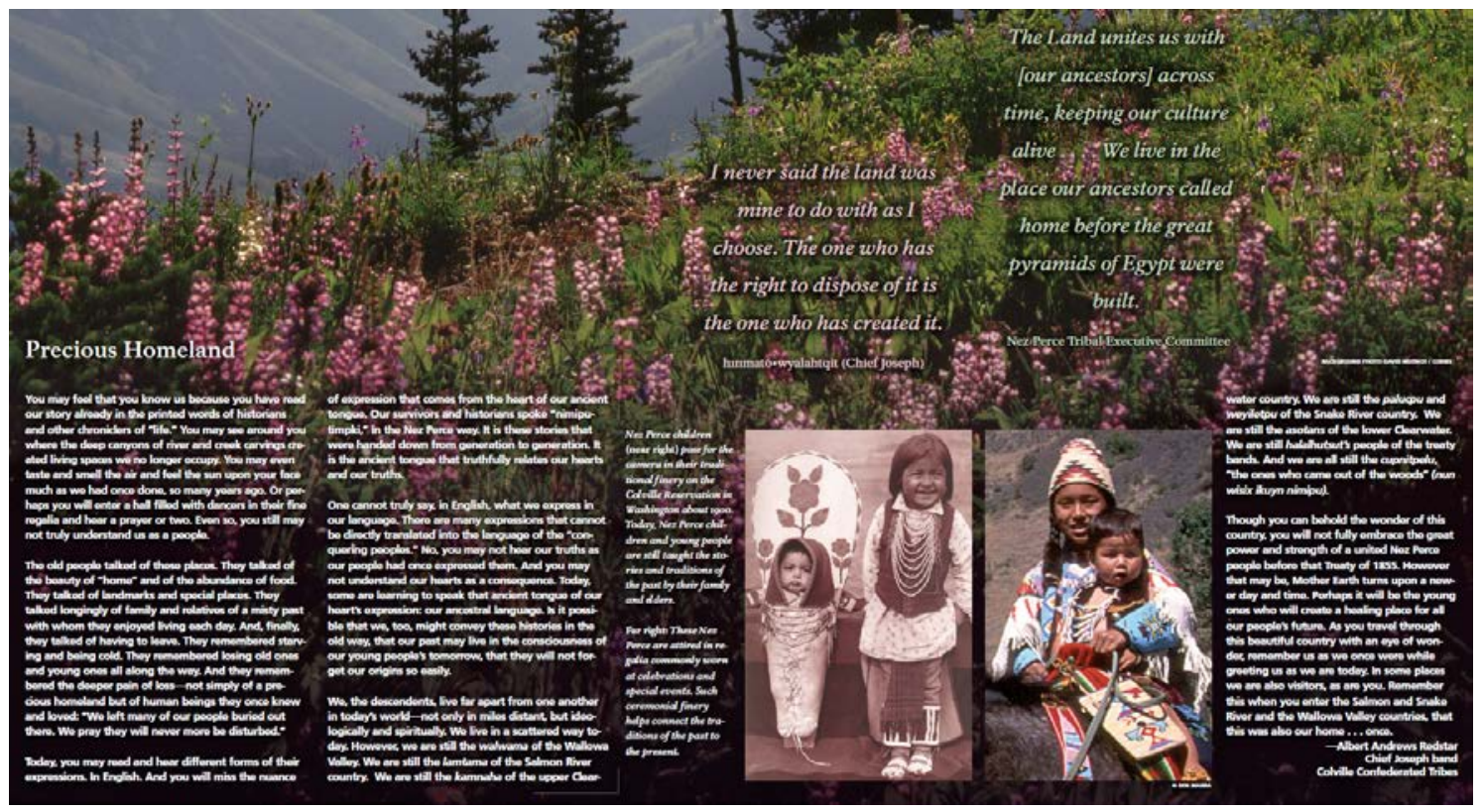

Note that his message is directly from a member of the Chief Joseph band of the Colville Confederated Tribes and that he is named. Also note that this message engages this visitor to reflect on the site's history and meaning. "In some places we are also visitors, as are you. Remember this when you enter the Salmon and Snake River and the Wallowa Valley countries, that this was also our home...once."

Figure 3: Site Welcome - Sacajawea Historical State Park

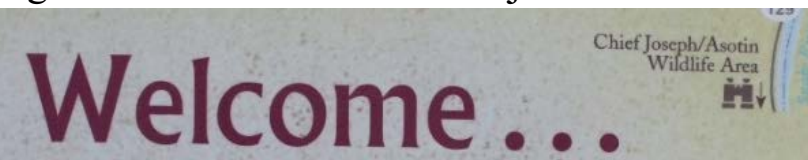

to the homelands of the American Indian tribes of the Columbia Plateau. As you travel the Lewis and Clark Trail and across tribal homelands, please be good stewards and respectful visitors.

- Leave no trace - help protect the environment and the plants and animals living here.

- Respect private property - do not trespass.

- Protect archaeological and cultural resources leave things where you find them. Report what you find.

Note that although this message is not directly from an Indigenous person or group, it still helps to orient the visitor to the site as a homeland to Indigenous peoples. 
- Consider including a land recognition that is culturally appropriate and has been discussed with culturally affiliated tribes and Indigenous populations. This could be in the form of statements at the beginning of live interpretive programs and tours, including a statement such as that at Ash Meadows National Wildlife Refuge which states, "Nuwuvi Ancestral Lands" under the site name on entrance signs, or providing an interpretive sign that provides land recognition(Spoon and Arnold 2016).

- Use contemporary imagery of Indigenous populations with color photos and contemporary people.

- Use Indigenous language beyond plant and animal names to emphasize Indigenous presence and culture. See Figure 4 and Figure 5 for examples.

Figure 4: Indigenous Language Interpretive Sign - "No ka Hanau ana o Kamehameha," Pu'ukoholā Heiau National Historic Site

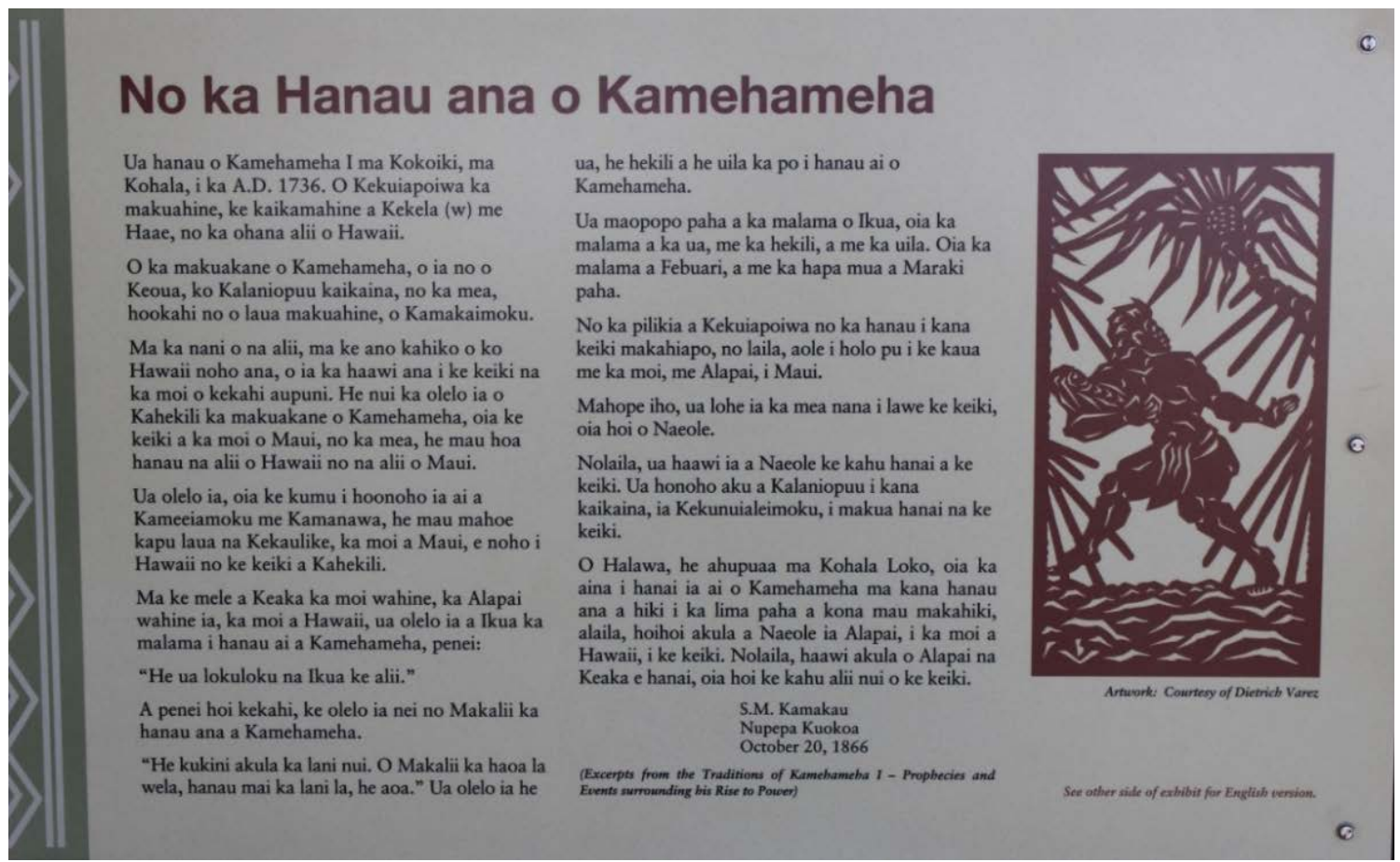

Note the entire interpretive text is in the Hawaiian language. The reverse side of this interpretive sign provided an English language version. 
Figure 5: Simple Indigenous Language Inclusion in Interpretive Sign - "Beaver or Money," Spokane House, Riverside State Park

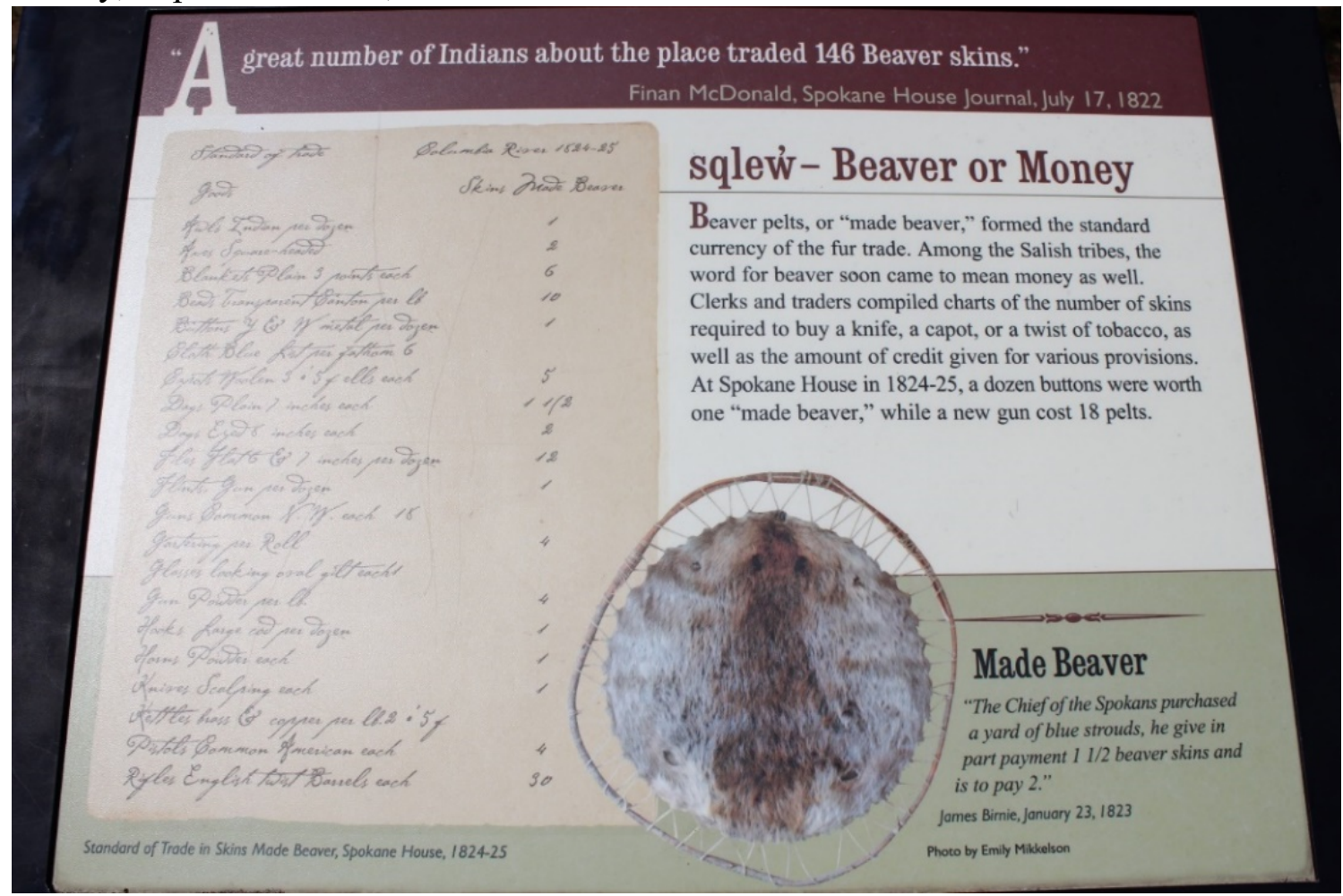

Note the signs heading with both the Spokane and English language. Although minimal language use, this serves as a reminder of the Indigenous presence at the site.

- Incorporate Indigenous voice throughout interpretation.

- Make interpretation multivocal by including the voices of many.

- Provide multiple perspectives and viewpoints throughout interpretation. This can be side-by-side and allow visitors to make conclusions for themselves. See Figure 6 for example. 
Figure 6: Multiple Perspectives Interpretation - "Viewpoints," Sacajawea Historical State Park

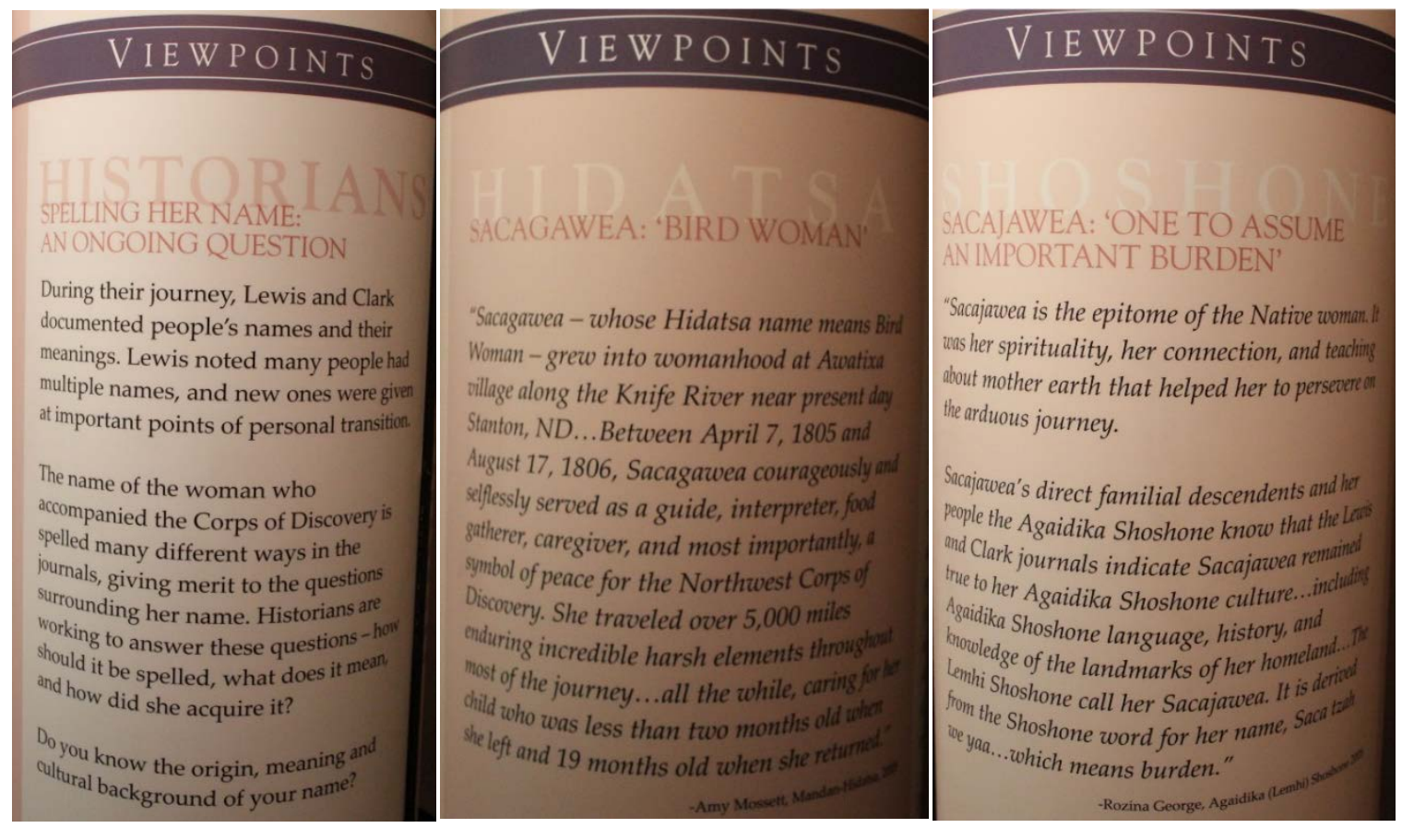

Note the three different perspectives provided from the views of historians, the Hidatsa, and the Shoshone.

- Extend interpretation beyond the confines of a historic structure on site or EuroAmerican history and timelines. When possible, timelines should extend from time immemorial through the present and into the future. See Figure 7 for example. 
Figure 7: Extended Interpretive Timeline - "Timeline of the Northern Plateau," Fort Spokane, Lake Roosevelt National Recreation Area

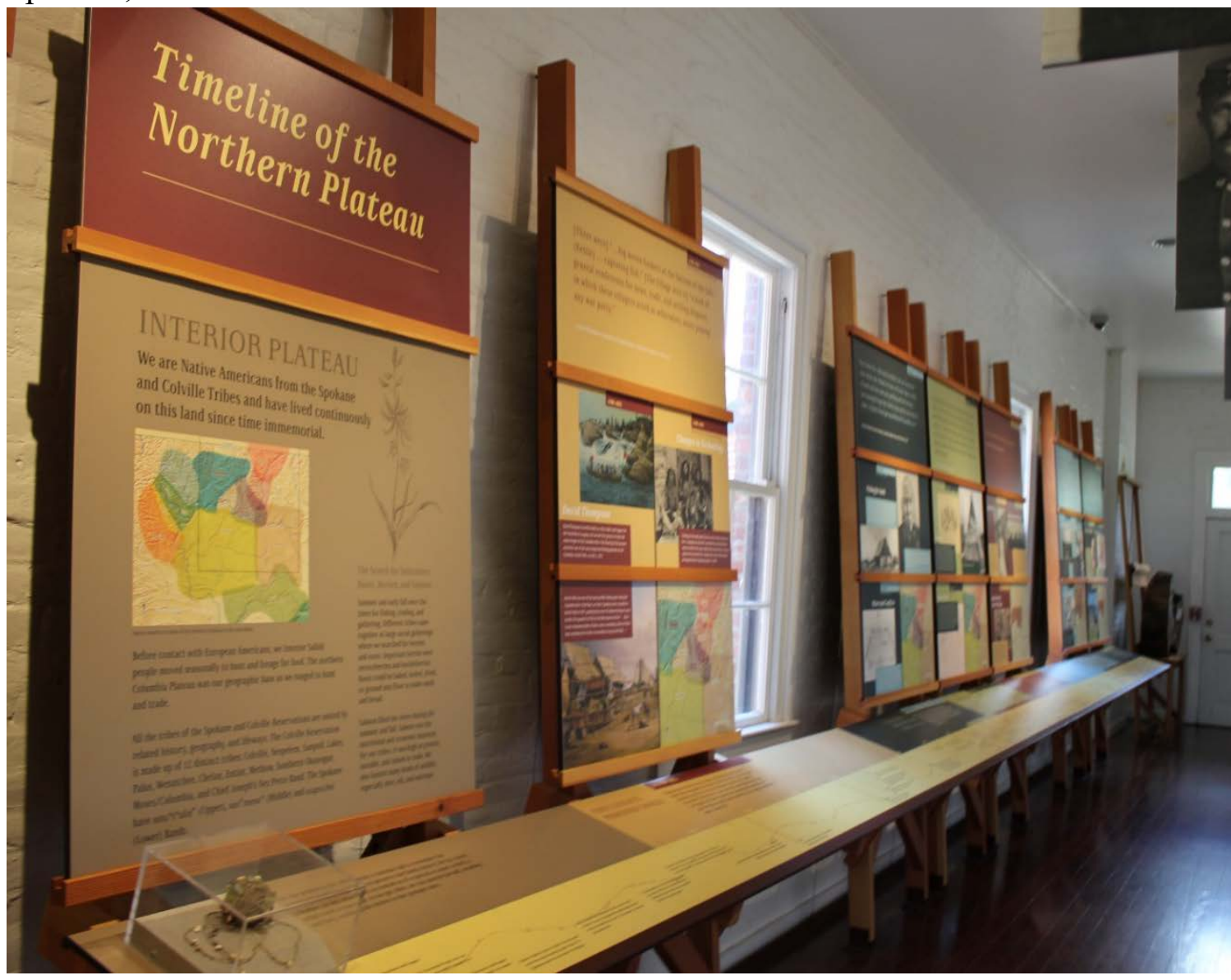

Note that this timeline begins with a statement from the Spokane and Colville Tribes explaining that they have "lived continuously on this land since time immemorial" and then continue until the present. Throughout the displays a representation of a calendar ball ties together oral history and later events in time.

- Link nature and the landscape with the story of the site, culture, and people.

- Share authority with Indigenous populations. Cite, quote, and reference Indigenous people and groups. Name Indigenous peoples now and in history.

- Demonstrate the living cultural presence of Indigenous people at the site.

- Portray contemporary people and events in discussions of topics such as living Indigenous populations and groups, recent activities at sites and elsewhere, and current indigenous practices. See Figure 8 and Figure 9 for examples. 
Figure 8: Contemporary People in Interpretation - "For Generations to Come," Sacajawea Historical State Park

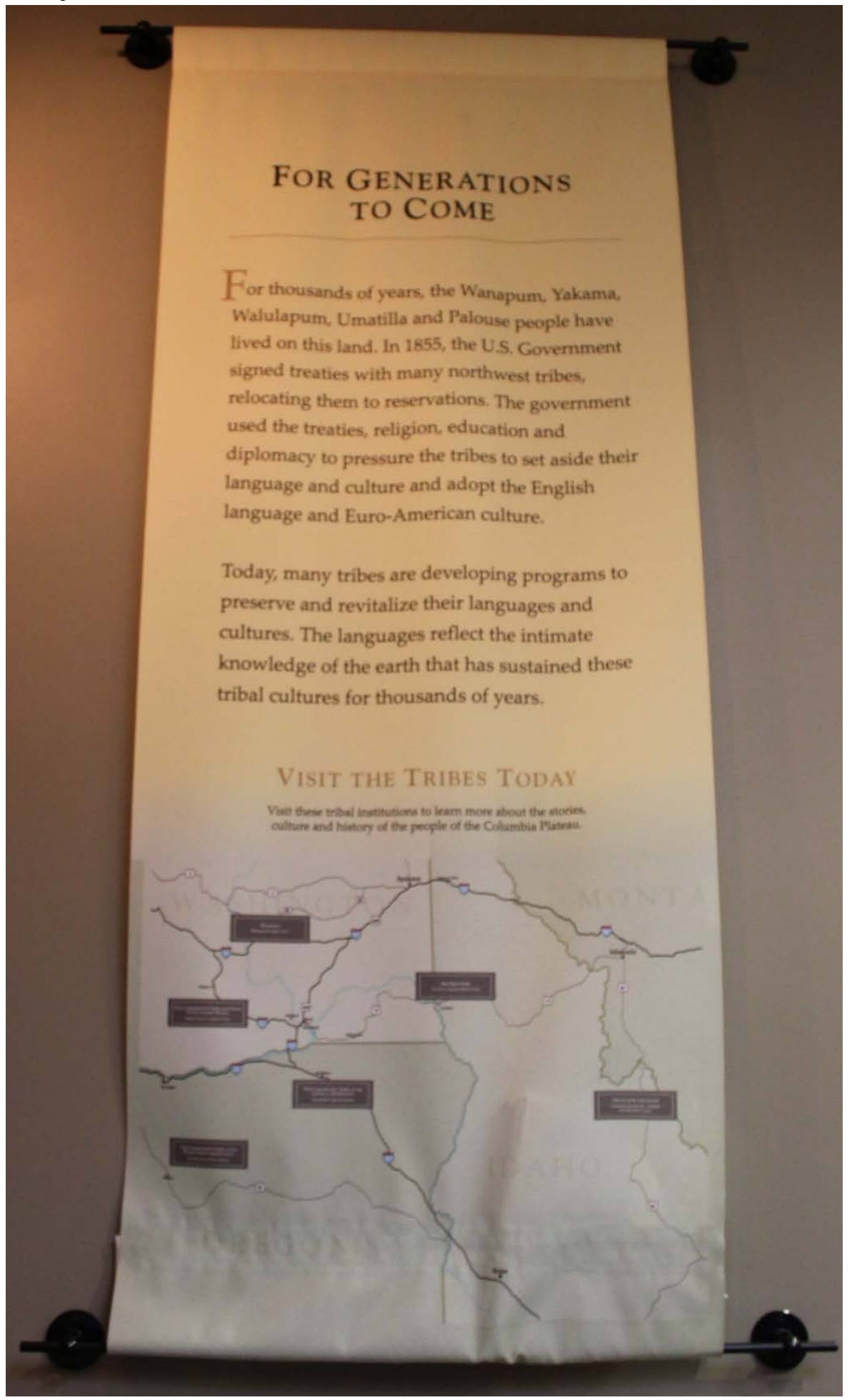

Note the discussion of current tribal programming and recommendations to visit the tribal institutions. 
Figure 9: Contemporary People in Interpretation - "Celebrating Hawaiian Culture,"

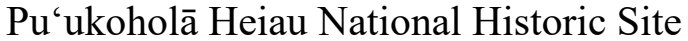

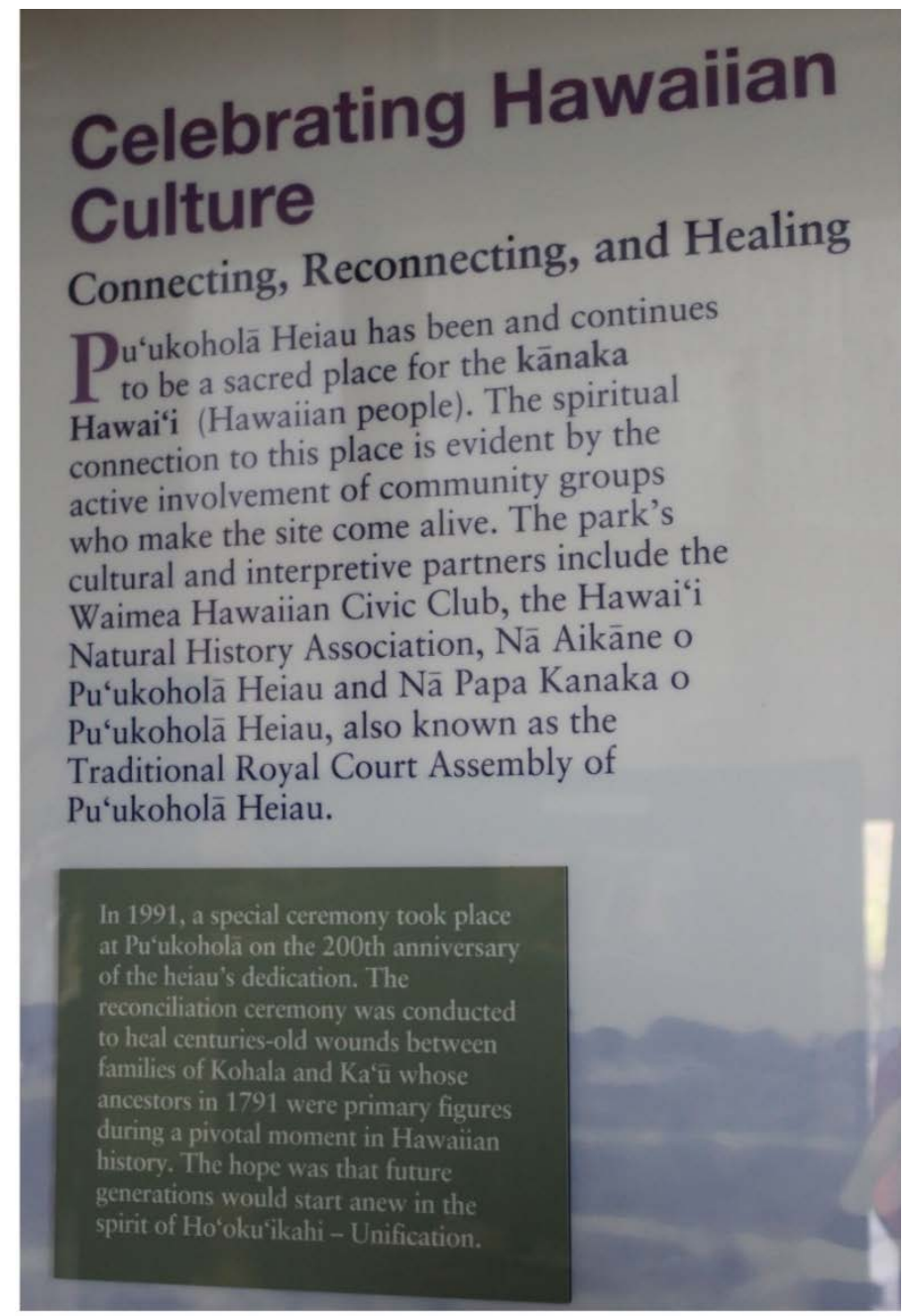

Note the discussion of current Hawaiian partners and a fairly recent event related to the site.

- Provide multiple ways for visitors to learn. Consider creating learning experiences that are hands, experiential, or interactive.

- Create programs and opportunities for Indigenous people to share their knowledge, stories, and experiences.

- Connect interested visitors with additional resources. Consider referring them to books, websites, and Indigenous cultural education institutions. 
- Create accessible interpretation. Consider offering multiple languages of interpretation through additional paper guides that translate interpretation. Consider creating interpretation for those visually and hearing impaired.

- Discuss difficult history and tell what really occurred at a site. Do not shy away from the difficult aspects of history.

- Create space for reflection and thought for interpretation that is challenging or difficult. Consider ideas such as a space for quiet reflection and decompression or a place for visitors to record their thoughts and reflections. See Figure 10 and Figure 11 for an example of a place for recording thoughts and reflections.

Figure 10: Site Comment Box - Fort Spokane, Lake Roosevelt National Recreation Area

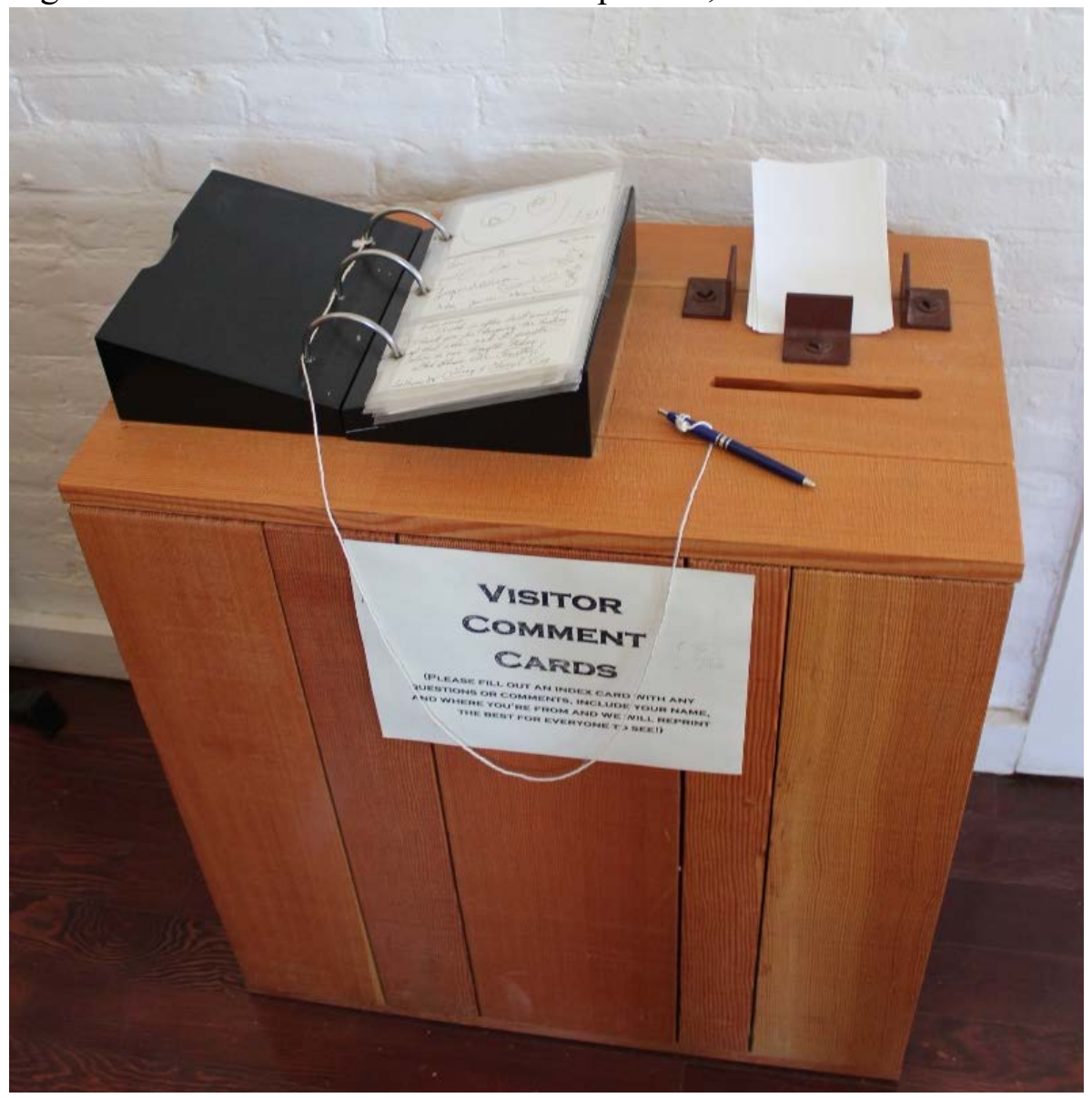

Note that at a site without a space for reflection this simple comment card station allows for visitor reflection after experiencing the interpretation. 
Figure 11: Visitor Reflections - Fort Spokane, Lake Roosevelt National Recreation Area
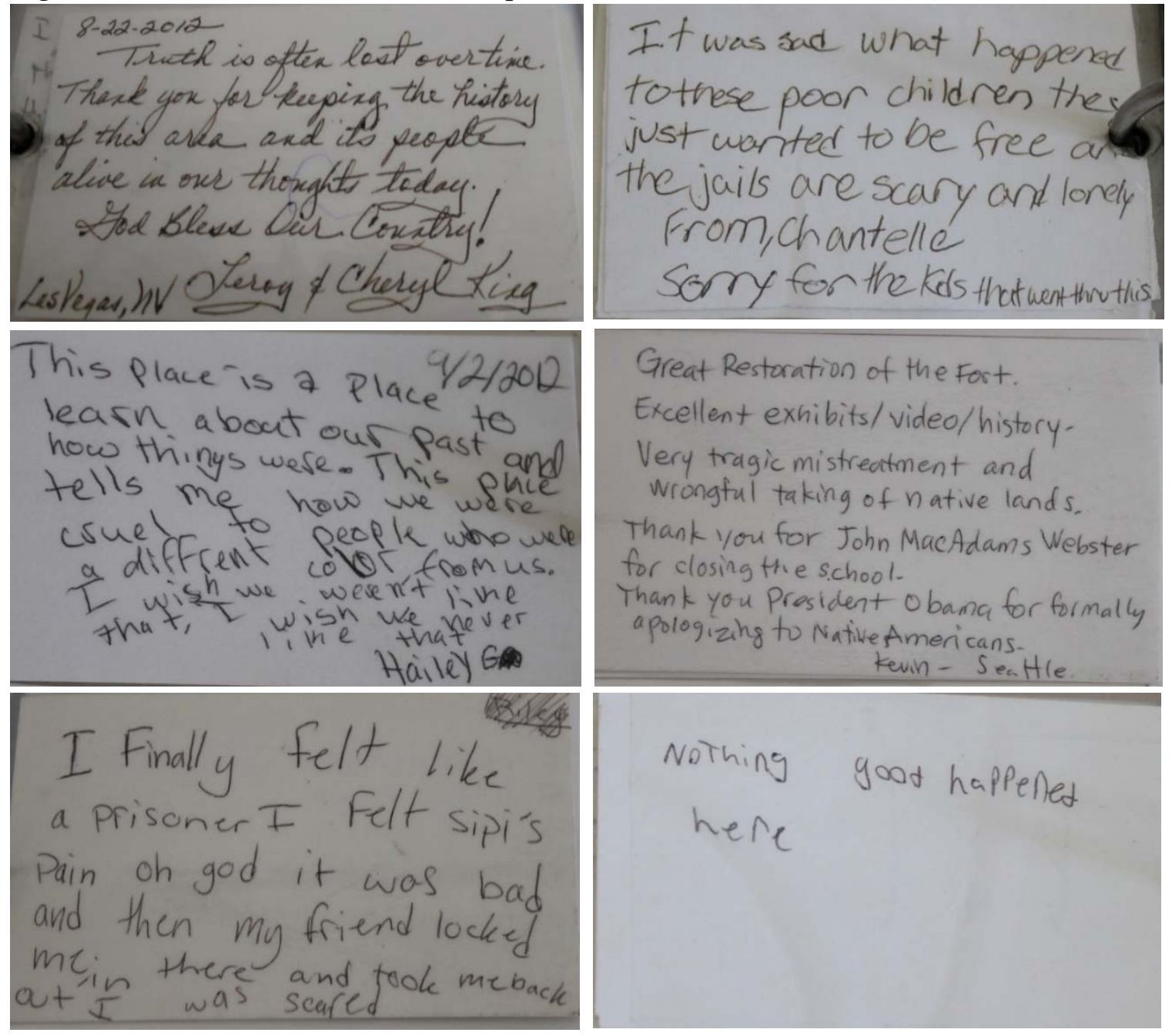

Note the feelings expressed in the comments written on the cards. This simple exercise helps visitors verbalize their feelings after being exposed to the difficult history of the site and boarding school.

\section{Cultural Centers and Programming}

- Allow and protect cultural practices at the site. Make spaces, including protected sites, available to cultural practitioners. Protect those involved in ceremonies and traditional practices by providing private spaces, guiding site visitors verbally and with signage, and by placing barriers. See Figure 12 for example. 
Figure 12: Designated Quiet Area Sign, Hawai'i Volcanoes National Park

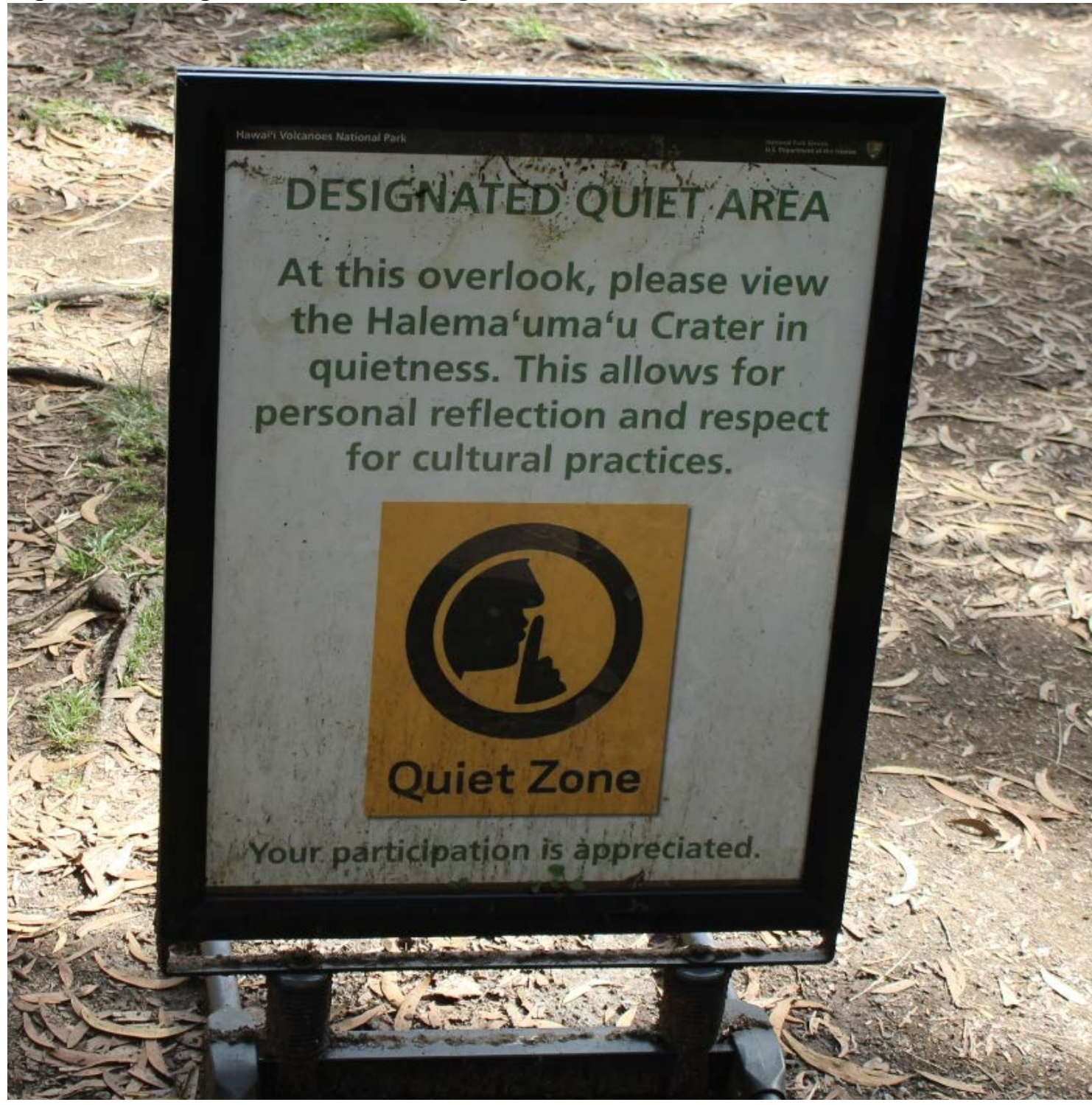

Note the request for quietness and respect.

- Create spaces for cultural demonstrations and practices. See Figure 13 and Figure 14 for examples. 
Figure 13: Hula Platform: Kahua Hula, Hawai'i Volcanoes National Park

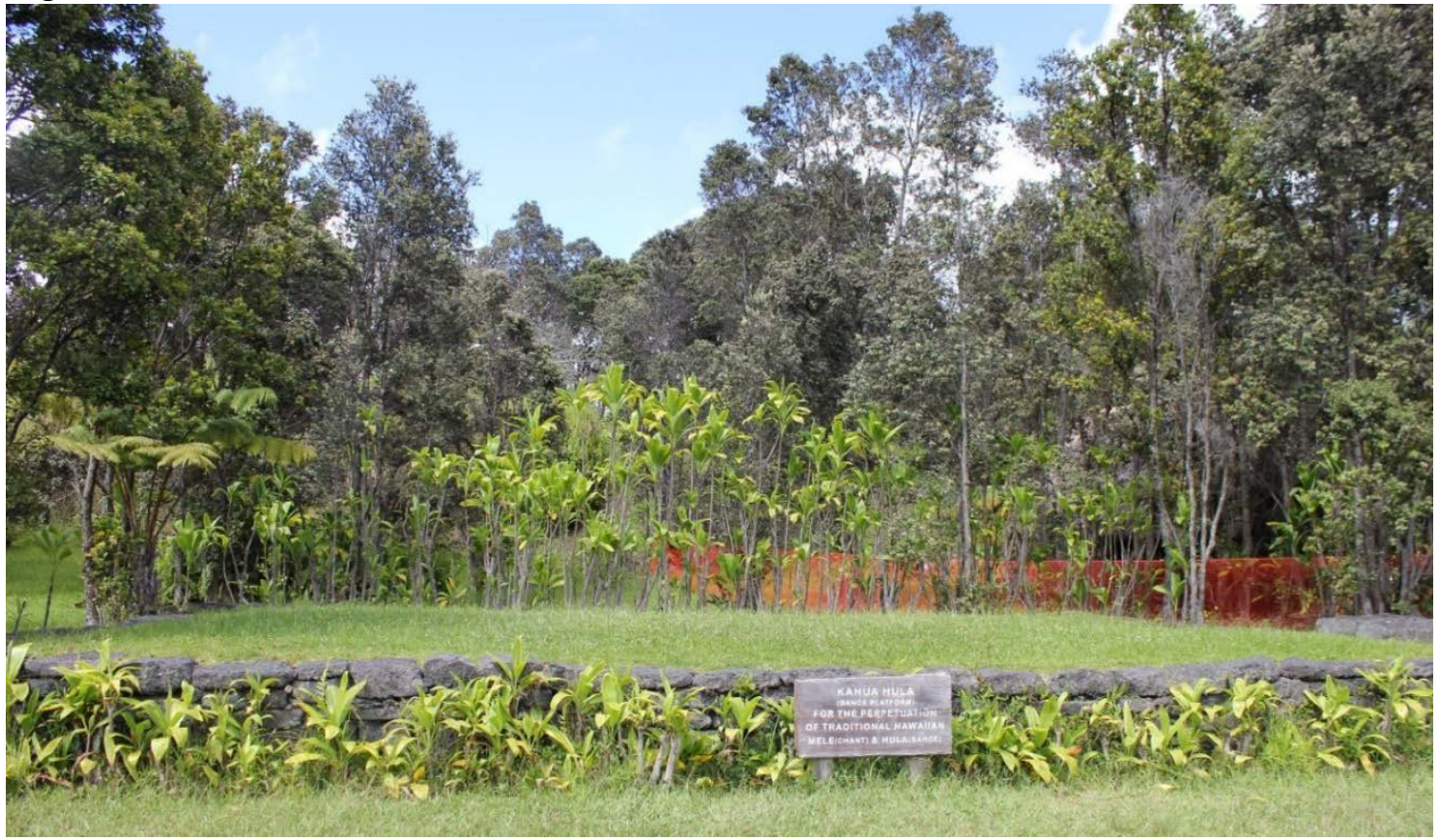

Note the space created for traditional Hula and chant.

Figure 14: Hale - Hawai'i Volcanoes National Park

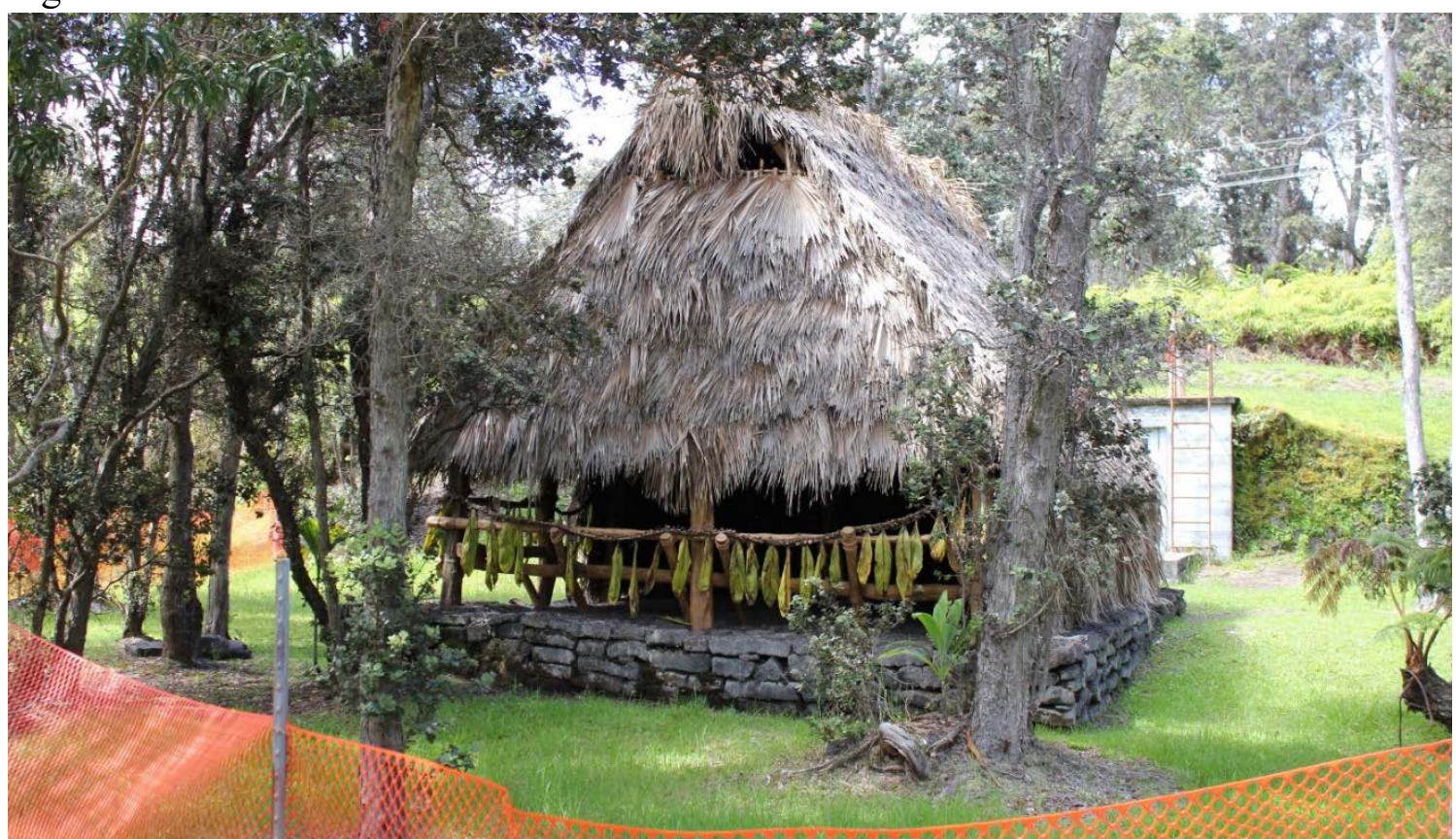

Note the structure still under construction. This space has been rebuilt and will be used for cultural education and as part of cultural demonstrations. 
- Create programming through collaboration. Collaboration can be with community members, community organizations, and site related non-profit organizations.

- Create programming that appeals to a variety of constituents. For example, the Volcano Arts Center has programming that ranges from Hawaiian cultural programs, scientific and academic programs, film and arts programs, and yoga programs.

- Establish large cultural events in collaboration with several partners.

- Provide opportunities for private cultural practice that is closed to the public.

- Work with partner organizations to fund some programs and events.

- Provide cultural practitioners with some form of stipend or compensation for their efforts. Cultural practitioners have spent time learning their crafts and this should be respected. Consider providing a stipend, materials, transportation and meals, tshirt, honorarium, or other forms of compensation.

- Create programs for youth education. Find ways to bring Indigenous youth to the site or to go to their community or school to provide education and programming.

- Consider external grants to fund programming and events.

\section{Relationships}

- Engage in regular and open conversations with Indigenous partners.

- Go out into the community and be a presence at events and programs of partners for site events and programming.

- Involve the Indigenous population in the entire decision-making process.

- Give actual power to Indigenous partners and strongly consider their recommendations and suggestions.

- Ask Indigenous populations and stakeholders what they want from and would like to see done at the site.

- Make information sharing a beneficial exchange for all parties involved.

- Involve Indigenous populations in the site as employees, interns, or through student learning programs. 
- Take time to fully learn and understand Indigenous populations' relationships with the site and landscape.

- Recognize that there are multiple views and understandings of the past and present. Enter into conversations with this understanding.

- Engage in site changes that will make Indigenous populations feel welcome and comfortable at sites with difficult histories. 


\section{REFERENCES CITED}

Anderson, Benedict. 1991. "Census, Map, Museum.” In Imagined Communities, 163185. London: Verso.

Baird, Melissa F. 2017. Critical Theory and the Anthropology of Heritage Landscapes. Gainesville: University Press of Florida.

Ballantyne, Roy, Jan Packer and Nigel Bond. 2012. "Interpreting Shared and Contested Histories: The Broken Links Exhibition." Curator: The Museum Journal, 55(2): 153166.

Ballantyne, Roy, and Karen Hughes. 2003. "Measure Twice, Cut Once: Developing a Research-Based Interpretive Signs Checklist." Australian Journal of Environmental Education, 19, 15-25.

Beck, Wendy E., D. Murvey, C. Perkins, and T. Perkins. 2005. "Aboriginal Ecotourism and Archaeology in Coastal NSW, Australia: Yarrawarra Place Stories Project.” In Indigenous Archaeologies: Decolonizing Theory and Practice, edited by C. Smith and H. M. Wobst, 226-241. London: Routledge.

Behar, Ruth. 2003. "Ethnography and the Book that was Lost." Ethnography, 4(1): 1539.

Benjamin, Stefanie, and Derek Alderman. 2018. "Performing a Different Narrative: Museum Theater and the Memory-Work of Producing and Managing Slavery Heritage at Southern Plantation Museums." International Journal of Heritage Studies, 24(3), 270-282.

Benton, Gregory M. 2009. "From Principle to Practice: Four Conceptions of Interpretation." Journal of Interpretation Research, 14(1): 7-32.

— 2011. "Visitor Perceptions of Cultural Resource Management at Three National Park Service Sites." Visitor Studies, 14(1): 84-99.

Bernard, H. Russell. 2011. Research Method in Anthropology: Qualitative and Quantitative Approaches. Oxford. Lanham, MD: AltaMira Press.

Brown, Marie Alohalani. 2019. "Forward." In The Past before Us: Mo 'okū 'auhau as Methodology, edited by Nālani Wilson-Hokowhitu, vii-ix. Honolulu: University of Hawaii Press.

Butler, Shelley Ruth. 2011. Contested Representations: Revisiting Into the Heart of Africa. Tonawanda, NY: University of Toronto Press. 
California State Parks. 2013. Interpretation Planning Workbook. Sacramento: Interpreation and Education Division, California State Parks. http://www.parks.ca.gov/pages/735/files/interpPlanningWorkbookWEB2013.pdf.

Corntassel, Jeff J. 2003. "Who is Indigenous? 'Peoplehood and Ethnonationalist Approaches to Rearticulating Indigenous Identity." Nationalism and Ethnic Politics, 9(1), 75-100.

Crenshaw, Kimberle. 1989. "Demarginalizing the Intersection of Race and Sex: A Black Feminist Critique of Antidiscrimination Doctrine, Feminist Theory and Antiracist Politics," University of Chicago Legal Forum, 1989(1): 139-167.

Cronon, William. 1996. "The Trouble with Wilderness; or, Getting Back to the Wrong Nature." In Uncommon Ground: Rethinking the Human Place in Nature, edited by William Cronon, 69-90. London: Norton and Company.

Deur, Douglas. 2012. An Ethnohistorical Overview of Groups with Ties to Fort Vancouver National Historic Site. Seattle: Pacific West Region, National Park Service, U.S. Dept. of the Interior.

Di Leonardo, Micaela. 1993. "What a Difference Political Economy Makes: Feminist Anthropology in the Postmodern Era." Anthropological Quarterly, 66(2): 76-80.

Edwards, Curtis. 1994. A Region 6 Interpretive Services Aid: Interpretive Project Guide Book. Portland: Okanogan National Forest, Pacific Northwest Region, U.S. Deparrtment of Agriculture. https://www.fs.usda.gov/Internet/FSE_DOCUMENTS/stelprdb5104524.pdf.

Ervin, Alexander M. 2005. Applied Anthropology: Tools and Perspectives for Contemporary Practice. $2^{\text {nd }}$ Edition. Boston: Pearson.

Farmer, Paul. 2004. “Anthropology of Structural Violence.” Current Anthropology 45(3): 305-325.

Haraway, Donna. 1991. "Situated Knowledge: The Science Question in Feminism and the Privilege of Partial Perspectives." In Simians, Cyborbs, and Women: The Reinvention of Nature, 183-201. New York: Routledge Press.

Harpers Ferry Center. 2009. Wayside Exhibits: A Guide to Developing Outdoor Interpretive Exhibits. National Park Service, U.S. Deptartment of the Interior. https://www.nps.gov/subjects/hfc/upload/Wayside-Guide-First-Edition.pdf. 
Harrison, Rodney. 2012. "Dialogical Heritage and Sustainability." In Heritage: Critical Approaches, 204-226. London: Routledge.

Hoelscher, Steven. 2011. "Heritage." In A Companion to Museum Studies, edited by Sharon Macdonald, 198-218. West Sussex: Blackwell Publishing.

Hunter, Joshua E. 2012. "Towards a Cultural Analysis: The Need for Ethnography in Interpretation Research.” Journal of Interpretation Research, 17(2): 47-58.

Jackson, Antoinette T. 2010. "Changing Ideas About Heritage and Heritage Resource Management in Historically Segregated COmmuntieis." Transforming Anthropology, 18(1): 88-90.

- 2016. Speaking for the Enslaved: Heritage Interpretation at Antebellum Plantation Sites. New York: Routledge.

Kimmerer, Robin W. 2013. Braiding Sweetgrass: Indigenous Wisdom, Scientific Knowledge and the Teachings of Plants. Minneapolis: Milkweed Editions.

Kryder-Reid, Elizabeth. 2016. “Conclusion.” In California Mission Landscapes: Race, Memory, and Politics of Heritage, 229-245. Minneapolis: University of Minnesota Press.

Krmpotich, Cara, and David Anderson. 2005. "Collaborative Exhibitions and Visitor Reactions: The Case of Nitsitapiisinni: Our Way of Life." Curator: The Museum Journal. 48(4): 377-405.

Langford, Theresa E. 2000. "Diversity at Fort Vancouver National Historic Site: Processes of Diversification in Historical Interpretation, Visitor Services, and Workforce Management." Master's Thesis, Oregon State University. Accessed February 4, 2019. http://ir.library.oregonstate.edu/xmlui/bitstream/handle/1957/28415/LangfordTheresa E2000.pdf?sequence $=3$.

LeCompte, Margaret D., and Jean J. Schensul. 2010. Designing and Conducting Ethnographic Research. Lanham, Maryland: AltaMira Press.

. 2013. Analysis and Interpretation of Ethnographic Data: A Mixed Methods Approach. Lanham, Maryland: AltaMira Press.

Little, Barbara J., and Paul A. Shackel. 2014. Archaeology, Heritage, and Civic Engagement: Working toward the Public Good. Walnut Creek, CA: Left Coast Press. 
Lonetree, Amy. 2012. Decolonizing Museums: Representing Native America in National and Tribal Museums. Chapel Hill: University of North Carolina Press.

Macdonald, Sharon. 2016. "Exhibiting Contentious and Difficult Histories: Ethics, Emotions and Reflexivity." In Museums, Ethics and Cultural Heritage, edited by Bernice L. Murphy. London: Routledge

McCall, Leslie. 2005. "The Complexity of Intersectionality." Signs: Journal of Women in Culture and Society, 30(3): 1771-1800.

National Park Service. 2007. Foundations of Interpretation Curriculum Content Narrative: Types of Interpretation. Electronic Document, http://www.nps.gov/idp/interp/101/Foundations Curriculum.pdf.

Onciul, Bryony. 2015. Museums, Heritage and Indigenous Voice: Decolonising Engagement. New York: Routledge.

Quinn, Traci, and Marianna Pegno. 2014. "Collaborating with Communities: New Conceptualizations of Hybridized Museum Practice." In Multiculturalism in Art Museums Today, edited by Joni Boyd Acuff and Laura Evans. Blue Ridge Summit: Rowman \& Littlefield Publishers.

Roseberry, William. 1994. "Marxism and Culture." In Anthropologies and Histories: Essays in Culture, History, and Political Economy, edited by William Roseberry, 3054. New Brunswick: Rutgers University Press.

Rosenkranz, Leah, Jeremy Spoon, and Doug Deur. 2020. Evaluating the Efficacy of Indigenous Representation on Government Managed Lands: A Study of Heritage Sites and Cultural Centers in the Pacific Northwest and Hawai' $i$ i. Portland, OR: Office of Applied Anthropological Research and Portland State University.

Schensul, Jean J., and Margaret D. LeCompte. 2013. Essential Ethnographic Methods: A Mixed Methods Approach. Lanham, Maryland: AltaMira Press.

Secretariat of the United Nations Permanent Forum on Indigenous Issues. 2009. "Introduction." In State of the World's Indigenous Peoples, edited by Department of Economic and Social Affairs, 1-9. New York: United Nations. https://www.un.org/esa/socdev/unpfii/documents/SOWIP/en/SOWIP_web.pdf.

Smith, Laurajane. 2006. Uses of Heritage. New York: Routledge.

Smith, Linda Tuhiwai. 1999. "Imperialism, History, Writing, and Theory.” In Decolonizing Methodologies: Research and Indigenous Peoples, 19-41. London: Zed Books Ltd. 
Smith, Linda Tuhiwai. 2010. Decolonizing Methodologies: Research and Indigenous Peoples. London: Zed Books.

Spoon, Jeremy. 2014. "Quantitative, Qualitative, and Collaborative Methods: Approaching Indigenous Ecological Knowledge Heterogeneity." Ecology and Society, 19(3): 33.

Spoon, Jeremy and Richard Arnold. 2012. "Collaborative Research and Co-Learning: Integrating Nuwuvi (Southern Paiute) Ecological Knowledge and Spirituality to Revitalize a Fragmented Land." Journal for the Study of Religion, Nature and Culture, 60(4). New York: Routledge.

. 2016. "Nuwuvi (Southern Paiute) Ancestral Territory, Spring Mountains National Recreation Area and Desert National Wildlife Refuge Complex, Nevada, USA." Online Case Study. World Conservation Union's (IUCN) Best Practice Guidelines: Cultural and Spiritual Significance of Nature in Protected Area Management and Governance. http://csvpa.org/library/nuwuvi-ancestralterritory/\#1466988272395-15918ac2-ea14

Thomas, David R. 2006. "A General Inductive Approach for Analyzing Qualitative Evaluation Data.” American Journal of Evaluation, 27(2): 237-246.

Tilden, Freeman. 2009. Interpreting Our Heritage. Chapel Hill: The University of North Carolina Press.

Trigger, David S., and Cameo Dalley. 2010. "Negotiating Indigeneity: Culture, Identity, and Politics." Reviews in Anthropology, 39(1): 46-65.

Trouillot, Michel-Rolph. 1995. Silencing the Past: Power and the Production of History. Boston: Beacon Press.

Ulysse, Gina. 2002. "Conquering Duppies in Kingston: Miss Tiny and Me, Fieldwork Conflicts, and Being Loved and Rescued." Anthropology and Humanism, 27(1): 1026.

United States Department of Interior. n.d. East Barracks Physical Inventory: Inventory Report. National Park Service, U.S. Dept. of the Interior.

2004. Long-Range Interpretive Plan: Fort Vancouver National Historic Reserve with Special Emphasis on Fort Vancouver National Historic Site and Vancouver Barracks. National Park Service, U.S. Dept. of the Interior. 
2008. Fort Vancouver National Historic Site General Management Plan 2003. National Park Service, U.S. Dept. of the Interior.

. 2011. East and South Vancouver Barracks Draft Master Plan and Environmental Assessment: Fort Vancouver National Historic Site, Clark County, Washington. National Park Service, U.S. Dept. of the Interior.

- 2016. Fort Vancouver National Historic Site. National Park Serivce, U.S. Dept. of the Interior.

- 2018. 2017 Annual Report. Fort Vancouver National Historic Site. National Park Service, U.S. Dept. of the Interior.

Uzzell, David L. 1998. “Interpreting Our Heritage: A Theoretical Interpretation.” In Contemporary Issues in Heritage and Environmental Interpretation: Problems and Prospects, edited by David L. Uzzell and R. Ballantyne, 11-25. London: The Stationary Office.

Vogt, Tom. 2016. "Fort Vancouver National Historic Site shoppette spruced up." The Columbian. October 4. Accessed April 22, 2018. http://www.columbian.com/news/ 2016/oct/04/fort-vancouver-national-historic-site-shoppette-spruced-up/.

Waterton, Emma, and Steve Watson. 2013. "Framing Theory: Towards a Critical Imagination in Heritage Studies." International Journal of Heritage Studies 19(6): 546-561.

Weisse, Anna, and Anne Ross. 2017. "Managing a contested cultural heritage place on K'gari (Fraser Island), Queensland, Australia.” Archaeology in Oceania, 52: 149-160.

Wells, Marcella D. 2009. Creating More Meaningful Visitor Experiences: Planning for Interpretation and Education. Denver: Bureau of Reclemation, U.S. Department of Interior. https://www.usbr.gov/recreation/publications/Interpretation-Education.pdf.

Winter, Tim. 2013. "Clarifying the Critical in Critical Heritage Studies.” International Journal of Heritage Studies, 19(6): 532-545.

Wrightson, Kelsey R. 2017. "The Limits of Recognition: The Spirit Sings, Canadian Museums and the Colonial Politics of Recognition." Museum Anthropology, 40(1): $36-51$.

Young, James E. 1993. The Texture of Memory: Holocaust Memorials and Meaning. Heritage and Memory 
New Haven: Yale University Press.

Zerubavel, Yael. 1995. Recovered Roots: Collective Memory and the Making of Israeli National Tradition. Chicago: The University of Chicago Press. 


\section{APPENDIX A: LIST OF RESEARCH PARTICIPANTS}

Mark Alvarez: Park Ranger and Limited Commission Officer, Fort Simcoe Historical State Park

Keola Awong: Chief of Interpretation, Pu'uhonua o Hōnaunau National Historical Park and Kaloko-Honokohau National Historical Park and former Area Manager, Kahuku Unit, Hawai'`i Volcanoes National Park

Denise Bausch: Chief of Interpretation and Education and Public Information Officer, Lake Roosevelt National Recreation Area and Ice Age Floods National Geologic Trail

Lynne Brougher: Former Chief of Interpretation, Lake Roosevelt National Recreation Area and Public Affairs Officer, Bureau of Reclamation at Grand Coulee Dam

Joel Johnson: Trades and Agriculture Interpreter, Fort Nisqually Living History Museum, Point Defiance Park

Nālei Kahakalau: Kanaka Maoli Cultural Adherent, Educator, Pu'ukohola Heiau National Historic Site Supporter

Ryan Karlson: Interpretive Program Manager, Washington State Parks and Recreation Commission

Mary Keffer: Interpretive Specialist II, Blue Mountain Area- Washington State Parks

Conall Kahaka'io Ravenscraft: Cultural Demonstrator and Practitioner, Hawai ${ }^{`}$ i Pacific Parks Association, Pu'uhonua o Hōnaunau National Historical Park

Nancy Keller-Scholz: Historical Interpreter Lead, Fort Nisqually Living History Museum, Point Defiance Park

Paul Neddo: Park Ranger, Centennial Trail and Spokane House Interpretive Center, Riverside State Park

Benjamin Saldua: Chief of Interpretation and Education, Pu'ukohola Heiau National Historical Site

Lane Sample: Education and Outreach Coordinator, Fort Nisqually Living History Museum, Point Defiance Park 
Emily C. Weiss: Director of Development and Galleries, Volcano Art Center

Please note that not all participants are included in this list, only those that agreed to be named are represented. 


\section{APPENDIX B: SITE DESCRIPTIONS}

\begin{tabular}{|c|c|c|c|}
\hline Site Name & Site Type & Location & Description \\
\hline $\begin{array}{l}\text { Fort Simcoe } \\
\text { Historical } \\
\text { State Park }\end{array}$ & $\begin{array}{l}\text { Heritage } \\
\text { Site }\end{array}$ & $\begin{array}{l}\text { Yakima } \\
\text { Indian } \\
\text { Reservation, } \\
\text { White Swan, } \\
\text { Washington }\end{array}$ & $\begin{array}{l}\text { This pre-Civil War fort is located within the } \\
\text { boundaries of the Yakima Indian Reservation. } \\
\text { Approximately } 38 \text { miles southwest of Yakima, } \\
\text { Washington, Fort Simcoe is surrounded by } \\
\text { farms, small towns, and hills. Listed on the } \\
\text { National Register of Historic Places, this site is } \\
\text { a day-use area with a primary focus on historic } \\
\text { preservation. Fort Simcoe features } \\
\text { reconstructed fort structures and interpretation } \\
\text { on the Yakima Nation, fort, Bureau of Indian } \\
\text { Affairs, and boarding school. }\end{array}$ \\
\hline $\begin{array}{l}\text { Nez Perce } \\
\text { National } \\
\text { Historical } \\
\text { Park } \\
\text { Visited Sites: } \\
\text { Spalding Site, } \\
\text { Craig Donation } \\
\text { Land Claim, } \\
\text { Fort Lapwai, } \\
\text { Lapwai } \\
\text { Mission, Saint } \\
\text { Joseph's } \\
\text { Mission, } \\
\text { Coyote's } \\
\text { Fishnet, \& Nez } \\
\text { Perce Village }\end{array}$ & $\begin{array}{l}\text { Heritage } \\
\text { Site }\end{array}$ & $\begin{array}{l}\text { Washington, } \\
\text { Idaho, } \\
\text { Montana, \& } \\
\text { Oregon }\end{array}$ & $\begin{array}{l}\text { Nez Perce National Historical Park consists of } \\
38 \text { separate sites, ranging across Nez Perce } \\
\text { homelands and four states. Many of these sites } \\
\text { are owned by agencies and people outside of } \\
\text { the National Park Service and managed } \\
\text { through cooperative agreements. The park } \\
\text { features interpretation on the living Nez Perce } \\
\text { culture and a range of events from throughout } \\
\text { history. Throughout the park there are } \\
\text { Indigenous heritage sites, sacred sites, } \\
\text { battlefields, missions, a fort, Lewis and Clark } \\
\text { expedition sites, burial sites, and more. The } \\
\text { park represents and preserves the continuum of } \\
\text { the Nez Perce culture and people, allowing for } \\
\text { the continued traditional use of the resources } \\
\text { within the park. }\end{array}$ \\
\hline $\begin{array}{l}\text { Fort } \\
\text { Spokane, } \\
\text { Lake } \\
\text { Roosevelt } \\
\text { National } \\
\text { Recreation } \\
\text { Area } \\
\text { Visited Sites: } \\
\text { Fort Spokane } \\
\& \text { Mission } \\
\text { Point }\end{array}$ & $\begin{array}{l}\text { Heritage } \\
\text { Site }\end{array}$ & $\begin{array}{l}\text { Northeastern } \\
\text { Washington, } \\
\text { Davenport, } \\
\text { Washington } \\
\text { \& Kettle } \\
\text { Falls, } \\
\text { Washington }\end{array}$ & $\begin{array}{l}\text { Located in northeastern Washington, Lake } \\
\text { Roosevelt National Recreation Area ranges } \\
\text { from Grand Coulee Dam to Onion Creek just } \\
\text { south of the U.S.-Canadian border. Located } \\
\text { within the park is the lake created by the } \\
\text { construction of the Grand Coulee Dam, Fort } \\
\text { Spokane, and St. Paul's Mission. The park } \\
\text { offers recreational activities as well as } \\
\text { interpretation of the area's history, including } \\
\text { the ice age floods, Fort Spokane's use as a } \\
\text { military fort, Indian boarding school, and } \\
\text { tuberculosis sanitarium, and the Kettle Falls } \\
\text { area's use as a traditional gathering and fishing } \\
\text { location, Old Fort Colville, and St. Paul's } \\
\text { Mission. Fort Spokane features historic } \\
\text { structures and foundations. }\end{array}$ \\
\hline
\end{tabular}




\begin{tabular}{|c|c|c|c|}
\hline Site Name & Site Type & Location & Description \\
\hline $\begin{array}{l}\text { Fort } \\
\text { Nisqually } \\
\text { Living } \\
\text { History } \\
\text { Museum, } \\
\text { Point } \\
\text { Defiance } \\
\text { Park }\end{array}$ & $\begin{array}{l}\text { Heritage } \\
\text { Site }\end{array}$ & $\begin{array}{l}\text { Tacoma, } \\
\text { Washington }\end{array}$ & $\begin{array}{l}\text { Located outside of downtown Tacoma, } \\
\text { Washington, the Fort Nisqually Living History } \\
\text { Museum is a representation of Fort Nisqually } \\
\text { in } 1855 \text {. Fort Nisqually was a site of trade and } \\
\text { global connections. The site features } \\
\text { interpretation of the history of Fort Nisqually } \\
\text { and the people that lived, worked, and traded } \\
\text { there. Live interpreters bring history to life and } \\
\text { involve visitors in experiencing history. }\end{array}$ \\
\hline $\begin{array}{l}\text { Pu'uhonua o } \\
\text { Hōnaunau } \\
\text { National } \\
\text { Historical } \\
\text { Park }\end{array}$ & $\begin{array}{l}\text { Heritage } \\
\text { Site }\end{array}$ & $\begin{array}{l}\text { Honaunau, } \\
\text { Hawai'i }\end{array}$ & $\begin{array}{l}\text { Pu'uhonua o Hōnaunau National Historical } \\
\text { Park is located on the western side of Hawai'i } i \\
\text { on the southern Kona coastline. The site } \\
\text { historically served as a residence for royal } \\
\text { chiefs and a place of sanctuary for warriors } \\
\text { and kapu breakers. Preserved in the park are } \\
\text { historic sites and features of the Royal } \\
\text { Grounds and sanctuary. The site interprets } \\
\text { traditional Hawaiian lifeways and continues } \\
\text { the connection between Native Hawaiians and } \\
\text { the sacred site. }\end{array}$ \\
\hline $\begin{array}{l}\text { Sacajawea } \\
\text { Historical } \\
\text { State Park }\end{array}$ & $\begin{array}{l}\text { Historical } \\
\text { Site and } \\
\text { Cultural } \\
\text { Center }\end{array}$ & $\begin{array}{l}\text { Pasco, } \\
\text { Washington }\end{array}$ & $\begin{array}{l}\text { This park, named for Sacagawea, the } \\
\text { Agaiduka Shoshoni woman who accompanied } \\
\text { the Lewis and Clark Corps of Discovery } \\
\text { Expedition, is located within Pasco city limits } \\
\text { and serves as a marine and day-use park. } \\
\text { Located at the confluence of the Columbia and } \\
\text { Snake River, this site is significant as a } \\
\text { gathering place of Indigenous peoples and as a } \\
\text { camping stop for the Corps of Discovery. The } \\
\text { park features interpretation on Sahaptian } \\
\text { speaking tribes, the Corps of Discovery, and } \\
\text { Sacagawea. }\end{array}$ \\
\hline $\begin{array}{l}\text { Spokane } \\
\text { House } \\
\text { Interpretive } \\
\text { Center, } \\
\text { Riverside } \\
\text { State Park }\end{array}$ & $\begin{array}{l}\text { Heritage } \\
\text { Site and } \\
\text { Cultural } \\
\text { Center }\end{array}$ & $\begin{array}{l}\text { Nine Miles } \\
\text { Falls, } \\
\text { Washington }\end{array}$ & $\begin{array}{l}\text { Riverside State Park provides recreational } \\
\text { opportunities to visitors, with multiuse trails, } \\
\text { water activities, and climbing. Approximately } \\
9.5 \text { miles northwest of Spokane, Washington, } \\
\text { the Spokane House site is located in an area } \\
\text { significant as an Indigenous gathering place } \\
\text { and hub for the fur trade. The Spokane House } \\
\text { serves as an interpretive center focusing on the } \\
\text { fur trade and the Indigenous population, with } \\
\text { an interpretive trail along the Spokane River. }\end{array}$ \\
\hline
\end{tabular}




\begin{tabular}{|c|c|c|c|}
\hline Site Name & Site Type & Location & Description \\
\hline $\begin{array}{l}\text { Hawai'i } \\
\text { Volcanoes } \\
\text { National Park }\end{array}$ & $\begin{array}{l}\text { Heritage } \\
\text { Site and } \\
\text { Cultural } \\
\text { Center }\end{array}$ & $\begin{array}{l}\text { Hawai'i } \\
\text { County, } \\
\text { Hawai'i }\end{array}$ & $\begin{array}{l}\text { Located in southern Hawai' } \mathrm{i} \text {, this park } \\
\text { serves multiple purposes. The park is home } \\
\text { to tow active volcanoes and multiple } \\
\text { endemic and endangered plants and animals. } \\
\text { This site was important in human } \\
\text { development on the island and is a site of } \\
\text { spiritual and cultural significance. } \\
\text { Interpretation throughout the park includes } \\
\text { discussions of the geography, volcanism, } \\
\text { ecosystems, endangered species, traditional } \\
\text { Hawaiian practices, Hawaiian history that } \\
\text { took place on the site, and Hawaiian spiritual } \\
\text { beliefs. }\end{array}$ \\
\hline $\begin{array}{l}\text { Pu'ukoholā } \\
\text { Heiau National } \\
\text { Historic Site }\end{array}$ & $\begin{array}{l}\text { Heritage } \\
\text { Site and } \\
\text { Cultural } \\
\text { Center }\end{array}$ & $\begin{array}{l}\text { Kawaihae, } \\
\text { Hawai'i }\end{array}$ & $\begin{array}{l}\text { Located on the northwest coast of Hawai'i, } \\
\text { Pu'ukoholā Heiau National Historic Site } \\
\text { (PUHE) sites on the 'Hill of the Whale,' } \\
\text { overlooking Kawaihae Bay and the ocean. } \\
\text { Pu'ukoholā Heiau, one of the finale major } \\
\text { temples constructed on the Hawaiian } \\
\text { Islands, was important in the unification of } \\
\text { the islands and Kamehameha's rule. The site } \\
\text { still stands as a memory of Kamehameha's } \\
\text { efforts and the unification of the Hawaiian } \\
\text { Islands. The park features interpretation on } \\
\text { the temples, Kamehameha, the unification of } \\
\text { the islands, John Young, and traditional } \\
\text { Hawaiian life. }\end{array}$ \\
\hline $\begin{array}{l}\text { Volcano Art } \\
\text { Center Gallery } \\
\text { and Volcano } \\
\text { Art Center } \\
\text { Niaulani } \\
\text { Campus }\end{array}$ & $\begin{array}{l}\text { Cultural } \\
\text { Center }\end{array}$ & $\begin{array}{l}\text { Volcano, } \\
\text { Hawai'i and } \\
\text { Hawai'i } \\
\text { Volcanoes } \\
\text { National } \\
\text { Park }\end{array}$ & $\begin{array}{l}\text { The Volcano Art Center is a nonprofit } \\
\text { organization, partnering with the National } \\
\text { Park Service, to showcase art from local } \\
\text { artists and offer programs for residents, kids, } \\
\text { and visitors. The Volcano Art Center Gallery } \\
\text { is located within Hawai'i Volcanoes } \\
\text { National Park in the historic } 1877 \text { Volcano } \\
\text { House Hotel. The Volcano Art Center } \\
\text { Niaulani Campus serves as the } \\
\text { administrative offices, a gallery, and an } \\
\text { educational facility in Volcano Village in the } \\
\text { Niaulani Rian Forest. Through art and } \\
\text { education, the Volcano Art Center works to } \\
\text { promote, develop, and perpetuate the } \\
\text { Hawaiian culture, environment, and arts. }\end{array}$ \\
\hline
\end{tabular}




\begin{tabular}{|l|l|l|l|}
\hline Site Name & Site Type & Location & Description \\
\hline $\begin{array}{l}\text { Mission } \\
\text { National } \\
\text { Historic Site }\end{array}$ & Supplementary & $\begin{array}{l}\text { Walla } \\
\text { Walla, } \\
\text { Washington }\end{array}$ & $\begin{array}{l}\text { This mission site is located west of the } \\
\text { Blue Mountains in southeast Washington. } \\
\text { Approximately seven miles west of Walla } \\
\text { Walla, Washington, Whitman Mission is a } \\
\text { historic mission site on the original land } \\
\text { settled by the Whitmans. Established to } \\
\text { bring Christianity to the Cayuse people, } \\
\text { the site was the location of the deaths of } \\
\text { the Whitmans and others at the mission. } \\
\text { Whitman Mission features interpretation } \\
\text { of the site's history and the Cayuse people, } \\
\text { while also serving as a memorial. }\end{array}$ \\
\hline $\begin{array}{l}\text { Kamakahonu } \\
\text { National } \\
\text { Historic } \\
\text { Landmark }\end{array}$ & $\begin{array}{l}\text { Supplementary } \\
\text { Site }\end{array}$ & $\begin{array}{l}\text { Kailua- } \\
\text { Kona, } \\
\text { Hawai'i }\end{array}$ & $\begin{array}{l}\text { Located in the northwest edge of Kailua } \\
\text { Bay, Kamakahonu National Historic } \\
\text { Landmark is located in Kailua-Kona on } \\
\text { the Island of Hawai'i. The site is surround } \\
\text { by tourist activities and a hotel. } \\
\text { Kamakahonu is a National Historic } \\
\text { Landmark and features interpretation on } \\
\text { the site's history and structures. The site } \\
\text { serves as a reminder of the Kamehameha I, } \\
\text { the capitol of the Kingdom of Hawai'i, the } \\
\text { ending of kapu, and the landing of the first } \\
\text { Christian missionaries on the islands. }\end{array}$ \\
\hline
\end{tabular}

\section{Background Resources Reviewed}

Ahu'ena Heiau Inc. “Ahu'ena Heiau: Malama I Ko Kakou Ho'olina, Preserving Our Past." Accessed April 5, 2020. https://ahuena-heiau.org/index.html.

BUCY Associates. 2003. Interpretive Master Plan for Fort Simcoe State Park. Corvallis, OR.

BRCA, Inc. 2015. Point Defiance Park: Master Plan Update. Tacoma, WA: Washington Metro Parks Tacoma. https://www.metroparkstacoma.org/wpcontent/uploads/2019/05/Point-Defiance-Park-Master-Plan-2015-FINAL-1.pdf.

Confluence. "River Sites: Sacajawea State Park." Last modified 2020. https://www.confluenceproject.org/river-site/sacajawea-state-park/.

Davis, Marty and Bruce Beyerl. 2005. Riverside State Park Management Plan. Olympia, WA: Washington State Parks and Recreation Commission. 
https://parks.state.wa.us/DocumentCenter/View/1547/Riverside-Management-PlanPDF.

Dunbar, Helene R. 1985. National Register of Historic Places Inventory - Nomination Form: Kamakahonu National Historic Landmark. Washington, D.C.: National Park Service. https://npgallery.nps.gov/NRHP/GetAsset/NHLS/66000288_text.

Fairleigh, Larry. 1998. Land Classification, Long-Term Boundary, and Acquisition, Surplus and Management Plan. Olympia, WA: Washington State Parks and Recreation Commission. https://parks.state.wa.us/DocumentCenter/View/11718/Land-Classification-LongTerm-Boundary-and-Acquisition--Surplus-and-Management-Plan-1998-PDF?bidId=.

Fielding, Andrew. 2010. Sacajawea State Park Management Plan. Olympia, WA: Washington State Parks and Recreation Commission. https://parks.state.wa.us/DocumentCenter/View/1551/Sacajawea-Management-PlanPDF?bidId $=$.

Gilbert, Cathy A. 1984. The Historic Landscape of Fort Spokane: A Preliminary Study, Coulee Dam National Recreation Area. Seattle, Washington: Cultural Resources Division, Pacific Northwest Region.

Hamilton, Dwight. N.d. History of Hawai ${ }^{`} i$ Volcanoes National Park. Hawai ${ }^{i} i$ USDI, National Park Service. http://www.npshistory.com/brochures/havo/history.pdf.

Kaser, Cara. 2007. National Register of Historic Places Registration Form: Sacajawea State Park. Washington, D.C.: State of National Park Service. https://npgallery.nps.gov/GetAsset/03bc3762-4cc3-445e-8a1a-37f636587768.

Metro Parks Tacoma. "Fort Nisqually.” Accessed March 10, 2020. https://www.metroparkstacoma.org/place/fort-nisqually-living-history-museum/.

__. "Point Defiance Park." Accessed March 10, 2020. https://www.metroparkstacoma.org/place/point-defiance-park/.

Moniz Nakamura, Jadelyn J. and Geoffery Mowrer. "The Establishment of Kilauea Military Camp: The Early Years 1898-1921." Hawaiian Journal of History 53(2019): 55-81. Accessed March 12, 2020. https://muse.jhu.edu/article/742974.

Nisqually Indian Tribe. "Heritage." Accessed March 10, 2020. http://www.nisquallynsn.gov/index.php https://www.metroparkstacoma.org/place/point-defiancepark $/$ heritage/. 
Richmond, Bruce M., Susan A. Cochran, and Ann E. Gibbs. 2008. Geologic Resource Evaluation of $\mathrm{Pu}$ 'uhonua $\mathrm{O}$ Hōnaunau National Historical Park, Hawai 'i; Part I, Geology and Coastal Landforms. Reston Virginia: U.S. Geological Survey Open-File Report 2008-1192. https://pubs.usgs.gov/of/2008/1192/of2008-1192.pdf.

United States Department of Interior, National Park Service. "Hawai'i Volcanoes National Park." Last modified February 21, 2020. https://www.nps.gov/havo/index.htm.

. "Lake Roosevelt National Recreation Area." Last modified September 23, 2019. https://www.nps.gov/laro/index.htm.

- “Kamakahonu, HI.” Last modified August 16, 2019. https://www.nps.gov/places/kamakahonu.htm.

. "Nez Perce National Historical Park.” Last modified February 6, 2020. https://www.nps.gov/nepe/index.htm.

_. "Pu'uhonua o Hōnaunau National Historical Park." Last modified May 18, 2018. https://www.nps.gov/puho/index.htm.

—_. "Pu'ukoholā Heiau National Historic Site." Last modified November 23, 2018. https://www.nps.gov/puhe/index.htm.

__. "Whitman Mission National Historic Site." Last modified October 26, 2019. https://www.nps.gov/whmi/index.htm.

. N.d. Long-Range Interpretive Plan, Nez Perce National Historical Park. http://www.npshistory.com/publications/nepe/lrip.pdf.

1996. Draft General Management Plan/Environmental Impact Statement, Nez Perce National Historical Park and Big Hole National Battlefield. https://archive.org/details/draftgeneralmana96nez/mode/1up.

1997. General Management Plan, Nez Perce National Historical Park and Big Hole National Battlefield.

- 2000. General Management Plan for Whitman Mission National Historic Site. https://www.nps.gov/whmi/learn/management/upload/whmigmp.pdf. 
2004. Cultural Landscape Inventory: 'Āinahou Ranch House and Gardens, Hawai'i Volcanoes National Park.

https://www.nps.gov/havo/learn/historyculture/upload/Ainahou-Ranch-House-andGardens-CLI_508.pdf.

2006. Cultural Landscape Inventory: Kīlauea Administration and Employee Housing Historic District, Hawai' ‘ Volcanoes National Park.

https://www.nps.gov/havo/learn/historyculture/upload/Kilauea-Admin-CLI_508.pdf.

. 2006. Whitman Mission National Historic Site: Long-Range Interpretive Plan. https://npgallery.nps.gov/GetAsset/3112a49f-c344-4fad-9768e03a680b3af7/original?.

_ 2009. "Pu'ukoholā Heiau National Historic Site." Pacific Island Network Quarterly 17: 6-7. Accessed March 9, 2020.

https://www.nps.gov/puhe/learn/nature/upload/pacn-news_20091007.pdf.

- 2012. Listing of Acreage (Summary).

https://irma.nps.gov/STATS/FileDownload/107.

- 2015. Foundation Document, Lake Roosevelt National Recreation Area. https://www.nps.gov/laro/getinvolved/upload/LARO_FD_PRINT-compressed.pdf.

_ 2015. Foundation Document, Pu'ukoholā Heiau National Historic Site. http://npshistory.com/publications/foundation-documents/puhe-fd-2015.pdf.

. 2016. General Management Plan, Hawai'i Volcanoes National Park. https://www.nps.gov/havo/learn/management/upload/Hawaii-Volcanoes-GeneralManagement-Plan_2016_508.pdf.

_ 2017. Foundation Document, Hawai' i Volcanoes National Park. http://npshistory.com/publications/foundation-documents/havo-fd-2017.pdf.

_ 2017. Foundation Document, Pu'uhonua o Hōnaunau National Historical Park. http://npshistory.com/publications/foundation-documents/puho-fd-2017.pdf.

Volcano Art Center. Forthcoming. "A Field Guide to the Ecology of Niaulani Rainforest (The Restoration of a Rainforest Treasure)." PDF file.

- N.d. Ni'aulani Trail Companion, The Natural and Human History of a Small Forest. http://volcanoartcenter.org/wp-content/uploads/2014/12/Trail-Companion.pdf. 
. "Volcano Art Center: Where People, Art and Nature Meet." Accessed March 9, 2020. https://volcanoartcenter.org/.

Washington State Parks and Recreation Commission. "Fort Simcoe Historical State Park.” Accessed March 4, 2020. https://parks.state.wa.us/509/Fort-Simcoe.

- "Riverside State Park.” Accessed March 4, 2020.

https://parks.state.wa.us/573/Riverside.

_. "Sacajawea Historical State Park.” Accessed March 4, 2020. https://parks.state.wa.us/575/Sacajawea.

2019. Spokane House: An interpretive guide to fur trading in the Pacific Northwest. Olympia, WA: Washington State Parks and Recreation Commission.

Whisman, Douglas M. 1974. National Register of Historic Places Inventory Nomination Form: Fort Simcoe State Park. Washington, D.C.: National Park Service. https://npgallery.nps.gov/NRHP/GetAsset/NRHP/74001994_text. 


\section{APPENDIX C: INFORMED CONSENT}

\section{Portland State University \\ Consent to Participate in Research \\ History and Memory in the Intersectionality of Heritage Spaces}

\section{Key Consultant Interview}

You are being invited to participate in a research study being conducted by Portland State University graduate student, Leah Rosenkranz. This study hopes to gain an understanding of the meaning and memory associated with sites and how history and memory influence aspects of sites, such as their use, programming, administration, and interpretation.

Participation in this study will take approximately one hour and you will be asked a series of questions. There are no known risks if you decide to participate in this research study, aside from potential emotional distress in response to questions or the loss of time spent participating in the research.

Your name and title will be used, if you provide consent. If this is an issue you can request that your name is not used in the reports on this study. Your participation in this study is completely voluntary. You have the right to choose not to participate or to withdraw your participation at any point in this study.

With your permission this interview will be audio recorded to better document the discussion. All records, including audio recordings, will be kept on a password protected computer.

If you have any questions, concerns, or complaints at any time about the research study, Leah Rosenkranz will be glad to answer them at 360-931-5653 or leah32@pdx.edu or Dr. Jeremy Spoon at 503-725-9729 or jspoon@pdx.edu.

If you have questions regarding your rights as a research participant, you may call the PSU Office for Research Integrity at 503-725-2227 or 1-877-480-4400. For more information, you may also access the IRB website at https://sites.google.com/a/pdx.edu/research/integrity.

I am grateful for your time, cooperation, and support.

\section{CONSENT}

You are making a decision whether to participate in this study. Your signature below indicates that you have read the information provided. By signing this consent form, you agree to participate in this study. A copy of this consent form will be provided to you.

Name of Adult Subject (print) Signature of Adult Subject Date 


\section{APPENDIX D: RESEARCH QUESTIONS}

\section{Heritage Site Key Consultant Interview}

I will conduct key consultant interviews during site visits with knowledge holders closely involved with the sites in roles such as managers, employees, community stakeholders, or have been involved in establishment of the space in its current state and use. I will conduct a total of 10-20 interviews across the five heritage sites and the five cultural centers. Interviews will use a semi-structured format and will be focused on each key consultant's knowledge of the space, its history, management, use, and ability to meet the needs of diverse stakeholders, while considering how site meaning is constructed and represented.

1. Please tell me about yourself and your role at this heritage site.

2. If you were involved with the establishment of this site and its interpretation, can you tell me about the process?

a. What were the goals of this process?

b. What was the message that was trying to be communicated to visitors?

3. If you are involved with the interpretation of this site to visitors, can you tell me about these processes?

4. Tell me about the interpretation of this place?

a. How do you feel about this interpretation?

b. What is effective about the interpretation?

c. What is ineffective about the interpretation?

5. What memories and stories do different populations connect with this place?

a. What memories and history do you associate with this place?

6. Do people relate to this space differently and associate it with different aspects of history?

7. How do you personally relate to this place and what makes it meaningful to you? 
8. How do these differences intermix in the space and its meaning?

9. How does this site share difficult or contested histories?

a. Is this effective and meaningful?

10. What do you feel are the most effective and meaningful ways to communicate and share difficult and contested histories with the public?

a. What are ineffective ways to communicate these histories?

11. Are there untapped potential and resources for sharing information at this site?

a. What has been fully utilized and what has not been used to its full potential?

12. What changes could improve the future relationships of stakeholders with this site?

13. What do you find most effective and successful about this heritage place? 


\section{Cultural Center Key Consultant Interview}

I will conduct key consultant interviews during site visits with knowledge holders closely involved with the sites in roles such as managers, employees, community stakeholders, or have been involved in establishment of the space in its current state and use. I will conduct a total of 10-20 interviews across the five colonial heritage sites and the five cultural centers. Interviews will use a semi-structured format and will be focused on each key consultant's knowledge of the space, its history, management, use, and ability to meet the needs of diverse stakeholders, while considering how site meaning is constructed and represented.

1. Please tell me about yourself and your role at this cultural center.

2. If you were involved with the establishment of the center, can you tell me about the process?

a. What were the goals of this process?

b. What was the message that was trying to be communicated to visitors?

3. If you are involved with the governance of this site, can you tell me about this process?

4. If you are involved with the management of this site, can you tell me about this process?

5. How is this place used by different populations?

a. If you use this place, how do you utilize it?

6. Tell me about the interpretation of this place?

a. How do you feel about this interpretation?

b. What is effective about the interpretation?

c. What is ineffective about the interpretation?

7. Tell me about the cultural programming at this cultural center?

a. How do you feel about this programming? 
b. What is effective about the programming?

c. What is ineffective about the programming?

8. What memories and stories do different populations connect with this place?

a. What memories and history do you associate with this place?

9. Do people relate to this space differently and associate it with different aspects of history?

10. How do you personally relate to this place and what makes it meaningful to you?

11. How do these differences intermix in this space and its meaning?

12. Are there untapped potential and resources for sharing information at this cultural center?

a. What has been fully utilized and what has not been used to its full potential?

13. What changes could improve the future relationships of stakeholders with this site and cultural center?

14. What do you find most effective and successful about this cultural center's interpretation?

15. What do you find most effective and successful about this cultural center's programming? 


\section{APPENDIX E: SITE EVALUATION RUBRIC}

This evaluation rubric is underdevelopment and will be completed with feedback from the Fort Vancouver National Historic Site Traditional Use Study partners. 